

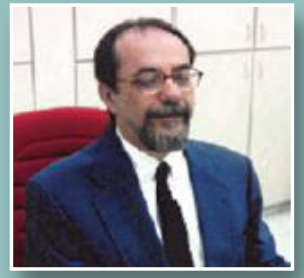

\section{EDITOR-IN-CHIEF}

FERNANDO MAURO LANÇAS

Universidade de São Paulo

Instituto de Química de São Carlos

13560-970 São Carlos (SP) - Brasil

editor@scientiachromatographica.com

\section{EDITORES ASSOCIADOS}

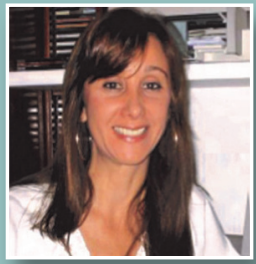

MARIA EUGÊNIA QUEIROZ PREPARO DE AMOSTRAS

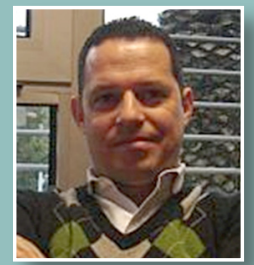

JOSÉ MANUEL F. NOGUEIRA PREPARO DE AMOSTRAS

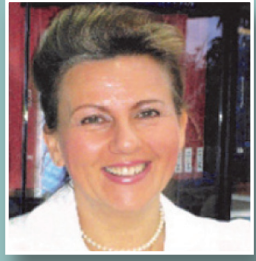

ELENA STASHENKO ESPECTROMETRIA DE MASSAS

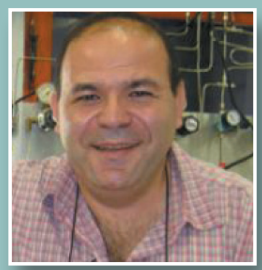

FABIO AUGUSTO CROMATOGRAFIA GASOSA

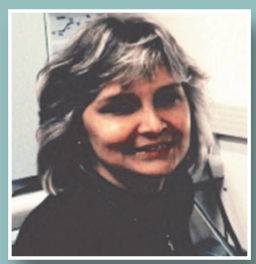

CLÁUDIA ZINI CROMATOGRAFIA GASOSA

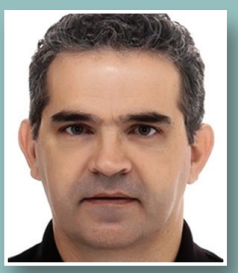

RENATO ZANELLA PREPARO DE AMOSTRAS

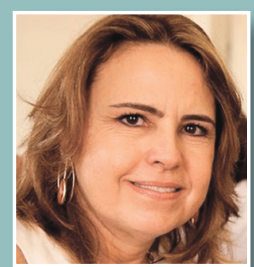

ISABEL C. S. FONTES JARDIM CROMATOGRAFIA LÍQUIDA

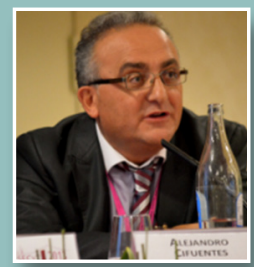

ALEJANDRO CIFUENTES TÉCNICAS ELETROFORÉTICAS

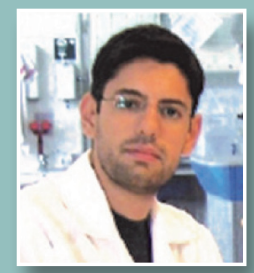

ÁLVARO J. SANTOS NETO TROUBLESHOOT ING

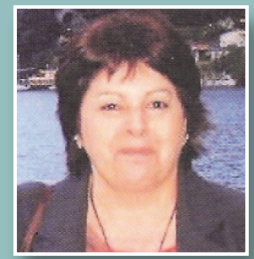

ELINA B. CARAMÃO CROMATOGRAFIA GASOSA

\section{CORPO EDITORIAL CONSULTIVO}

Daniel Armstrong - EUA

Dietrich von Bauer - Chile

Fábio Augusto - Brasil

Fátima Dutra - Brasil

Flávio Leite - Brasil

Frank Svec - EUA

Harold McNair - EUA

Humberto Gómez - México

Isabel Cristina Sales Fontes Jardim - Brasil

Jailson B. de Andrade - Brasil

Janusz Pawliszyn - Canadá

Kiyoratsu Jinno - Japão

Luigi Mondello - Itália

Marcos Eberlin - Brasil

Marina Tavares - Brasil

Milos Novotny - EUA

Milton Lee - EUA

Norberto Peporine Lopes - Brasil

Phillip Marriott - Austrália

Pierina Bonato - Brasil

Quézia Cass - Brasil

Renato Zanella - Brasil

\section{ENDEREÇO DO PERIÓDICO}

\section{Scientia Chromatographica}

Rua Princesa Isabel, 265 - Jardim Paraíso

13.561-140 - São Carlos (SP) - Brasil

Fone/Fax: (16) 3501-4140

periodico@scientiachromatographica.org

www.scientiachromatographica.com

Ficha catalográfica elaborada pela Seção de Aquisição e Tratamento da Informação do SBI/IQSC

Scientia Chromatographica / Associação Internacional de Cromatografia. - vol.11 n.4 (out./dez. 2019). São Carlos: Associação Internacional de Cromatografia, 2019.

Trimestral

ISSN 1984-4433

1. Cromatografia. 2. Lanças, Fernando Mauro, editor chefe. 
Periódico Trimestral do Instituto Internacional de Cromatografia
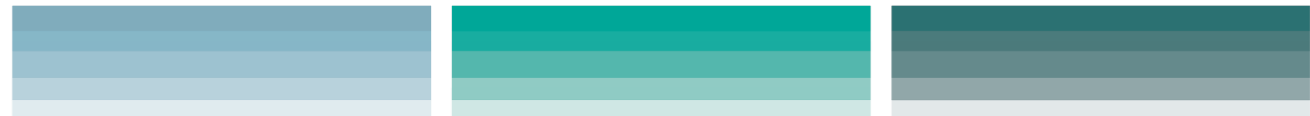

Scientia Chromatographica 2019 | Volume 11 | Número 4

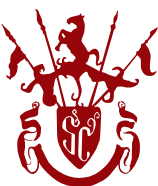




\section{thermoscientific}

Incorrect (interference)

Quantitation peak

Resolution $35 \mathrm{~K}$

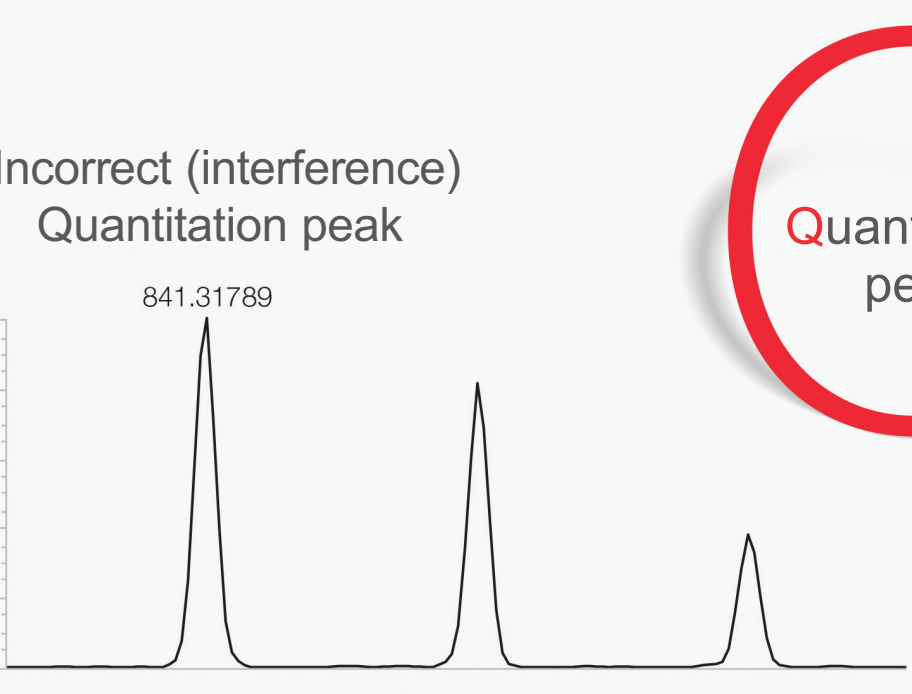

peak

\section{A Quantificação do Amanhã fornece certeza na análise complexa de hoje}

Espera-se que os equipamentos analíticos permitam resolver os desafios mais críticos com respostas confiáveis. Os laboratórios analíticos de hoje precisam mais que equipamentos de ponta. Eles precisam do melhor equipamento, e de soluções abrangentes. Uma solução que possa triar, identificar e quantificar mais compostos do que era possivel anteriormente. A Quantificação do Amanhã pode capacitar seu laboratório com poderosas ferramentas analíticas e soluções de fluxo de trabalho que irão permitir a você atingir os desafios analíticos de hoje e do futuro. Assegurando maior produtividade, eficiência e sucesso para sua organização.

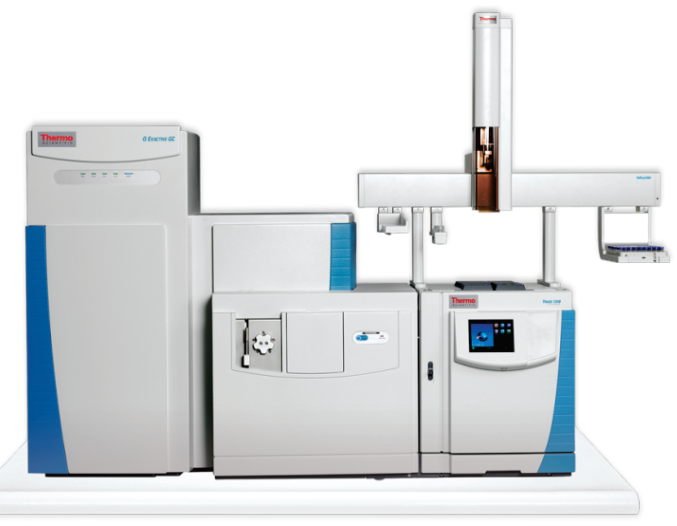

Thermo Scientific Exactive ${ }^{\mathrm{m}}$ GC Plus MS oferece alta sensibilidade, seletividade e velocidade para uma ampla faixa de metabólitos, pesticidas e poluentes para análises targeted e non-targeted.

Para conhecer mais a respeito da Quantificação do Amanhã e como ela pode fazer a diferença em seu laboratório hoje, visite www.thermofisher.com/Quantitation 
MICROEXTRAÇÃO

Novas perspectivas em técnicas de microextração estática

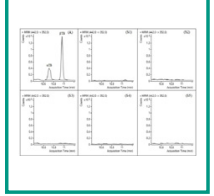

\section{GC-MS/MS x LC-MS/MS}

GC-MS/MS versus LC-MS/MS for unambiguous identification of $\alpha$ and $\beta$-trenbolone in bovine urine

Amanda Lemes Silveira, Adriana Ferreira Faria

UHPLC

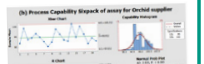

Efficient UPLC and spectrophotometric MC methods for simultaneous determination of cefixime and sodium benzoate in their dosage form and in its degradation product of cefixime-E Isomer. Application of lean six sigma and in-vitro dissolution studies 167

Mahmoud A. Mohamed

LASEAC Meeting Report

Riva 2020

Instituto Internacional de Cromatografia.

Bookstore 193

Normas para Publicação 194 


\section{alinetwork \\ Um jeito inteligente de \\ começar a semana bem informado}

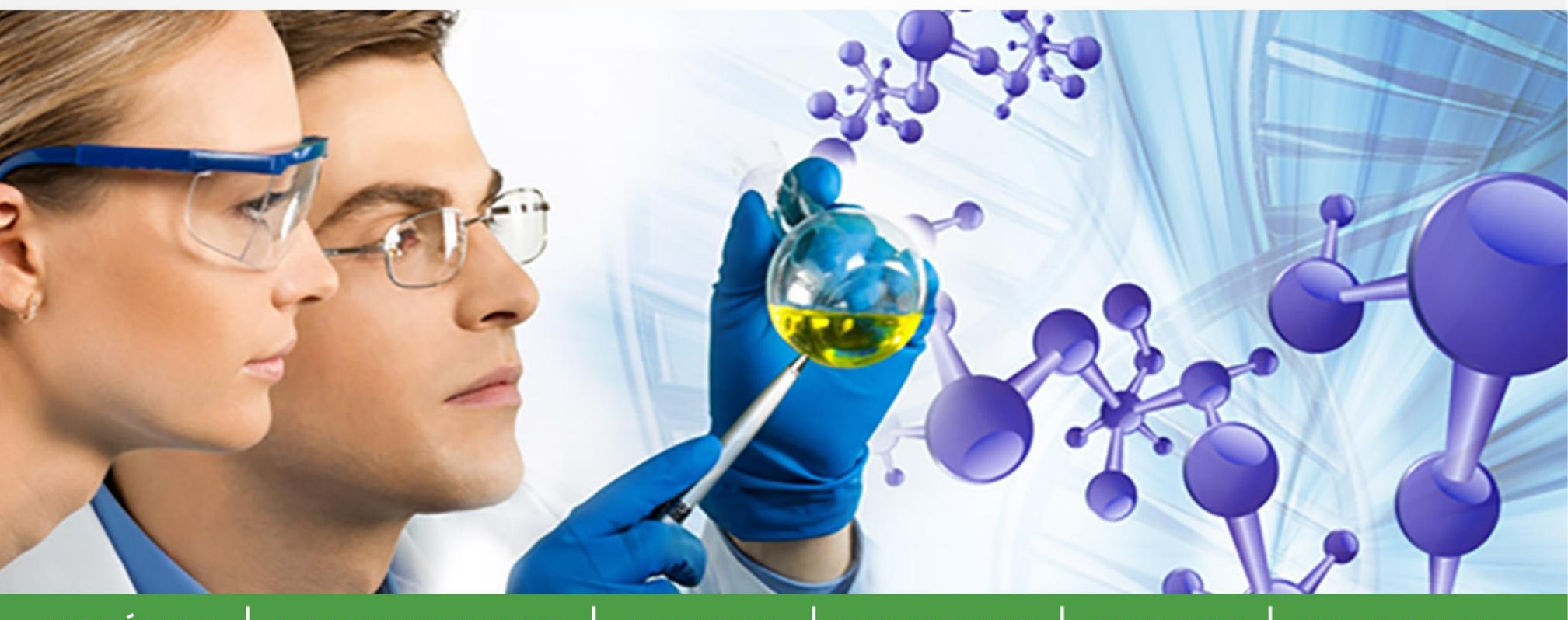

NOTÍCIAS | LANÇAMENTOS | ARTIGOS | ESPECIAIS | CURSOS | CARREIRA

Assine nossas newsletters llabnetwork

e fique por dentro das principais

notícias do mercado

de análises clínicas

e instrumentação

científica.

\section{$f \cdot 0.0$ in}

Siga-nos nas redes sociais
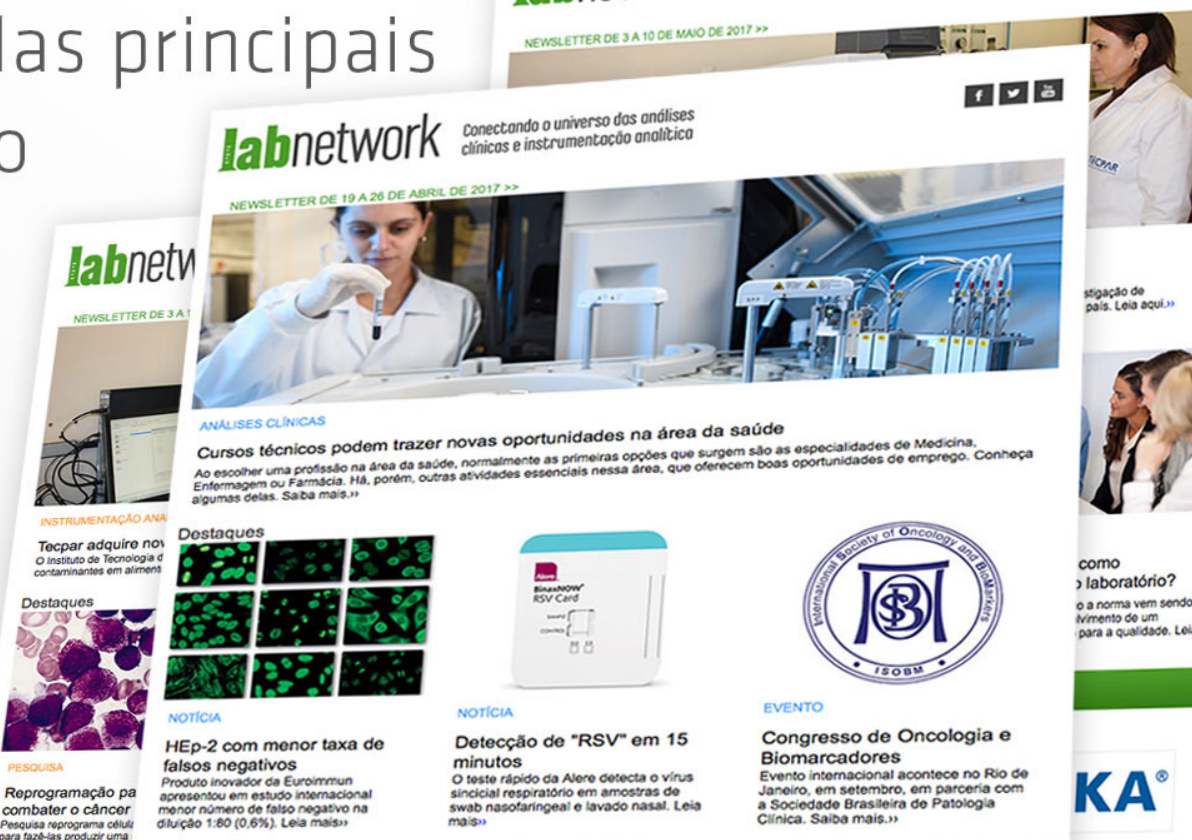

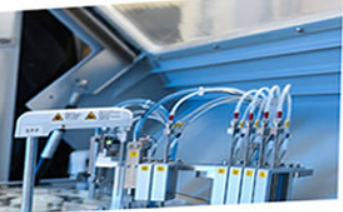

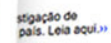
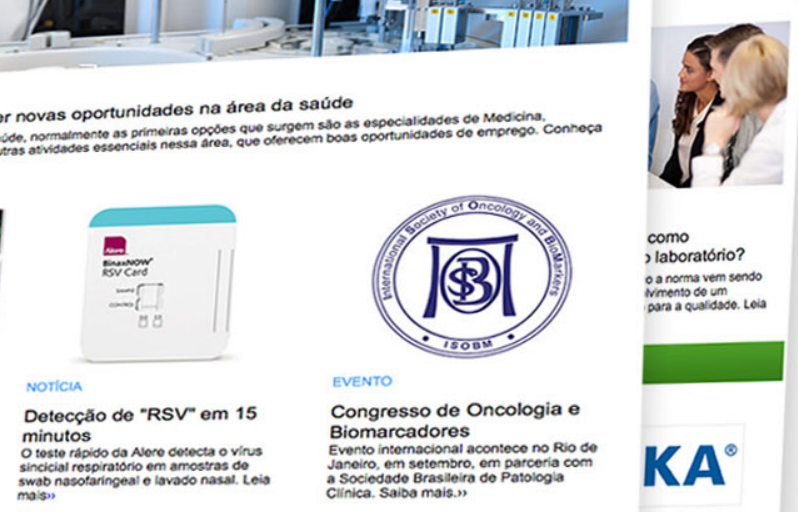

como
, laboratorio?

oa norma vem sendo
Nimento do um
para a qualidsoce. Lois

(15034.

Congresso de Oncologia e

Biomarcadores

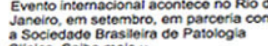




\section{Scientia Chromatographica}

\section{Volume 11, Número 4 de 2019}

Com este número chegamos ao final do Volume 11 do periódico Scientia Chromatographica.

Foi mais que uma década de extenso trabalho na captação, avaliação preliminar, revisão, edição e finalização de mais de uma centena de artigos científicos nos mais diferentes aspectos das técnicas cromatográficas foram abordados. Desde estudos fundamentais até aplicações; desde o desenvolvimento de dispositivos instrumentais até colunas especiais como quirais; desde sistemas analíticos em macro escala até nanoLC; desde o uso de detectores simples, até espectrometria de massas em tandem, uma diversidade de enfoques foi assegurada.

Foi mais um ano no qual a distribuição eletrônica do Scientia foi gratuita tanto para os leitores, quanto para os autores, sem burocracia. Basta entrar no website do periódico, localizar o artigo de interesse e baixar o mesmo sem sequer se identificar. Esperamos que os leitores tenham gostado desta simplicidade para obter os artigos de interesse.

Chegando ao final de mais um número, esperamos que o Scientia continue a contar com o interesse de nossos leitores e autores, inclusive de outros países, como tem sido visto nos últimos volumes do periódico.

Desejamos a todos um final de ano bastante festivo, e que a cromatografia continue a separar as moléculas e unir as pessoas. 


\section{Novas perspectivas em técnicas de microextração estática}

\section{Alessandra Honjo Ide, José \\ Manuel Florêncio Nogueira*}

Centro de Química Estrutural

and Departamento de Química e

Bioquímica, Faculdade de Ciências,

Universidade de Lisboa, 1749-016

Lisboa, Portugal

*DQB/FCUL, Campo Grande Ed. C8

1749-016 Lisboa, Portugal

Tel.: +351-217500899

nogueira@fc.ul.pt

\begin{abstract}
Resumo
A determinação vestigial de compostos orgânicos prioritários ou emergentes em matrizes com elevada complexidade, exige o recurso a técnicas analíticas adequadas para o preparo da amostra prévia à análise instrumental. Nas últimas três décadas, as técnicas de microextração estática têm evidenciado grande preponderância na monitorização de contaminantes orgânicos em diversos tipos de amostras, em combinação com a grande seletividade e sensibilidade da instrumentação analítica moderna. Embora a literatura proponha diversas técnicas de microextração, muitas das abordagens, para além de onerosas, apresentam diversas limitações do ponto de vista prático, são ambientalmente questionáveis e exigem aperfeiçoamento com a finalidade de poderem ser facilmente aplicadas em rotina.

Recentemente, foram introduzidos dispositivos analíticos de última geração

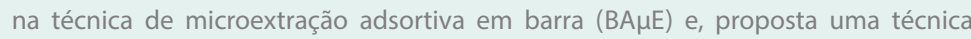

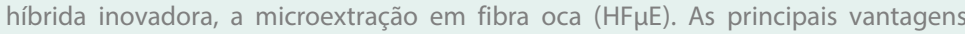
destas novas abordagens são, para além dos dispositivos poderem ser facilmente preparados no próprio laboratório, a grande simplicidade, fácil manipulação, elevado custo-benefício, sustentabilidade ecológica, assim como exequibilidade para o trabalho de rotina.
\end{abstract}

A presente contribuição pretende perspetivar um outro olhar sobre as vantagens das técnicas de microextração estática, com especial ênfase para as inovações introduzidas pelas metodologias $\mathrm{BA} \mu \mathrm{E}$ e $\mathrm{HF} \mu \mathrm{E}$, como ferramentas analíticas alternativas para a monitorização vestigial de contaminantes orgânicos com impacto.

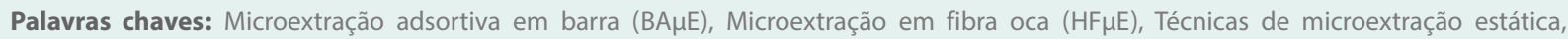
Tecnologia de amostragem por flutuação, Amostras reais

\footnotetext{
Abstract

The trace determination of priority or emerging organic compounds in matrices with high complexity, requires the use of appropriate analytical techniques for sample preparation prior to instrumental analysis. In the last three decades, the static microextraction techniques have shown great preponderance to monitor organic contaminants in different types of samples, in combination with the great selectivity and sensitivity of the modern analytical instrumentation. Although the literature proposes several microextraction techniques, most of the approaches, apart from being expensive, present several limitations from the practical point of view, are environmentally questionable and require improvement in order to be easily applied in routine.

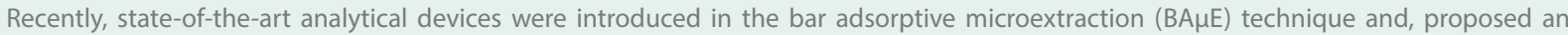
innovative hybrid technique, the hollow fiber microextraction $(\mathrm{HF} \mu \mathrm{E})$. The main advantages of these new approaches are, in addition to the devices being easily prepared at the laboratory, the great simplicity, easy handling, high cost-benefit, ecological sustainability, as well as feasibility for routine work.

The present contribution intends to envisage another perspective on the advantages of static microextraction techniques, with special emphasis on the innovations introduced by $\mathrm{BA \mu E}$ and $\mathrm{HF \mu E}$ methodologies, as alternative analytical tools for monitoring traces of organic
} 
contaminants with impact.

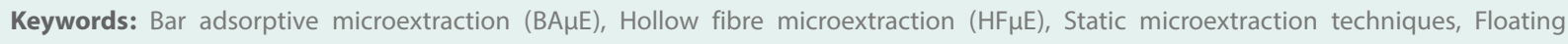
sampling technology, Real samples

\section{Introdução}

A análise direta de contaminantes orgânicos em matrizes complexas é uma tarefa árdua de efetuar, uma vez estes compostos ocorrerem genericamente quase sempre em concentrações vestigiais juntamente com dezenas ou mesmo centenas de potenciais interferentes. Na esmagadora maioria das situações, a preparação ou preparo da amostra é uma obrigação indispensável para enriquecimento prévio à aplicação de técnicas cromatográficas e/ou hifenadas adequadas, podendo esta tarefa ser responsável por mais de $80 \%$ do tempo despendido em muitos dos protocolos analíticos [1].

Nos últimos anos, as técnicas convencionais de preparo de amostras que envolvem extração líquido-líquido ou extração em fase sólida têm vindo a ser amplamente substituídas por técnicas inovadoras para o enriquecimento e pré-concentração dos analitos alvo, capazes de incrementar quer a sensibilidade quer a seletividade analíticas [2]. Mesmo assim, estas tendências emergentes visaram, numa primeira fase, a miniaturização dos dispositivos analíticos, diminuição do volume da amostra, bem como a redução ou mesmo a eliminação de solventes orgânicos tóxicos em linha com os princípios da química analítica verde [3].

Neste âmbito, as técnicas de microextração estática introduzidas nas últimas três décadas, têm vindo a adquirir maior visibilidade, face ao notável desempenho e demonstração de eficácia no domínio da análise vestigial em diversos tipos de matrizes, como etapa de enriquecimento prévia à análise instrumental. Porém, nas técnicas de microextração estática, o meio extrator tanto pode ser à base de fases sólidas como de líquidas. Na atualidade, de entre as abordagens de microextração estática baseadas em fases sólidas, destacam-se a extração em fase sólida dispersiva (DSPE) $[4,5]$, a microextração em fase sólida (SPME) [6, 7], a extração sortiva em barra de agitação (SBSE) $[8,9]$ e, mais recentemente, a microextração adsortiva em barra $(\mathrm{BA} \mu \mathrm{E})[10,11]$. Em alternativa, as técnicas de microextração estática baseadas em líquidos, mais referenciados na literatura, são a microextração em gota única (SDME) [12, 13], a microextração em fase líquida suportada com fibra oca (HF-LPME) [14, 15] e a microextração líquido-líquido dispersiva (DLLME) $[16,17]$. A figura 1 reproduz imagens dos dispositivos e aparatos analíticos relativos às principais técnicas de microextração estática baseadas em fases líquidas (a) e sólidas (b), atualmente mais usadas em análise vestigial durante o processo de preparo de amostras.
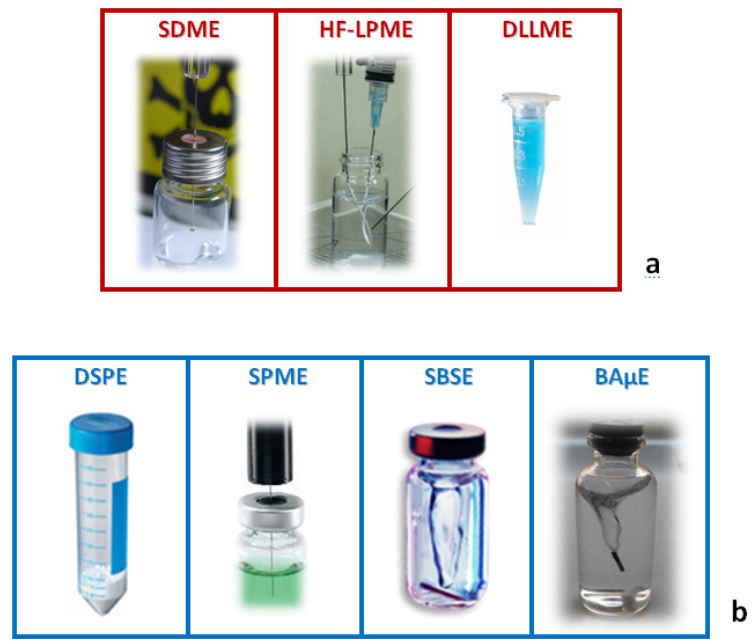

Figura 1. Imagens dos dispositivos e aparatos analíticos, relativos às principais técnicas de microextração estática baseadas em fases líquidas (a) e sólidas (b), atualmente mais usadas em análise vestigial. 
Muitas das técnicas de microextração estática referidas apresentam diversas outras vantagens, nomeadamente, maior facilidade de manipulação, baixo custo e capacidade para operar em rotina. Mesmo assim, para além dos benefícios introduzidos, algumas destas metodologias apresentam ainda diversas limitações do ponto de vista prático, morosidade e dificuldade de interface ou associação com os sistemas de instrumentação convencionais. Neste contexto, a presente contribuição tem como objetivo abordar novas perspetivas recentemente propostas, no domínio das técnicas de microextração estática, com o intuito de superar algumas das insuficiências anteriormente referidas.

\section{Vantagens e limitações das técnicas modernas de preparo de amostras}

Sendo o preparo da amostra o procedimento mais relevante e limitativo em qualquer processo analítico, uma vez ser o principal responsável por eventuais erros associados e significativo dispêndio de tempo, é de todo justificável o grande desenvolvimento neste domínio que vem acontecendo nas últimas décadas. Embora sejam propostas na literatura diversas técnicas diferenciadas para enriquecimento de amostras, é praticamente impossível eleger apenas uma que seja considerada como de abordagem universal sendo, portanto, obrigatório tomar sempre em consideração as características do(s) analito(s) alvo, do tipo de matriz envolvida, assim como do teor expectável. Apesar das técnicas de microextração frequentemente adotadas serem dedicadas à análise vestigial em amostras complexas é, todavia, fundamental o conhecimento objetivo das caraterísticas quer de volatilidade quer de polaridade dos compostos alvo envolvidos, no sentido de se selecionar a mais adequada para cada caso em apreço. Genericamente, compostos orgânicos apolares ou com caraterísticas mais hidrofóbicas $\left(\log K_{\mathrm{O} / \mathrm{W}} \geq 3\right)$ são mais facilmente microextraídos por solventes orgânicos imiscíveis em meios aquosos, embora os mais polares ou hidrofílicos $\left(\log K_{\mathrm{O} / \mathrm{W}}<3\right)$, sejam melhor retidos em materiais poliméricos ou sólidos devendo-se, neste sentido, atender a esta diferenciação objetiva. Por outro lado, de entre as técnicas de microextração anteriormente referidas, é igualmente difícil selecionar uma que apresente simultaneamente simplicidade, baixo custo, facilidade de manipulação, seja completamente ecológica e com possibilidade de automatização, evidenciando todas elas vantagens e inconvenientes neste domínio. As técnicas de microextração baseadas em fases sólidas como a SPME, a SBSE, a BA $\mu$ E ou a DSPE, para além de serem de fácil aplicação, são consideradas amigas do ambiente, podendo ainda as duas primeiras ser automatizadas e facilmente usadas em rotina com diversas configurações (ex., imersão, in-tube e headspace) [18, 19]. Mesmo assim, qualquer destas técnicas necessita sempre de uma etapa de retroextração, genericamente realizada por dessorção líquida (LD) ou térmica (TD), dependendo das propriedades físico-químicas dos analitos alvo e da instrumentação envolvida, sendo a última opção ecologicamente mais favorável, uma vez tratar-se de uma abordagem isenta de solventes orgânicos, i.e., solventless ou solvent-free. Por outro lado, a TD é apenas compatível com sistemas de cromatografia em fase gasosa (GC) e, dedicada exclusivamente, para compostos com caraterísticas desde voláteis a semi-voláteis. Em contrapartida, apesar da LD ser mais versátil e abrangente, menos onerosa e até permitir reanálises, a principal limitação encontra-se associada ao maior tempo despendido face à exigência dos diversos passos envolvidos, tornando a manipulação do utilizador incompatível em ambiente de rotina. Contrariamente às anteriores, as técnicas de microextração baseadas em fases líquidas, como a SDME, a HF-LPME ou mesmo a DLLME, permitem o fácil enriquecimento com cinética rápida e, possibilitam ainda, elevado fator de concentração. Todavia, mesmo apesar de utilizarem materiais, solventes e aparatos expeditos, para além de pouco onerosas, exigem do ponto de vista prático diversos passos durante os ensaios experimentais sendo, igualmente, de difícil automatização.

Não obstante as diversas desvantagens apontadas pelas técnicas mencionadas, é imperativa a introdução 
de ideias inovadoras, ou estratégias simples, para o desenvolvimento de abordagens dedicadas à análise de rotina, que apresentem elevado custo-benefício e sejam compatíveis com os sistemas instrumentais convencionais disponíveis em laboratórios comuns de química analítica. Acresce que um outro desafio consiste em alcançar o compromisso entre a qualidade dos resultados e a operacionalidade das metodologias utilizando, contudo, processos analíticos simplificados, de fácil utilização e impacto ambiental negligenciável. Nesta perspetiva, foram recentemente propostas duas abordagens inovadoras, nomeadamente o aperfeiçoamento da técnica BA $\mu \mathrm{E}$ [20] e, a introdução de uma técnica híbrida, a microextração em fibra oca $(\mathrm{HF} \mu \mathrm{E})$ [21] que, para além de poderem funcionar complementarmente, visam solucionar diversas das limitações anteriormente mencionadas.

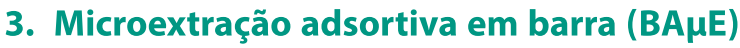

\subsection{Fundamentos e principais características}

A técnica BA $\mu \mathrm{E}$ foi proposta por J.M.F. Nogueira e colaboradores em 2010 [10, 11, 22], tendo sido inicialmente concebida para solucionar a limitação da SBSE para analitos polares, uma vez esta última, apesar de ambientalmente favorável, utilizar exclusivamente polidimetilsiloxano (PDMS), um polímero vocacionado para analitos hidrofóbicos [23]. Neste sentido, esta abordagem analítica enquadrou-se como alternativa complementar e promissora, fundamentalmente para a determinação vestigial de compostos com características mais polares, tendo demonstrado excelente desempenho em diversos domínios de aplicações, nomeadamente na monitorização de subprodutos da desinfeção de água para consumo humano [24], compostos derivados aromáticos [25-27], pesticidas [28-37], produtos farmacêuticos, de higiene e cuidado pessoal [38-47], esteroides e hormonas [48, 49], drogas de abuso [50], biomarcadores [51], entre outras classes de compostos, numa ampla gama de matrizes ambientais, alimentares, farmacêuticas, forenses e biológicas.
Nesta técnica são utilizados dispositivos analíticos constituídos por um substrato à base de polipropileno (PP) contendo geometria cilíndrica, onde são fixados os materiais sorventes finamente divididos. Um dos aspetos claramente diferenciadores, comparativamente a muitas outras técnicas de microextração, é a possibilidade dos dispositivos $\mathrm{BA} \mu \mathrm{E}$ poderem ser preparados e, de forma muito simples em qualquer laboratório, evitando a dependência e os elevados custos geralmente associados às tecnologias apenas disponíveis comercialmente. Originalmente, os dispositivos BA $\mu \mathrm{E}$ possuíam dimensões com 15,0 mm de comprimento e 3,0 mm em diâmetro e eram revestidos com fase sorvente contendo massa compreendida entre 1 e 5 mg. Durante a etapa de microextração e, por serem menos densos que a água, os dispositivos flutuam na amostra junto ao vórtice gerado com recurso a agitação magnética convencional. É justamente durante esta etapa que ocorre o enriquecimento através da difusão dos analitos do seio da amostra para a fase sorvente. Esta inovadora abordagem de enriquecimento, designada por 'tecnologia de amostragem por flutuação', é vantajosa uma vez evitar a ocorrência de choques mecânicos entre os dispositivos e as paredes dos frascos de amostragem, resultantes da rápida agitação magnética, que poderiam promover a desagregação da fase sorvente. Uma das principais vantagens da técnica $\mathrm{BA} \mu \mathrm{E}$, consiste na possibilidade da escolha da fase sorvente mais seletiva, de acordo com as características de polaridade dos analitos envolvidos tentando-se, desta forma, alcançar a máxima eficiência durante a etapa de microextração. Neste contexto, são utilizados materiais nanoestruturados contendo textura conveniente, porosidade bem desenvolvida ao nível dos mesoporos e possuindo centros ativos adequados, aos quais os compostos polares são facilmente adsorvidos por fenômenos eletrostáticos e dispersivos (propriedades de adsorção/dessorção) ou ainda através de outro tipo de interações. Refira-se que os sorventes sólidos que têm vindo a ser usados pela técnica $\mathrm{BA} \mu \mathrm{E}$ são fundamentalmente carvões ativados (ACs) [22, 29, 40, 41] e polímeros [22, 29, 35, 40, 41], mas também, polímeros molecularmente impressos [33], nanotubos de carbono [47], quer adquiridos comercialmente quer preparados laboratorialmente, por exemplo, a partir de materiais com 
diversa origem, destacando-se os biomateriais [32, 38, 46]. Quando finamente divididos, estes materiais caracterizamse ainda por possuírem áreas superficiais consideráveis (> $\left.900 \mathrm{~m}^{2} \mathrm{~g}^{-1}\right)$ e apresentarem grande capacidade sortiva (100$500 \mu \mathrm{g}$ analito/mg sorvente) que, contrariamente a outras abordagens, se tornam ideais para a determinação vestigial de compostos orgânicos mais polares, podendo contudo responder a uma ampla gama de polaridade [22].

Apesar de todas as vantagens e robustez já evidenciadas pela técnica $\mathrm{BA} \mu \mathrm{E}$, nomeadamente excecional relação custo-benefício, fácil aplicabilidade e a possibilidade de selecionar a fase sorvente mais conveniente para cada aplicação em particular, existem ainda limitações pontuais passíveis de serem aperfeiçoadas. Recentemente, foram introduzidos alguns progressos [30] que consistiram fundamentalmente na redução da dimensão do dispositivo $\mathrm{BA} \mu \mathrm{E}$ para metade do tamanho original, com o intuito de se eliminar diversos passos que incluíam a evaporação e 'troca de solvente', para além de possibilitarem a diminuição substancial do volume em solvente orgânico (de 1,5 $\mathrm{mL}$ para apenas $200 \mu \mathrm{L}$ ) necessário à etapa de retroextração, com todas as vantagens ecológicas que isso representa. Apesar da retroextração ter evoluído para uma etapa que recorre a volume de solvente da ordem dos microlitros ( $\mu \mathrm{LD})$, manteve-se limitativa do ponto de vista prático, uma vez continuar a persistir a necessidade de manipulação de diversos passos. Recorde-se, neste contexto, que após a etapa de microextração, o dispositivo é removido do frasco de amostragem e transferido para um insert, contendo um solvente orgânico adequado, colocado dentro de um vial convencional $(2 \mathrm{~mL})$ sendo, de seguida, efetuado tratamento ultrassónico. Posteriormente, retirase o dispositivo do insert e sela-se o vial, contendo o microextrato orgânico resultante, podendo de imediato, ser submetido a análise instrumental. Por conseguinte, nesta tecnologia continuam inequivocamente a persistir diversos passos de manipulação, particularmente durante a etapa de retroextração, sendo por esse motivo, de difícil adequação ao regular trabalho de rotina.

\subsection{Dispositivos $B A \mu E$ de última geração}

No sentido de superar diversas das limitações anteriormente mencionadas, foram recentemente propostas inovações na técnica $\mathrm{BA} \mu \mathrm{E}$ que, para além de proporcionarem a alteração das dimensões dos dispositivos, consistiram ainda na simplificação global do procedimento experimental, através da introdução de um 'ciclo analítico inovador', formado por uma etapa de retroextração realizada em apenas um único passo [20, 52]. Nesta perspetiva, foram introduzidos dispositivos $\mathrm{BA} \mu \mathrm{E}$ de última geração como os apresentados na figura $2 \mathrm{a}$, constituídos por substratos à base de nylon contendo geometria cilíndrica, dimensões menores $(7,5 \mathrm{~mm}$ de comprimento e $1,0 \mathrm{~mm}$ em diâmetro) e maior flexibilidade que os originais, sendo a fixação das fases sorventes em tudo efetuada de forma semelhante. Por outro lado, os novos dispositivos $\mathrm{BA} \mu \mathrm{E}$ foram ainda concebidos para o melhoramento de diversos aspetos, nomeadamente, o aumento da razão de fase $(\beta)$ entre o sorvente e a matriz da amostra durante a etapa de microextração, mas também para a diminuição drástica do volume $(100 \mu \mathrm{L})$ de solvente envolvido na etapa de retroextração e, que fosse considerado aceitável, do ponto de vista da sustentabilidade ecológica. Para além disso, uma vez os dispositivos serem preparados com materiais simples e de muito baixo custo, foram concebidos para serem descartáveis, ou seja, utilizados apenas uma única vez por amostra, evitando assim potenciais contaminações sobretudo quando está implícita análise vestigial. Deste modo, no novo ciclo analítico proposto, após a etapa de microextração, o dispositivo analítico é retirado do frasco de amostragem $(25 \mathrm{~mL})$, sendo igualmente colocado num insert, contendo um solvente orgânico adequado, dentro de um vial e, de seguida, selado sem qualquer tipo de manipulação adicional. Após vortex, o vial contendo o microextrato conjuntamente com o dispositivo BA $\mu \mathrm{E}$ fica imediatamente disponível para ser colocado no amostrador automático e apto a ser analisado. Face à pequena dimensão e flexibilidade apresentada pelos dispositivos BA $\mu \mathrm{E}$ de última geração, a etapa da retroextração é realizada num único passo, sem a necessidade da remoção do dispositivo do insert, havendo espaço suficiente para a entrada da agulha da seringa aquando da injeção automática. Refira-se 
que esta operação decorre sem qualquer risco de dano para a agulha do injetor ou, qualquer outro tipo de problema técnico sendo, por esse motivo, totalmente compatível com os sistemas de amostradores convencionais e proporcionar trabalho de rotina. A figura 3 reproduz o esquema do ciclo analítico inovador relativo ao procedimento experimental
Em suma, a técnica $\mathrm{BA} \mu \mathrm{E}$ foi basicamente concebida para dar resposta à monitorização de compostos orgânicos prioritários e emergentes, principalmente os que apresentam características mais hidrofílicas, uma vez

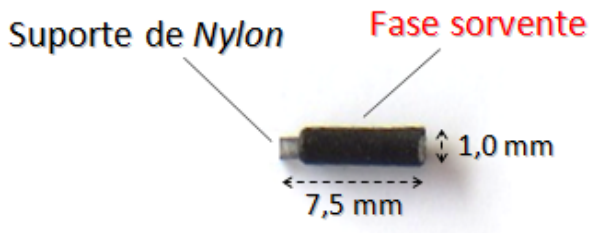

a

\section{Membrana oca de Teflon (Solvente imobilizado )}

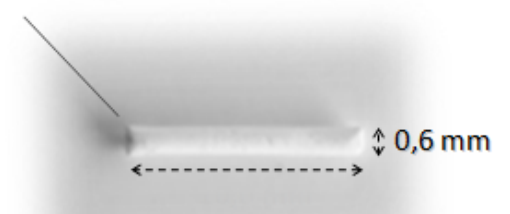

b

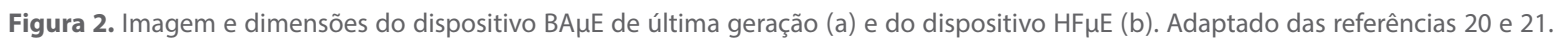

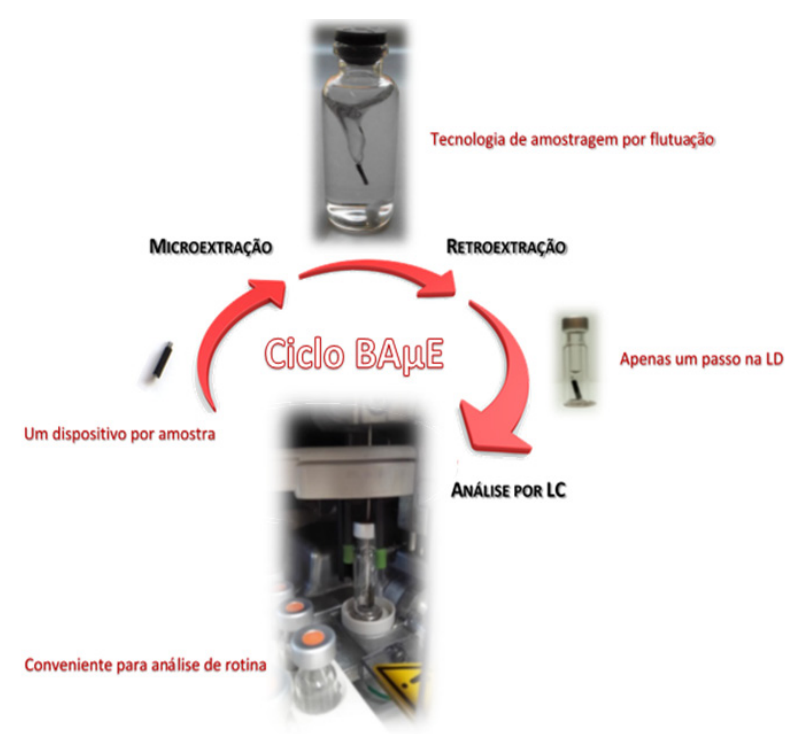

Figura 3. Ciclo analítico inovador introduzido com os dispositivos $\mathrm{BA} \mu \mathrm{E}$ de última geração. Adaptado da referência 20.

proposto para os dispositivos $\mathrm{BA} \mu \mathrm{E}$ de última geração, observando-se uma abordagem claramente vantajosa quer do ponto de vista da simplicidade para o utilizador e custobenefício, quer ainda para a sustentabilidade ecológica e produtividade analítica. serem melhor microextraídos de meios aquosos através de sorventes nanoestruturados. Contudo, esta metodologia tem igualmente demonstrado grande eficácia para uma gama alargada de compostos com impacto que se apresentam mais hidrofóbicos, sendo por este motivo uma técnica tanto vocacionada para associação com sistemas de cromatografia líquida de alta eficiência(HPLC) como de GC.

\subsection{Aplicações dos dispositivos BA $\mathrm{HE}$ de última geração}

Para demonstrar o desempenho analítico das inovações introduzidas, os novos dispositivos $\mathrm{BA} \mu \mathrm{E}$ foram testados eficazmente na determinação vestigial de fármacos antidepressivos (bupropiona, trazodona, citalopram e amitriptilina) em amostras biológicas como plasma e urina [20] e, de filtros UV (ácido 2-fenil-5benzemidazol sulfônico e ácido 5-benzoil-4-hidroxi-2metóxi-benzeno sulfónico), em matrizes ambientais e cremes de proteção solar [52]. As metodologias foram desenvolvidas, otimizadas e validadas, tendo evidenciado excelente desempenho na análise vestigial dos compostos 
alvo referidos, com recurso a análise por HPLC e deteção por rede de díodos (DAD) em ambas as aplicações. A figura 4 reproduz perfis cromatográficos obtidos a partir da monitorização vestigial de antidepressivos numa amostra de urina (a) e de filtros UV num creme de proteção solar (b) por $\mathrm{BA} \mu \mathrm{E}-\mu \mathrm{LD} / \mathrm{HPLC}-\mathrm{DAD}$, onde é notória grande seletividade e sensibilidade. A introdução dos dispositivos $\mathrm{BA} \mu \mathrm{E}$ de última geração, permitiu que esta técnica apresentasse ainda maior simplicidade, ser mais amiga do usuário e do ambiente, e inequivocamente compatível com o trabalho de rotina.
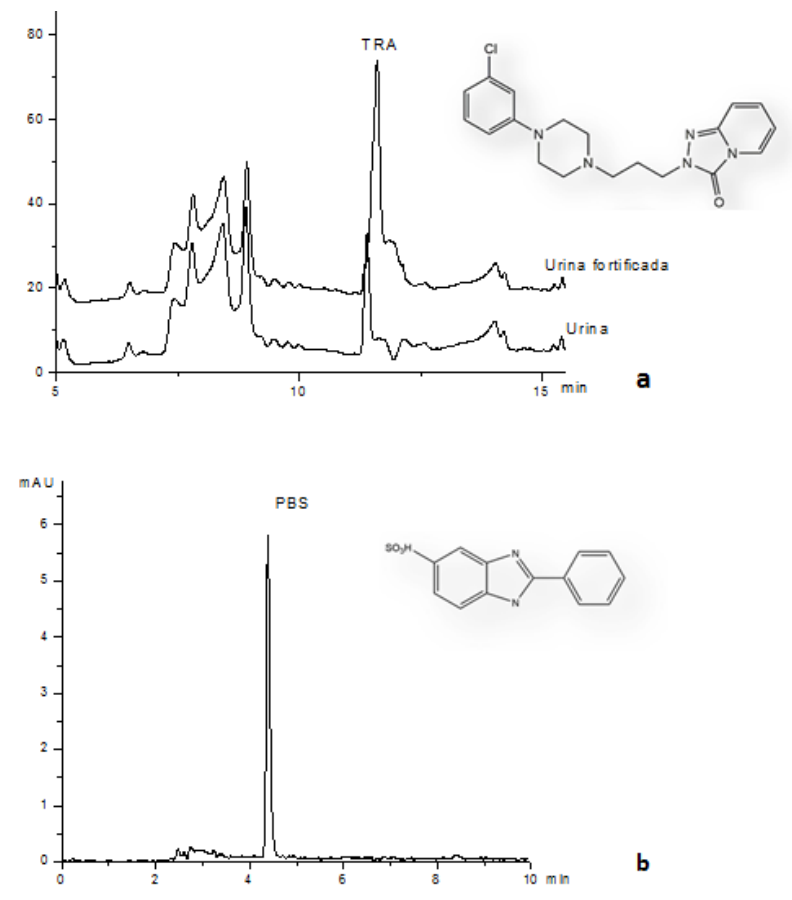

Figura 4. Cromatogramas exemplificando a aplicação da técnica $\mathrm{BA} \mu \mathrm{E}-\mu \mathrm{LD}$, usando os dispositivos de última geração, na determinação vestigial de fármacos antidepressivos numa amostra de urina (a) e de filtros UV num creme de proteção solar (b), seguido de análise por HPLC-DAD. TRA: trazodona; PBS: ácido 2-fenil-5-benzemidazol sulfónico. Adaptado das referências 20 e 52.

Por último, refira-se que face ao enorme sucesso analítico alcançado, a técnica $\mathrm{BA} \mu \mathrm{E}$ tem continuado a ser alvo de outros aperfeiçoamentos e conceções inovadoras, destacando-se a recente proposta dos dispositivos de alto rendimento [53].

\section{Microextração em fibra oca (HF $\mu \mathrm{E})$}

\subsection{Conceitos e principais características}

A microextração em fibra oca $(\mathrm{HF} \mu \mathrm{E}$ - hollow fiber microextraction), é uma técnica inovadora proposta igualmente para a análise vestigial de compostos orgânicos em matrizes reais $[21,54]$. A técnica $\mathrm{HF} \mu \mathrm{E}$ pode ser entendida como uma abordagem híbrida, uma vez reunir conjuntamente as principais caraterísticas diferenciadoras de diversas técnicas de microextração estática, nomeadamente da HF-LPME, da SDME e da BA $\mu$ E. Esta metodologia surgiu como alternativa simples e prática relativamente aos métodos analíticos de microextração bem estabelecidos que recorrem a fibras ou membranas ocas $[14,15,55,56]$, os quais envolvem sempre diversos passos de manipulação durante o processo de enriquecimento, como é o caso particular da HF-LPME. Genericamente, esta técnica inclui, a utilização de microseringas para inserção do solvente no lúmen da membrana, selagem das pontas para a etapa de microextração, corte das extremidades seladas para retirar alguns $\mu \mathrm{L}$ do solvente enriquecido para posterior injeção instrumental, não sendo por esse motivo, nem prática nem conveniente para a aplicação em contexto de rotina. Contrariamente, na técnica $\mathrm{HF} \mu \mathrm{E}$, a etapa de microextração é efetuada com um dispositivo analítico como o reproduzido na figura $2 \mathrm{~b}$, constituído por uma pequena membrana oca em PP com geometria cilíndrica, contendo $10,0 \mathrm{~mm}$ de comprimento e 0,6 mm em diâmetro interno, sendo um material de muito baixo custo. Do ponto de vista prático e, para a etapa de microextração, o dispositivo é embebido durante alguns segundos num solvente orgânico conveniente, ocorrendo a respetiva imobilização na membrana oca, retendo um volume médio de cerca de $25 \mu \mathrm{L}$. De seguida, o dispositivo $\mathrm{HF} \mu \mathrm{E}$ é inserido no frasco de amostragem contendo $25 \mathrm{~mL}$ de amostra conjuntamente com uma barra convencional de teflon para agitação magnética, sendo de seguida fechado. Para além da elevada relação de fase $(\beta=1000)$ que 
proporciona e grande capacidade de partição dos analitos para o solvente orgânico, a etapa de microextração apresenta cinética rápida, sendo esta abordagem uma vantagem inequívoca relativamente a algumas das metodologias de preparo de amostras baseadas em fases líquidas. Nesta perspetiva, o dispositivo $\mathrm{HF} \mu \mathrm{E}$ usa a mesma membrana da técnica HF-LPME, um solvente orgânico conforme acontece na técnica SDME e opera sob a tecnologia de amostragem por flutuação como na técnica BA $\mu$ E. Após alcançado o equilíbrio, o dispositivo analítico é removido do frasco de amostragem e inserido num insert, contendo um solvente orgânico conveniente $(100 \mu \mathrm{L})$, dentro de um vial, para a posterior etapa de retroextração. Seguidamente, o vial é selado e, após vortex, fica imediatamente apto para posterior análise instrumental. Para além de demonstrar extraordinária facilidade de manipulação, recorre a um volume negligenciável de solvente orgânico durante a etapa de retroextração, em linha com a sustentabilidade ecológica, sendo uma técnica fundamentalmente vocacionada para associação com GC.

Em analogia com o novo ciclo analítico proposto para a técnica $\mathrm{BA} \mu \mathrm{E}$, que recorre a dispositivos de última geração, a etapa de retroextração é de igual modo efetuada num único passo face às reduzidas dimensões e flexibilidade do dispositivo $\mathrm{HF} \mu \mathrm{E}$, sem a necessidade de remoção do mesmo, uma vez haver espaço suficiente para a posterior operação de injeção. Neste sentido, a técnica $\mathrm{HF} \mu \mathrm{E}$ pode ser facilmente combinada com os amostradores automáticos convencionais dos sistemas instrumentais comuns, particularmente de GC, sendo igualmente uma abordagem abrangente e dedicada à aplicação em rotina. A figura 5 apresenta o esquema do ciclo analítico associado à técnica $\mathrm{HF} \mu \mathrm{E}$, sendo em tudo similar ao da figura 3.

Uma das vantagens diferenciadoras desta abordagem consiste em apresentar cinética rápida durante a etapa de microextração, no qual ocorre o fenómeno de partição dos analitos entre a amostra aquosa e o solvente orgânico imobilizado na membrana oca. Neste contexto, o solvente usado no dispositivo $\mathrm{HF} \mu \mathrm{E}$ determina a afinidade dos analitos do seio da amostra para a fase líquida extratora. Assim, o solvente deve de

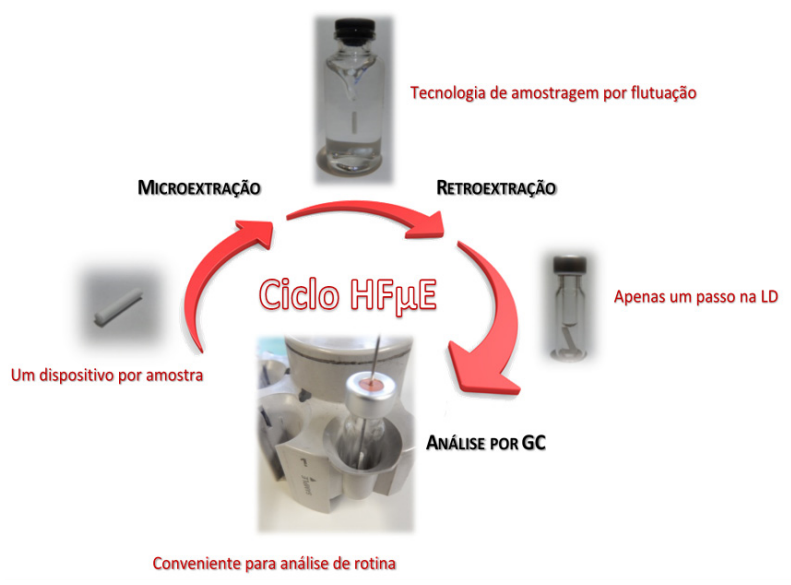

Figura 5. Ciclo analítico inovador introduzido com os dispositivos HF $\mu$ E. Adaptado da referência 21.

ser cuidadosamente selecionado tomando-se em linha de conta duas características fundamentais, nomeadamente, a volatilidade e a solubilidade que apresenta no meio aquoso durante a etapa de microextração. Deste modo, o solvente orgânico adotado deve possuir um ponto de ebulição suficientemente adequado no sentido de evitar a ocorrência de perdas por evaporação. Por outro lado, a solubilidade em água é outro fator relevante, uma vez que se o solvente apresentar elevada miscibilidade, poderem ocorrer perdas para o seio da matriz da amostra durante a etapa de microextração, diminuindo desta forma, a eficiência do processo. Como exemplo de solventes orgânicos que apresentam características compatíveis com a técnica $\mathrm{HF} \mu \mathrm{E}$, destacam-se o tolueno, o octanol, o diclorometano, os hidrocarbonetos alifáticos (ex. n-heptano, n-octano e $n$-nonano) entre outros, devendo o mesmo ser sempre criteriosamente selecionado para cada aplicação em particular. A técnica $\mathrm{HF} \mu \mathrm{E}$ foi fundamentalmente concebida para dar resposta a compostos alvo com caraterísticas mais hidrofóbicas e, portanto, melhor microextraídos por solventes face à maior solubilidade que evidenciam em meio orgânico, assim como à rápida cinética promovida por partição. Como técnica afim à $\mathrm{BA} \mu \mathrm{E}$, a $\mathrm{HF} \mu \mathrm{E}$ pode considerar-se complementar e, ser uma opção alternativa, sempre que os compostos alvo sejam predominantemente apolares e esteja implícita análise vestigial. 


\subsection{Aplicações da técnica HF $\mu E$}

No sentido de demonstrar o desempenho desta nova abordagem, a aplicação da técnica $\mathrm{HF} \mu \mathrm{E}$ seguida de análise por GC acoplada a espetrometria de massa (MS) foi testada com enorme sucesso na análise vestigial de hidrocarbonetos aromáticos policíclicos (PAHs) [21] e de pesticidas organoclorados (OCPs) [54] em diferentes tipos de matrizes reais. Neste contexto, foram estudados 18 PAHs (naftaleno, 1-metilnaftaleno, 2-metilnaftaleno, acenaftileno, acenafteno, fluoreno, fenantreno, antraceno, fluoranteno, pireno, benzo[a]antraceno, criseno, benzo[a]fluoranteno, benzo[k]fluoranteno, benzo[a] pireno, indeno[1,2,3-cd]pireno, dibenzo[a,h]antraceno e benzo[g,h,i]perileno), tendo sido microextraídos com membranas contendo $n$-nonano imobilizado, possibilitando tempos de equilíbrio reduzidos ( $1 \mathrm{~h}$ ) e alcançado limites de deteção ao nível das partes-por-trilião $\left(2,5\right.$ - 6,0 ng L $\left.{ }^{-1}\right)$. A metodologia demonstrou, de forma abrangente, excelente desempenho na análise de PAHs em diversos tipos de matrizes, nomeadamente amostras ambientais (água superficial, efluentes e solo), alimentares (chá) e biológicas (fígado de peixe).

A partir da aplicação aos OCPs foi ainda possível introduzir um aperfeiçoamento na técnica $\mathrm{HF} \mu \mathrm{E}$, tendo-se usado simultaneamente duas fibras por amostra contendo, cada uma, diferentes solventes (tolueno e heptano) imobilizados. Desta forma, reduziu-se significativamente o tempo de equilíbrio ( $2 \mathrm{~h}$ ) e incrementou-se a seletividade da metodologia, tendo sido estudados 17 OCPs $(\alpha-B H C$, $\gamma$-BHC, $\beta$-BHC, heptacloro, aldrin, heptacloro epóxido, $\gamma$-clordano, $\alpha$-clordano, $\alpha$-endosulfan, 4,4'-DDE, dieldrin, endrin, $\beta$-endosulfan, 4,4'-DDD, endrin aldeído, 4,4'-DDT e metoxicloro) em amostras ambientais (água potável, efluentes e solo) e alimentares (chá e tomate). A figura 6 reproduz perfis cromatográficos obtidos a partir da monitorização vestigial de PAHs num efluente aquoso (a) e de OCPs numa amostra de tomate (b) por HF $\mu \mathrm{E}-\mu \mathrm{LD} / \mathrm{GC}$ MS, onde é notória a grande seletividade e sensibilidade alcançadas.
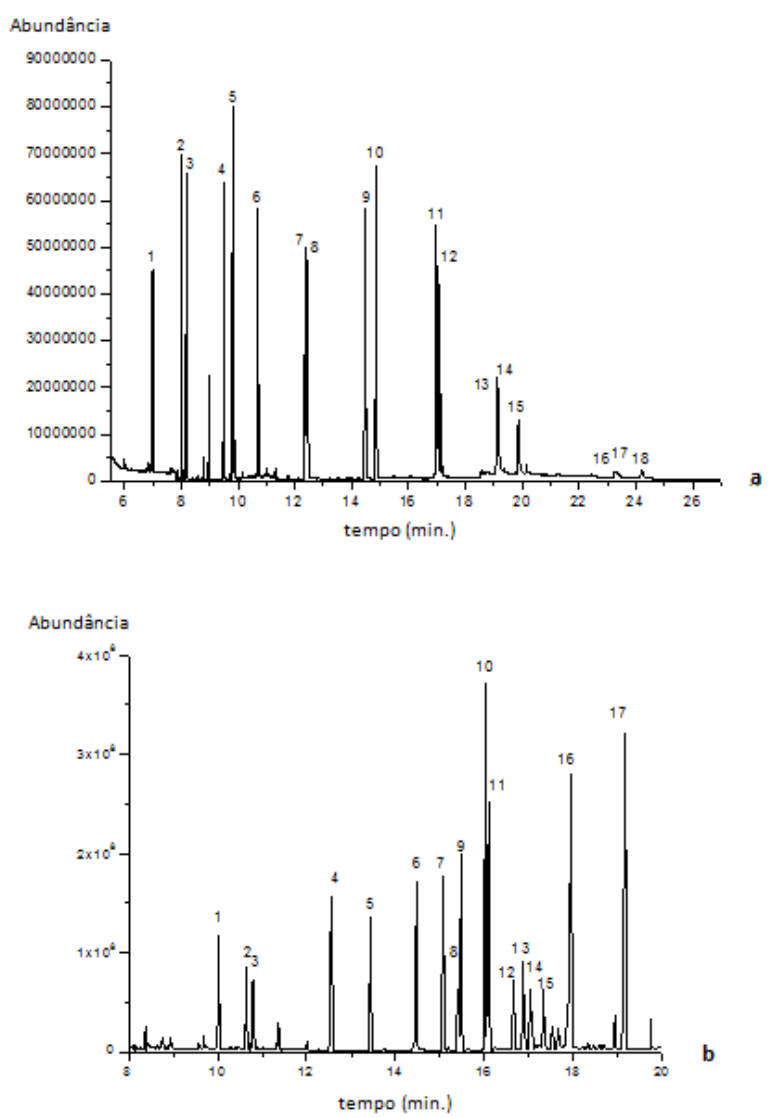

Figura 6. Cromatogramas exemplificando a aplicação da técnica $\mathrm{HF} \mu \mathrm{E}-\mu \mathrm{LD}$ na monitorização vestigial de PAHs num efluente aquoso (a) e de OCPs numa amostra de tomate (b), seguido de análise por GC-MS. PAHs: 1. naftaleno, 2. 1-metilnaftaleno, 3. 2-metilnaftaleno, 4. acenaftileno, 5. acenafteno, 6. fluoreno, 7. fenantreno, 8. antraceno, 9. fluoranteno, 10. pireno, 11. benzo[a]antraceno, 12. criseno, 13. benzo[a]fluoranteno, 14. benzo[k]fluoranteno, 15. benzo[a]pireno, 16. indeno[1,2,3-cd]pireno, 17. dibenzo[a,h]antraceno, 18. benzo[g,h,i] perileno; OCPs: 1. $\alpha$-BHC, 2. $\gamma$-BHC, 3. $\beta$-BHC, 4. heptacloro, 5. aldrin, 6. heptacloro epóxido, 7. $\gamma$-clordano, 8. $\alpha$-clordano, 9. $\alpha$-endosulfan, 10. 4,4'-DDE, 11. dieldrin, 12. endrin, 13. $\beta$-endosulfan, 14. 4,4'-DDD, 15. endrin aldeído, 16. 4,4'-DDT, 17. metoxicloro. Adaptado das referências 21 e 54 .

Os resultados obtidos demonstram que a técnica $\mathrm{HF} \mu \mathrm{E}$ é muito promissora, quando comparada com outras abordagens de microextração citadas na literatura, uma vez ser simples, de fácil aplicação em rotina, baixo custo e com consumo negligenciável de solventes orgânicos, ou seja, em linha com as tendências ecológicas atuais. 


\section{Conclusões}

Face à grande importância da etapa de preparo de amostras em qualquer protocolo analítico, a presente contribuição pretende perspetivar um outro olhar sobre as vantagens das técnicas de microextração estática, com especial ênfase para as inovações recentemente introduzidas, através das metodologias $\mathrm{BA \mu E}$ e $\mathrm{HF} \mu \mathrm{E}$, como ferramentas analíticas promissoras para a monitorização vestigial de contaminantes prioritários e emergentes com impacto.

Para além dos dispositivos analíticos poderem ser facilmente preparados no próprio laboratório, a grande simplicidade, fácil manipulação, elevado custobenefício, sustentabilidade ecológica, assim como o notável desempenho e exequibilidade que evidenciam para o trabalho de rotina, demonstram ainda ser alternativas analíticas credíveis para a microextração vestigial de compostos orgânicos com polaridade abrangente em matrizes com elevada complexidade.

\section{Agradecimentos}

Os autores agradecem à "Coordenação de Aperfeiçoamento de Pessoal de Nível Superior" pela bolsa de doutorado (CAPES BEX 0394-14-9) e à "Fundação para a Ciência e a Tecnologia" (Portugal) pelo financiamento (UIDB/00100/2020). 


\section{Referências}

[1] Chen Y, Guo Z, Wang X, Qiu C. Sample preparation. J. Chromatogr. A. 2008; 1184(1-2): 191-219.

[2] Borges KB, de Figueiredo EC, Queiroz MEC. Preparo de amostras para análise de compostos orgânicos. RJ-Brasil. LTC. 2015.

[3] Raynie DE, Modern extraction techniques. Anal. Chem. 2010; 82(12): 4911-4916.

[4] Islas G, Ibarra IS, Hernandez P, Miranda JM, Cepeda A. Dispersive solid phase extraction for the analysis of veterinary drugs applied to food samples: A review. Int. J. Anal. Chem. 2017; 1-16.

[5] Cabrera LC, Martins ML, Primel EG, Prestes OD, Adaime MB, Zanella R. Extração em fase sólida dispersiva na determinação de resíduos e contaminantes em alimentos. Sci. Chromatogr. 2012; 4(3): 227-240.

[6] Arthur CL, Pawliszyn J. Solid phase microextraction with thermal desorption using fused silica optical fibers. Anal. Chem. 1990; 62(19): 2145-2148.

[7] Valente ALP, Augusto F. Microextração por fase sólida. Química Nova. 2000; 23(4): 523-530.

[8] Baltussen E, Sandra P. Stir bar sorptive extraction (SBSE), a novel extraction technique for aqueous samples: theory and principles. J. Microcolumn. 1999; 11(10): 737-747.

[9] Nogueira JMF. Extração sortiva em barra de agitação (SBSE): Uma metodologia inovadora para microextração estática. Sci. Chromatogr. 2012; 4(4): 1-11.

[10] Neng NR, Silva ARM, Nogueira JMF. Adsorptive micro-extraction techniques -Novel analytical tools for trace levels of polar solutes in aqueous media. J. Chromatogr. A. 2010; 1217(47): 7303-7310.

[11] Nogueira JMF. Microextração adsortiva em barra (BA $\mu$ E): Um conceito analítico inovador para microextração estática. Sci. Chromatogr. 2013; 5(4): 275-283.

[12] Jeannot M, Cantwell FF. Solvent microextraction into a single drop. Anal. Chem. 1996; 68(13): 2236-2240.

[13] Pinto IP, Pedroso MP. Microextração em gota única (SDME): Fundamentos e aplicações. Sci. Chromatogr. 2015; 7(3): $183-198$.

[14] Pedersen-Bjergaard S, Rasmussen KE. Liquid - liquid - liquid microextraction for sample preparation of biological fluids prior to capillary electrophoresis. Anal. Chem. 1999; 71(14): 2650-2656.

[15] Merib J, Carasek E, Microextração em fase líquida suportada com fibra oca (HF-LPME): Fundamentos e aplicações recentes. Sci. Chromatogr. 2013; 5(4): 249-262.

[16] Rezaee M, Assadi Y, Milani Hosseini MR, Aghaee E, Ahmadi F, Berijani S. Determination of organic compounds in water using dispersive liquid-liquid microextraction. J. Chromatogr. A. 2006; 1116(1-2): 1-9.

[17] Moreira BJ, Yokoya JMC, Gaitani CM. Microextração líquido-líquido dispersiva (DLLME): fundamentos, inovações e aplicações biológicas. Sci. Chromatogr. 2014; 6(3): 186-204.

[18] Toffoli AL, Lanças FM. Recentes avanços da microextração em fase sólida no tubo (in-tube SPME) e sua aplicação em análises ambientais e alimentícias. Sci. Chromatogr. 2015; 7(4): 297-315.

[19] Queiroz MEC, Melo LP, Recentes avanços da in-tube SPME-LC para bioanálises. Sci. Chromatogr. 2013; 5(3): $167-179$.

[20] Ide AH, Nogueira JMF. New-generation bar adsorptive microextraction (BA $\mu$ E) devices for a better eco-user-friendly analytical approach - Application for the determination of antidepressant pharmaceuticals in biological fluids. J. Pharm. Biomed. Anal. 2018; 153: 126-134.

[21] Ide AH, Nogueira JMF. Hollow fiber microextraction: A new hybrid microextraction technique for trace analysis. Anal. Bioanal. Chem. 2018; 410: 2911-2920.

[22] Nogueira JMF. Novel sorption-based methodologies for static microextraction analysis: A review on SBSE and related techniques. Anal. Chim. Acta. 2012; 757: 1-10.

[23] Nogueira JMF. Stir-bar sorptive extraction: 15 years making sample preparation more environment-friendly, TrAC. 2015; 71: 214-223.

[24] Neng NR, Nogueira JMF. Determination of short chain carbonyl compounds in drinking water matrices by bar adsorptive microextraction (BA $\mu \mathrm{E})$ with in-situ derivatization. Anal. Bioanal. Chem. 2010; 398: 3155-3163.

[25] Neng NR, Nogueira JMF, Determination of phenol compounds in surface water matrices by bar adsorptive microextraction-high performance liquid chromatography-diode array detection. Molecules. 2014; 19(7): 9369-9379. 
[26] Neng NR, Sequeiros RCP, Nogueira JMF. Combining bar adsorptive microextraction with capillary electrophoresis-Application for the determination of phenolic acids in food matrices. Electrophoresis. 2014; 35(17): 2488-2494.

[27] Neng NR, Nogueira JMF. Monitoring trace levels of hydroxy aromatic compounds in urine matrices by bar adsorptive microextraction (BA $\mu$ E). Anal. Meth. 2017; 9(36): 5260-5265.

[28] Neng NR, Mestre AS, Carvalho AP, Nogueira JMF. Powdered activated carbons as effective phases for bar adsorptive microextraction $(\mathrm{BA} \mu \mathrm{E})$ to monitor levels of triazinic herbicides in environmental water matrices. Talanta. 2011; 83(5): $1643-1649$.

[29] Almeida C, Nogueira JMF. Comparison of the selectivity of different sorbent phases for bar adsorptive microextraction Application to trace level analysis of fungicides in real matrices. J. Chromatogr. A. 2012; 1265: 7-16.

[30] Almeida C, Strzelczyk R, Nogueira JMF. Improvements on bar adsorptive microextraction (BA $\mu$ E) technique - Application for the determination of insecticide repellents in environmental water matrices. Talanta. 2014; 120: 126-134.

[31] Bernarda JR, Ahmad SM, Almeida C, Neng NR, Nogueira JMF. Application of bar adsorptive microextraction-large-volume injection-gas chromatography-mass spectrometric method for the determination of trace levels of agrochemicals in real matrices. J. Braz. Chem. Soc. 2015; 26(10): 2150-2158.

[32] Dias AN, da Silva AC, Simao V, Merib J, Carasek. A novel approach to bar adsorptive microextraction: Cork as extractor phase for determination of benzophenone, triclocarban and parabens in aqueous samples. Anal. Chim. Acta. 2015; 888: 59-66.

[33] Andrade FN, Ide AH, Neng NDR, Lanças FM, Nogueira JMF. Determination of trace levels of triazines in corn matrices by bar adsorptive microextraction with a molecularly imprinted polymer. J. Sep. Sci. 2016; 39(4): 756-761.

[34] Calado BB, Ahmad SM, Almeida C, Neng NR, Nogueira JMF. Determination of trace levels of irgarol in estuarine water matrices by bar adsorptive microextraction. J. Chromatogr. Sci. 2016; 54(8): 1453-1459.

[35] de Souza MP, Rizzetti TM, Francesquett JZ, Prestes OD, Zanella R. Bar adsorptive microextraction (BA $\mu$ E) with a polymeric sorbent for the determination of emerging contaminants in water samples by ultra-high performance liquid chromatography with tandem mass spectrometry. Anal. Methods. 2018; 10(7): 697-705.

[36] Ahmad SM, Gomes MI, Ide AH, Neng NR, Nogueira JMF. Monitoring traces of organochlorine pesticides in herbal matrices by bar adsorptive microextraction - Application to black tea and tobacco. Int. J. Environ. Anal. Chem. 2019; 1-15.

[37] dos Santos AL, Krause LC, Schneider JK, Nogueira, JMF, Caramão EB. Evaluation of alpha- and beta-endosulfan residues in teas and yerba mate infusions by bar adsorptive microextraction and large volume injection-gas chromatography mass spectrometry. J. Braz. Chem. Soc. 2020; 31(3): 550-555.

[38] Neng NR, Mestre AS, Carvalho AP, Nogueira JMF. Cork-based activated carbons as supported adsorbent materials for trace level analysis of ibuprofen and clofibric acid in environmental and biological matrices. J. Chromatogr. A. 2011; 1218(37): 6263-6270.

[39] Neng NR, Nogueira JMF. Development of a bar adsorptive micro-extraction-large-volume injection-gas chromatography-mass spectrometric method for pharmaceuticals and personal care products in environmental water matrices. Anal. Bioanal. Chem. 2012; 402(3): 1355-1364.

[40] Almeida C, Stępkowska A, Alegre A, Nogueira JMF. Determination of trace levels of benzophenone-type ultra-violet filters in real matrices by bar adsorptive micro-extraction using selective sorbent phases. J. Chromatogr. A. 2013; 1311: 1-10.

[41] Almeida C, Nogueira JMF. Determination of trace levels of parabens in real matrices by bar adsorptive microextraction using selective sorbent phases. J. Chromatogr. A. 2014; 1348: 17-26.

[42] Ahmad SM, Almeida C, Neng NR, Nogueira JMF. Bar adsorptive microextraction (BA $\mu$ E) coated with mixed sorbent phases Enhanced selectivity for the determination of non-steroidal anti-inflammatory drugs in real matrices in combination with capillary electrophoresis. J. Chromatogr. B. 2016; 1008: 115-124.

[43] Ide AH, Ahmad SM, Neng NR, Nogueira JMF. Enhancement for trace analysis of sulfonamide antibiotics in water matrices using bar adsorptive microextraction (BA $\mu$ E). J. Pharm. Biomed. Anal. 2016; 129: 593-599.

[44] Ahmad SM, Ide AH, Neng NR, Nogueira JMF. Application of bar adsorptive microextraction to determine trace organic micropollutants in environmental water matrices. Int. J. Environ. Anal. Chem. 2017; 19

[45] Almeida C, Ahmad SM, Nogueira JMF. Bar adsorptive microextraction technique - Application for the determination of pharmaceuticals in real matrices. Anal. Bioanal. Chem. 2017; 409(8): 2093-2106.

[46] Mafra G, Oenning AL, Dias AN, Merib J, Budziak D, da Silveira CB, Carasek E. Low-cost approach to increase the analysis throughput of bar adsorptive microextraction $(\mathrm{BA} \mu \mathrm{E})$ combined with environmentally friendly renewable sorbent phase of recycled diatomaceous earth. Talanta. 2017; 178: 886-893. 
[47] Abujaber F, Ahmad SM, Neng NR, Martin-Doimeadios RCR, Bernardo, FJG, Nogueira JMF. Bar adsorptive microextraction coated with multi-walled carbon nanotube phases - Application for trace analysis of pharmaceuticals in environmental waters. J. Chromatogr. A. 2019; 1600: 17-22.

[48] Ahmad SM, Almeida C, Neng NR, Nogueira JMF. Application of bar adsorptive microextraction (BA $\mu$ E) for anti-doping control screening of anabolic steroids in urine matrices. J. Chromatogr. B. 2014; 969: 35-41.

[49] Almeida C, Nogueira JMF. Determination of steroid sex hormones in real matrices by bar adsorptive microextraction (BA $\mu$ E). Talanta. 2015; 136: 145-154.

[50] Neng NR, Ahmad SM, Gaspar H, Nogueira JMF. Determination of mitragynine in urine matrices by bar adsorptive microextraction and HPLC analysis. Talanta. 2015; 144: 105-109.

[51] Oenning AL, Mores L, Dias AN, Carasek E. A new configuration for bar adsorptive microextraction (BA $\mu$ E) for the quantification of biomarkers (hexanal and heptanal) in human urine by HPLC providing an alternative for early lung cancer diagnosis. Anal. Chim. Acta. 2017; 965: 54-62.

[52] Ide AH, Nogueira JMF. Determination of hydrophilic UV filters in real matrices using new-generation bar adsorptive microextraction devices. Separations 2019; 45(6): 1-11.

[53] Ahmad SM, Nogueira JMF, High throughput bar adsorptive microextraction: A novel cost-effective tool for monitoring benzodiazepines in large number of biological samples. Talanta 2019; 199: 195-202.

[54] Ide AH, Nogueira JMF. Dual-hollow fiber microextraction (dual-HF $\mu$ E) - Application for monitoring trace levels of organochlorine pesticides in real matrices. Int. J. Environ. Anal. Chem. 2019; in press

[55] Pedersen-Bjergaard S, Rasmussen KE. Liquid-phase microextraction with porous hollow fibers, a miniaturized and highly flexible format for liquid-liquid extraction. J. Chromatogr. A. 2008; 1184(1-2): 132-142.

[56] Jiang X, Lee HK. Solvent bar microextraction. Anal Chem. 2004; 76(18): 5591-5596. 


\section{GC-MS/MS versus LC-MS/MS for unambiguous identification of $\alpha$ and $\beta$-trenbolone in bovine urine}

\section{Amanda Lemes Silveira, Adriana Ferreira Faria*}

Department of Chemistry, Institute of Exact Sciences, Federal University of Minas Gerais, Belo Horizonte, Brazil.

*Department of Chemistry, Institute of Exact Sciences, Federal University of Minas Gerais, Av. Antonio Carlos, 6627, Pampulha - Belo Horizonte - MG - CEP 31270-901, Brasil. adriana@qui.ufmg.br

\section{Abstract}

This work involves the optimization of LC-MS/MS and GC-MS/MS methods for determination of $\alpha$ and $\beta$-trenbolone in bovine urine. The parameters recovery, repeatability and intermediate precision in both methods met the acceptance criteria of the Codex Alimentarius: recovery between $83.5-114 \%$ and repeatability and intermediate precision with RSD between $5.1-14.5 \%$ and $9.8-25.5 \%$ respectively, for concentrations higher than $1 \mu \mathrm{g} \mathrm{kg}^{-1}$. These methods were applied to the analyses of 5 real samples suspected of contamination. The analyses showed that derivatization with MSTFA $/ I_{2}$ followed by pure MSTFA, was an important tool to prevent false positive results. The use of microwave assisted derivatization reduced significantly the analysis time by GC-MS/MS.

Keywords: bovine urine, gas chromatography tandem mass spectrometry, liquid chromatography tandem mass spectrometry, microwave assisted derivatization, trenbolone. 


\section{Introduction}

Trenbolone is a synthetic anabolic steroid with androgenic properties and is considered an exogenous growth promoter. Trenbolone is administered to beef cattle to increase the feed efficiency and production profitability in the form of esters: acetate, hexahydrobenzylcarbonate and enanthate (1). In Canada and the USA, the use of trenbolone is approved (2-3). However, in Europe (4) and many other parts of the world, such as Brazil (5), its use is banned and the minimum required performance limit (MRPL) is $2 \mu \mathrm{g} \mathrm{kg}^{-1}$ in bovine urine (6). Trenbolone acetate implants are the most commonly used in beef cattle. After application, trenbolone acetate is hydrolyzed to $17 \beta$-trenbolone, the most active biological form of trenbolone, and excreted primarily as $17 \alpha$-trenbolone metabolite (7). Therefore, the determination of $17 \alpha$-trenbolone and $17 \beta$-trenbolone in bovine urine has been used to identify the use of trenbolone acetate.

Literature data indicate that liquid chromatography (LC) is the preferred analytical technique for identification and quantification of trenbolone in bovine urine (8-16); however, gas chromatography/mass spectrometry (GC/ MS) is also used (17-22). Sample preparation of these methods is based on trenbolone hydrolysis, which is mainly excreted in urine in the form of glucuronide and sulfate, followed by liquid-liquid extraction (LLE) and/ or solid phase extraction (SPE). GC methods presented the disadvantage of the additional derivatization step, but showed better chromatographic resolution and high sensitivity, when compared to LC methods.

The derivatization of 4,9,11-triene conjugated compounds, such as trenbolone, still pose difficulties due to the keto function in their structures. The combination of N-methyl-N-(trimethylsilyl)-trifluoracetamide (MSTFA) with catalysts may be the solution for these difficulties. Several reagents were used for derivatization of trenbolone: methoxylamine hydrochloride/pyridine followed by N,O-Bis(trimethylsilyl)trifluoroacetamide (BSTFA) (17); O-methylhydroxylamine hydrochloride/ pyridine followed by MSTFA/ trimethylsilylimidazole (TMSI) (20); TMSI:BSTFA (22) and MSTFA/I 2 (18, 21). MSTFA $/ I_{2}$ forms derivatives with specific mass spectra for $\alpha$ and $\beta$-trenbolone, at very low concentration levels, making it possible to unambiguously identify the presence of trenbolone in bovine urine (18).

In this work, GC-MS/MS and LC-MS/MS methods were optimized and applied to analysis of $17 \alpha$-trenbolone and $17 \beta$-trenbolone in bovine urine samples suspected of contamination. The GC-MS/MS method involved derivatization with $M S T F A / I_{2}$, followed by pure MSTFA, employing for the first time microwave assisted derivatization, which significantly reduced the analysis time.

\section{Experimental}

\subsection{Reagents, buffer solutions and cartridges}

All reagents were of analytical grade. Methanol was acquired from Tedia (Fairfield, USA); glacial acetic acid, enzyme $\beta$-glucuronidase from Helix pomatia (type-2, $\geq 100,000$ units $/ \mathrm{mL}$ ), diethyl ether, MSTFA and 2,2,4-trimethylpentane (isooctane) were purchased from Sigma-Aldrich (Saint Louis, USA); n-hexane was acquired from Vetec (Rio de Janeiro, Brazil); acetone was provided by J. T. Baker (Philipsburg, USA); resublimed iodine, hydrochloric acid and 2-amino-2-hydroxymethylpropane1,3-diol (TRIS) were purchased from Êxodo Científica (São Paulo, Brazil); anhydrous sodium acetate was provided by Neon Comercial (São Paulo, Brazil). Ultrapure water was generated by Milli-Q Millipore system (Billerica, USA).

Sodium acetate buffer $2 \mathrm{~mol} \mathrm{~L}^{-1}$ (pH 5.2) was prepared from a mixture of sodium acetate with acetic acid. TRIS solution $2 \mathrm{~mol} \mathrm{~L}^{-1}$ ( $\mathrm{pH} 9.5$ ) was prepared from a mixture of TRIS with hydrochloric acid.

HLB Supel cartridges (200 mg/6 mL) were purchased from Sigma-Aldrich (Saint Louis, USA) and aminopropylsilane cartridges Sep-Pak (200 mg/6 mL) were purchased from Waters (São Paulo, Brazil). 


\subsection{Standards and standard solutions}

The anabolic standards $\alpha$-trenbolone ( $\alpha \mathrm{TB})$ and $\beta$-trenbolone $(\beta \mathrm{TB})$ were acquired from Toronto Research Chemicals (North York, Canada). The internal standard methyltestosterone-D3 (MTT-D3) was acquired from RVIM National Institute for Public Health and the Environment (Bilthoven, The Netherlands).

$\begin{array}{ccccc} & \text { Individual } & \text { stock } & \text { standard solutions } \\ \text { were } & \text { prepared } & \text { at } & \text { a } & \text { concentration of }\end{array}$
$200 \mu \mathrm{g} \mathrm{mL}^{-1}$ by dissolving the mass of each compound in methanol. The anabolic working standard solution was prepared by diluting the stock standard solution in methanol to a final concentration of $0.10 \mu \mathrm{g} \mathrm{mL}^{-1}$. All solutions were stored at $-20^{\circ} \mathrm{C}$.

\subsection{Instrumentation}

The samples were incubated (TE-420EI Tecnal incubator, Piracicaba, Brazil), centrifuged (CR4i Thermo Electron Corporation centrifuge Ohio, USA) and shaken in a vortex (Ika Genius 3, Wilmington, USA). Next, the samples were dried in a shaking bath (BT-25 Yamato, Tokyo, Japan), derivatized in microwave oven (Philco PMS25N2, Pennsylvania, USA) and, finally, dried in a sample concentrator (Dri-Block DB-3 Techne, Stone, UK).

\subsection{LC-MS/MS system}

LC-MS/MS system consisted of a Agilent 1200 series liquid chromatography system equipped with an autosampler and a quaternary pump (Agilent Technologies, Santa Clara, USA) coupled to an API 5000 triple quadrupole mass spectrometer with a turbo ion spray interface (Applied Biosystems, Foster City, USA). Both systems and data treatment were controlled by Analyst 1.5.1 software (Applied Biosystems, Foster City, USA). Separation was achieved on a Poroshell 120 EC-C18 column $(50 \times 3.0 \mathrm{~mm}$, $2.7 \mu \mathrm{m}$ ) (Agilent Technologies, Santa Clara, USA) using an Acquity UPLC BEH C18 vanguard pre-column (5 x 2.1 $\mathrm{mm}, 1.7 \mu \mathrm{m}$ ) (Waters, Milford, USA). Flow rate used was
$0.7 \mathrm{~mL} \mathrm{~min}{ }^{-1}$, column temperature was set at $40{ }^{\circ} \mathrm{C}$ and injection volume was $10 \mu \mathrm{L}$. A gradient elution programmer was used with solvent A (ultrapure water) and solvent B (methanol) as follows: from 0 to $0.50 \mathrm{~min}$, the percentage of B was kept at $60 \%$ and linearly increased to $80 \%$ up to $2.50 \mathrm{~min}$; from 2.50 to $2.51 \mathrm{~min}$, B linearly increased to $100 \%$ and was kept constant up to $3.00 \mathrm{~min}$; from 3.00 to $4.50 \mathrm{~min}$, B linearly decreased to $60 \%$, and was kept up to $6 \mathrm{~min}$. Electrospray ionization was operated in the positive mode, and the source block temperature was set at $600{ }^{\circ} \mathrm{C}$ with a capillary voltage of $5.5 \mathrm{kV}$. Nitrogen gas was used as desolvation agent and as nebulizer gas at a flow rate of $50 \mathrm{psi}$, and argon was used as collision gas at a flow rate of 4 psi. Date acquisition was performed in selected reaction monitoring (SRM) and two characteristic SRM transitions were monitored for each analyte. For $\alpha \mathrm{TB}$ and $\beta \mathrm{TB}$, the precursor ion was $271.2 \mathrm{~m} / \mathrm{z}$ and product ions were 199.2 and $253.2 \mathrm{~m} / \mathrm{z}$, with declustering potential of 101 and $100 \mathrm{~V}$, collision energy of 37 and $39 \mathrm{~V}$ and collision cell exist potential of 24 and $14 \mathrm{~V}$, respectively. For MTT-D3, the precursor ion was $306.3 \mathrm{~m} / \mathrm{z}$ and product ion was 91.0, with declustering potential of $111 \mathrm{~V}$, collision energy of 39 $\mathrm{V}$ and collision cell exist potential of $20 \mathrm{~V}$.

\subsection{GC-MS/MS system}

GC-MS/MS system consisted of a gas chromatography $7890 \mathrm{~B}$ with triple quadrupole mass spectrometer 7000C (Agilent Technologies, Santa Clara, USA). Separation was performed in a column HP-5MS (30 m, 0.25 mm I.D., film thickness $0.25 \mu \mathrm{m}$ ) from J \& W column (Agilent Technologies, Santa Clara, USA), using helium (White Martins, Belo Horizonte, Brazil) as carrier gas. The chromatographic method used was optimized and validated by our group (23). The electronic beam on the mass spectrometer was set at $70 \mathrm{eV}$ in the electron ionization mode and was operated in the SRM mode. The selected precursor ions were 442.0 and $449.0 \mathrm{~m} / \mathrm{z}$ and product ions were 352.0 and $323.0 \mathrm{~m} / \mathrm{z}$ for $\alpha \mathrm{TB}$ and $\beta \mathrm{TB}$, respectively, and collision energy was $25 \mathrm{eV}$. 


\subsection{Sample preparation}

The enzymatic hydrolysis, extraction and clean-up procedures consisted of: [1] $2 \mathrm{~mL}$ sodium acetate buffer and $50 \mu \mathrm{L} \beta$-glucuronidase from Helix pomatia were added to $5 \mathrm{~mL}$ of bovine urine for enzymatic hydrolysis, performed in an incubator under gentle stirring at $37.5^{\circ} \mathrm{C}$ for $16 \mathrm{~h}$; [2] next, $\mathrm{pH}$ was adjusted to 9.5 by adding $4 \mathrm{~mL}$ TRIS solution; [3] $5 \mathrm{~mL}$ diethyl ether were added for analyte extraction, then, a mixture was vortexed for $30 \mathrm{~s}$ and centrifuged at $4000 \mathrm{rpm}$ for $10 \mathrm{~min}$; [4] the organic phase was transferred to a $15 \mathrm{~mL}$ flask. This procedure was repeated once more and the organic phases were combined; [5] the extract was evaporated to dryness under nitrogen stream in shaking bath at $50{ }^{\circ} \mathrm{C}$ and the residue was redissolved with a mixture of $1.5 \mathrm{~mL}$ of methanol and $3 \mathrm{~mL}$ of ultrapure water; [6] $2 \mathrm{~mL}$ of hexane were added to the extract, which was vortexed for $30 \mathrm{~s}$ and centrifuged at $4000 \mathrm{rpm}$ for $10 \mathrm{~min}$ and, then, the organic phase was discarded. This procedure was repeated once more and the aqueous phases were combined; [7] the extract was transferred to a HLB cartridge (pre-conditioned with $5 \mathrm{~mL}$ of methanol and $5 \mathrm{~mL}$ of ultrapure water), which was washed with $5 \mathrm{~mL}$ of ultrapure water and $5 \mathrm{~mL}$ of methanol/water $(55: 45 \mathrm{v} / \mathrm{v})$ solution; [8] the aminopropylsylane cartridge (pre-conditioned with $5 \mathrm{~mL}$ of methanol and 5 of $\mathrm{mL}$ acetone) was coupled to the HLB cartridge, and the analytes were eluted with 5 and $3 \mathrm{~mL}$ of acetone, consecutively; [9] the eluate was evaporated to dryness under nitrogen stream in shaking bath at $50{ }^{\circ} \mathrm{C}$, and residue was re-dissolved with $500 \mu \mathrm{L}$ of methanol/water $(55: 45 \mathrm{v} / \mathrm{v})$ solution, vortexed for $30 \mathrm{~s}$ and transferred to a vial and injected in the LCMS/MS system. For GC-MS/MS analysis, this extract was dried under nitrogen stream in a sample concentrator at $60{ }^{\circ} \mathrm{C}$ and conducted to derivatization.

For blank bovine urine samples, an aliquot of the working standard solution was added before step [1].

\subsection{Derivatization for GC/MS/MS system}

Derivatization with MSTFA/ ${ }_{2}$, followed by pure MSTFA, consisted of: [1] $15 \mu \mathrm{L}$ of MSTFA/I $\mathrm{I}_{2}(0.3 \%$ $\mathrm{m} / \mathrm{v}$ ) were added to the dry extract, vortexed and kept at rest at room temperature for $5 \mathrm{~min}$; [2] the mixture was dried under nitrogen stream in a sample concentrator at $60{ }^{\circ} \mathrm{C}$. Then, $25 \mu \mathrm{L}$ of pure MSTFA were added, vortexed and derivatized using a conventional microwave oven for $2 \mathrm{~min}$ at $900 \mathrm{~W}$; [3] the mixture was again evaporated to dryness under nitrogen stream in a sample concentrator at $60{ }^{\circ} \mathrm{C}$ and the derivatized residue was re-dissolved in $100 \mu \mathrm{L}$ of isooctane, and was then injected in the GC-MS/ MS system.

\subsection{Experiments to determine linearity, recovery and precision \\ The calibration curves were prepared at} six concentration levels $(1.0 ; 1.5 ; 2.0 ; 2.5 ; 3.0$ and $4.0 \mu \mathrm{g} \mathrm{kg}^{-1}$ ) by spiking blank bovine urine samples with working standard solution volumes ranging from 0 to $200 \mu \mathrm{L}$. For LC-MS/MS analysis, $100 \mu \mathrm{L}$ of internal working standard solution were added to each point, and the ratio of the analyte peak areas to the internal standard peak area was employed in the preparation of the calibration curves. For GC-MS/MS analysis, analyte peak areas were used in the preparation of the calibration curves. Each point of the calibration curve was prepared in triplicate and the analytes were extracted according to the procedure previously described. The F-test was applied at $95 \%$ confidence level to evaluate the homogeneity of the response variances and the determination coefficient $\left(\mathrm{R}^{2}\right)$ for linear fit of the curves (24).

To evaluate precision and recovery, aliquots of $5.0 \mathrm{~mL}$ blank bovine urine were spiked at levels 1.0 and 1.5 $\mathrm{x}$ MRPL, in six replicates. The experiment was repeated by a second analyst on another day to evaluate intermediate precision. Recovery was calculated by the ratio between estimated concentration and nominal concentration. Precision was estimated from the relative standard deviation (RSD) of the estimated concentrations for six replicates at each level intra-day (repeatability) and for the results inter-day and inter-analyst (intermediate precision). 


\section{Results and Discussion}

\subsection{LC-MS/MS analysis}

In the LC-MS/MS analysis, 5 bovine urine samples presented intense signals for $\alpha \mathrm{TB}$ and minor signals for $\beta T B$, for both the quantification transition $(271.4 \rightarrow 199.2)$ and the confirmation transition $(271.4 \rightarrow 253.2)$. However, small shifts in the relative retention times $(2.92-3.36 \%)$ of the analytes in real samples were observed when compared with the spiked blank sample (Figure 1). These small deviations in the relative retention times, and the fact that the quantification and identification transitions were identical, led to the suspicion that the samples were contaminated with TB. Taking into account that urine is a complex matrix, composed mainly of water, urea, creatine, ammonia and inorganic salts, other metabolites from the diet and/or medication could be present. Therefore, a substance with the same transitions as TB and similar interaction with the stationary phase of the chromatographic column may be found in the samples, generating analytical signals in the LC-MS/MS chromatogram.

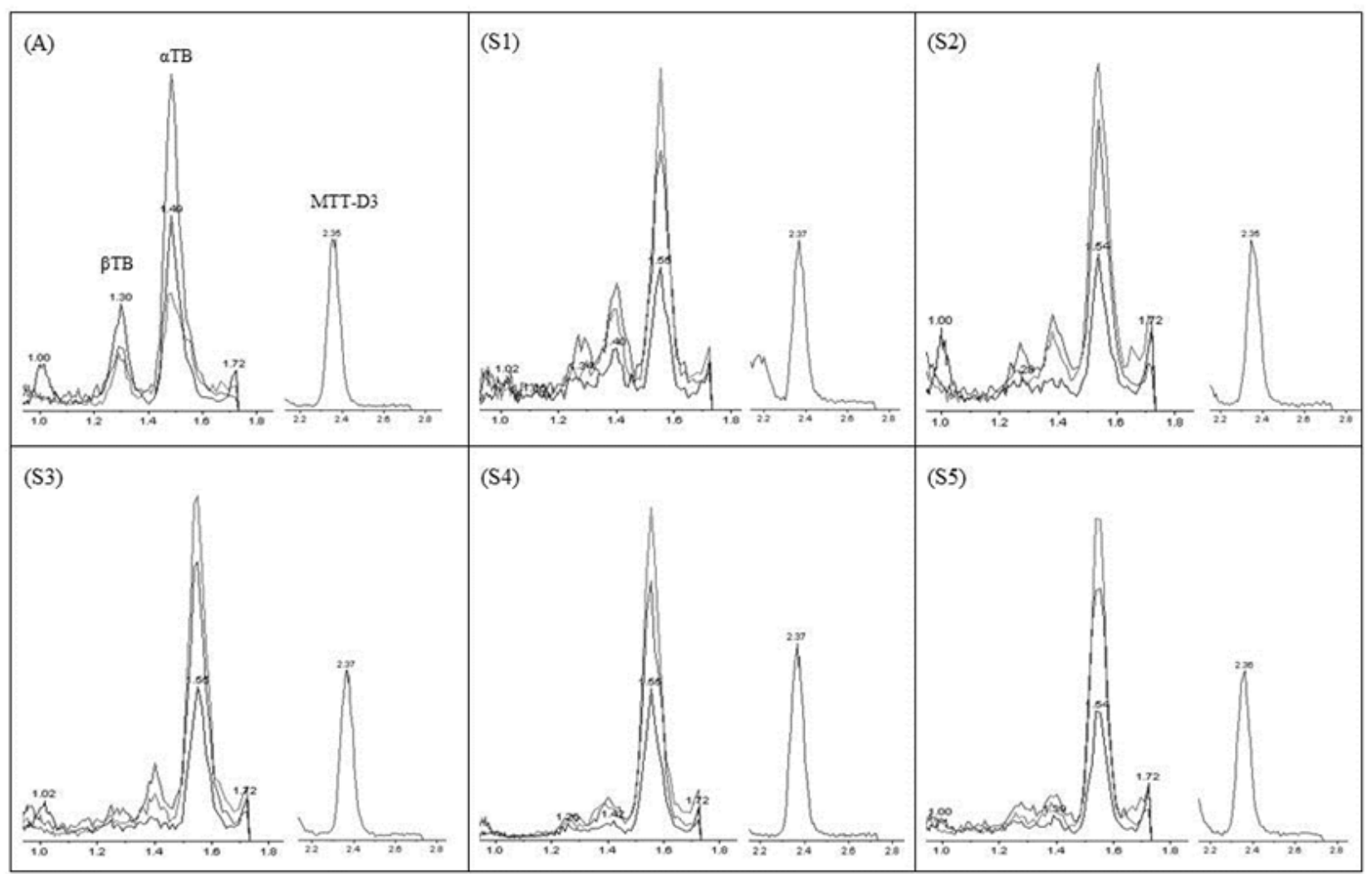

Figure 1. LC-MS/MS chromatograms for blank bovine urine spiked with $1 \mu \mathrm{g} \mathrm{kg}^{-1}$ of $\alpha$ TB and $\beta T B(A)$ and bovine urine samples (S1, S2, S3, S4 and S5)

\subsection{GC-MS/MS analysis}

The GC-MS/MS analysis of these samples was performed using a specific derivatization for conjugated 4,9,11-triene compounds, with $\mathrm{MSTFA} / \mathrm{I}_{2}$ followed by pure MSTFA. GC-MS/MS chromatograms did not provide any signal in the retention times of $\alpha \mathrm{TB}$ and $\beta \mathrm{TB}$, for the two transitions evaluated for the suspected samples (Figure 2). Thereby, this specific derivatization for conjugated 4,9,11-triene compounds is an important tool to prevent 
false positive results for TB, despite being an additional step in sample preparation.

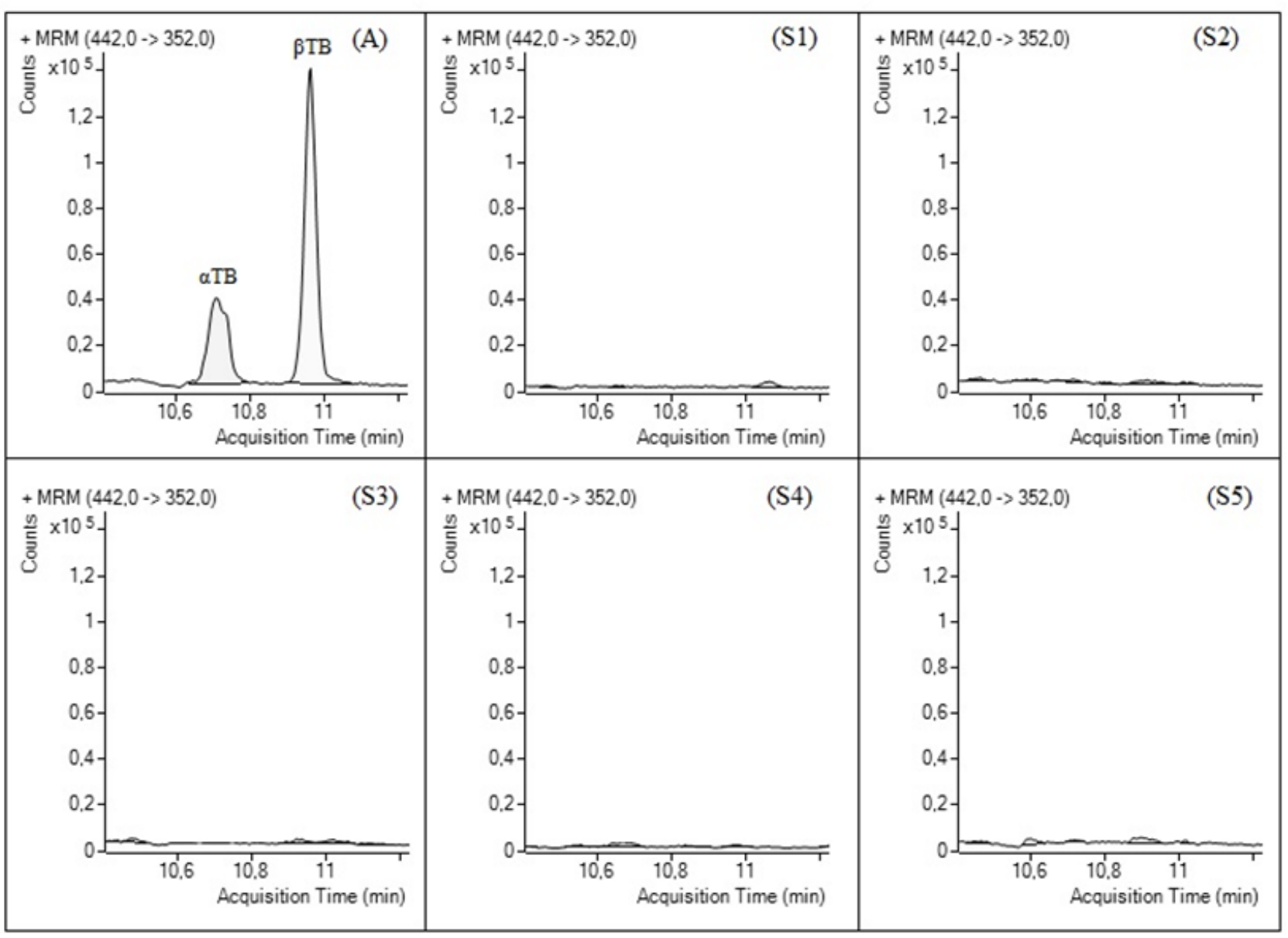

Figure 2. GC-MS/MS chromatograms for blank bovine urine spiked with $1 \mu \mathrm{g} \mathrm{kg}{ }^{-1}$ of $\alpha$ TB and $\beta$ TB (A) and bovine urine samples (S1, S2, S3, S4 and S5) for quantification transition $(442.0 \longrightarrow 352.0)$

The derivatization reaction used in this work was based on $(18,21)$, exclusively for conjugated 4,9,11-triene compounds, including $\alpha \mathrm{TB}$ and $\beta \mathrm{TB}$. In the present work, the second derivatization was conducted in a microwave oven, thus providing a total reaction time $(7 \mathrm{~min})$ much shorter when compared to the conventional heating derivatization reaction and the derivatization reaction at room temperature, which require $43 \mathrm{~min}(21)$ and $90 \mathrm{~min}$ (18), respectively.
Full scan mass spectra for $\alpha \mathrm{TB}$ and $\beta \mathrm{TB}$ in methanol, derivatized with MSTFA/I ${ }_{2}$ followed by pure MSTFA, are shown in Figure 3. The fragmentation pattern was different for each isomer. The ion at $\mathrm{m} / \mathrm{z} 449$ was more abundant in the mass spectrum of $\alpha \mathrm{TB}$ while the ion at $\mathrm{m} / \mathrm{z}$ 442 was more abundant in the $\beta$ TB mass spectrum. The base peak in the two spectra was the ion at $\mathrm{m} / \mathrm{z} 73$, and was attributed to the trimethylsilyl radical cation. The other significant fragments showed similar relative intensities, and the molecular ion in both spectra was measured at $\mathrm{m} / \mathrm{z}$ 
539. These results were in agreement with the works of

Maume et al. (18) and Wozniak et al. (21).
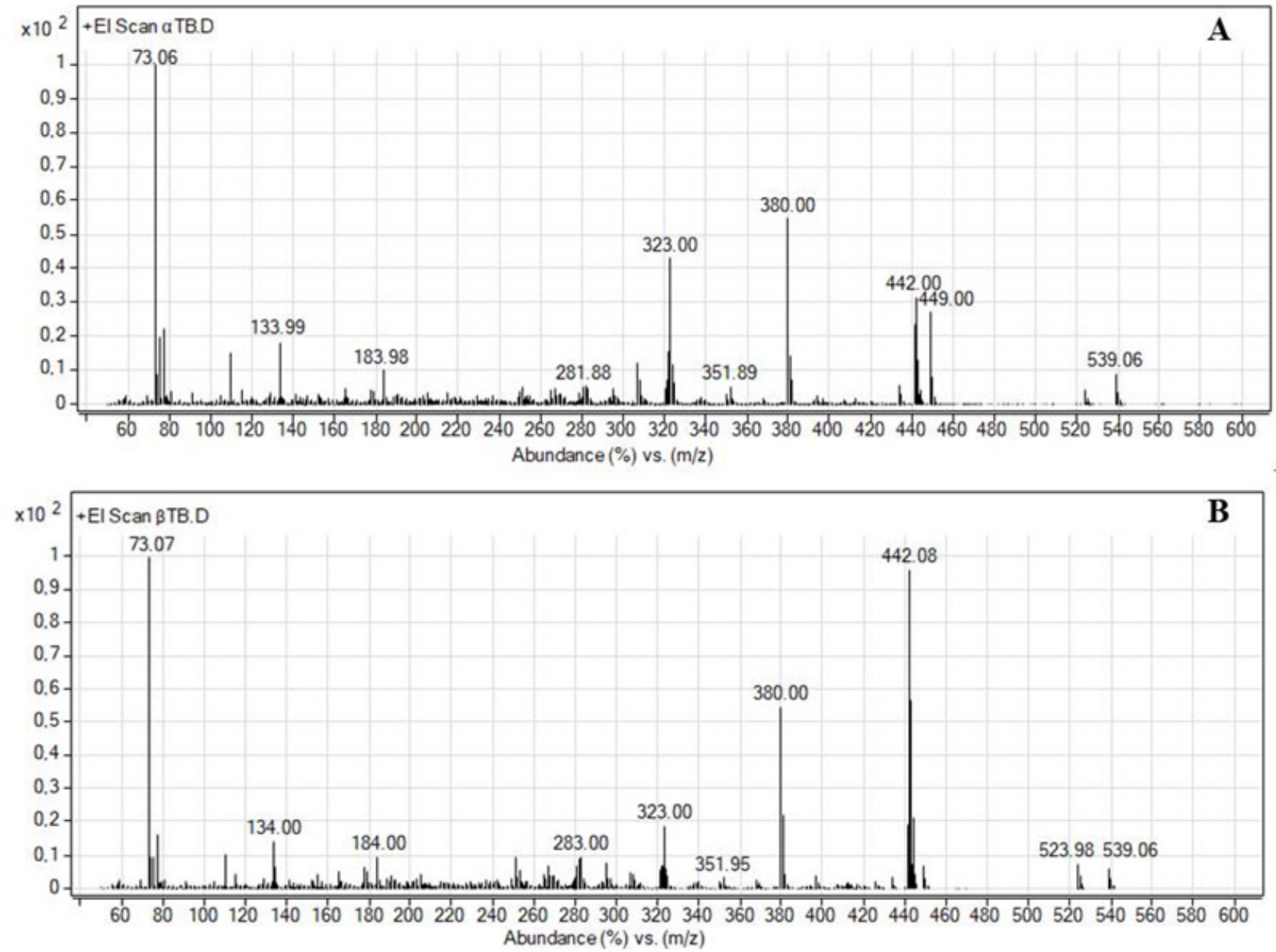

Figure 3. Mass spectra of $\alpha$ TB (A) e $\beta T B$ (B) after derivatization with MSTFA/I2 followed by pure MSTFA

Based on the full scan mass spectra (Figure 3), a mechanism was proposed (Figure 4). Its main steps are: nucleophilic attack of the carbonyl group, at the C-3 position, on the silicon atom, catalyzed by iodine; nucleophilic attack of the N-methyltrifluoracetamide group, on the carbon at the $\mathrm{C}-4$ position followed by silylation of the hydroxyl group, at the $\mathrm{C}-17$ position. The present proposal was in agreement with the works of Maume et al. (18) and Wozniak et al. (21). 


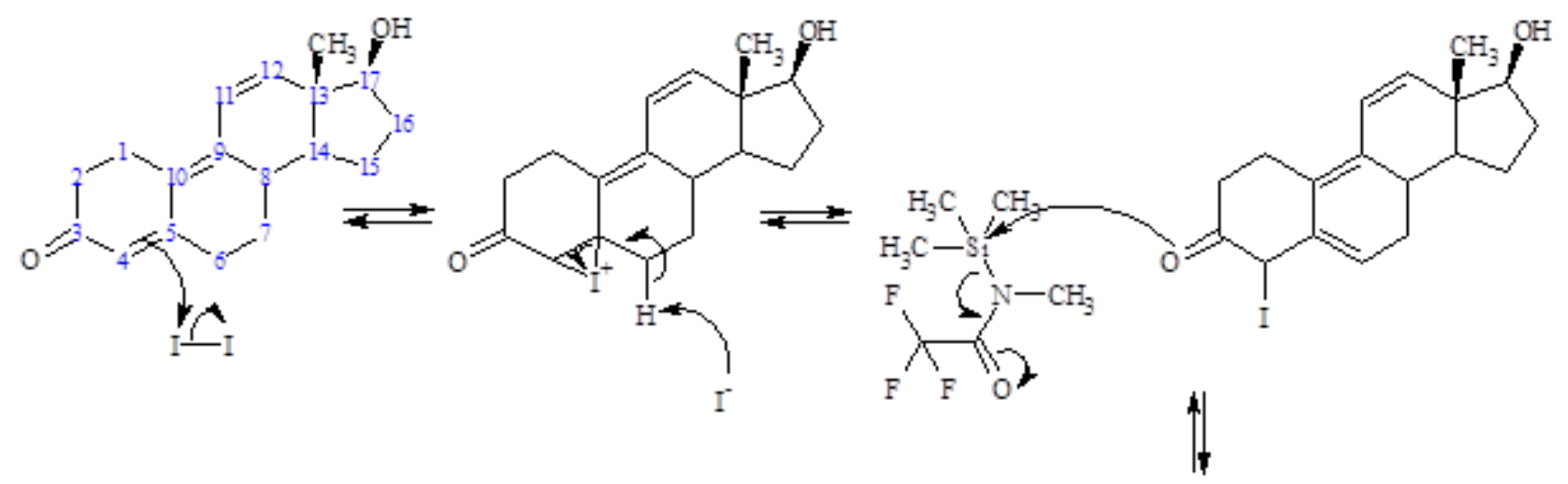<smiles>CN(C(=O)CN(C)[Si](C)(C)CC(F)(F)F)[Si](C)(C)C</smiles>

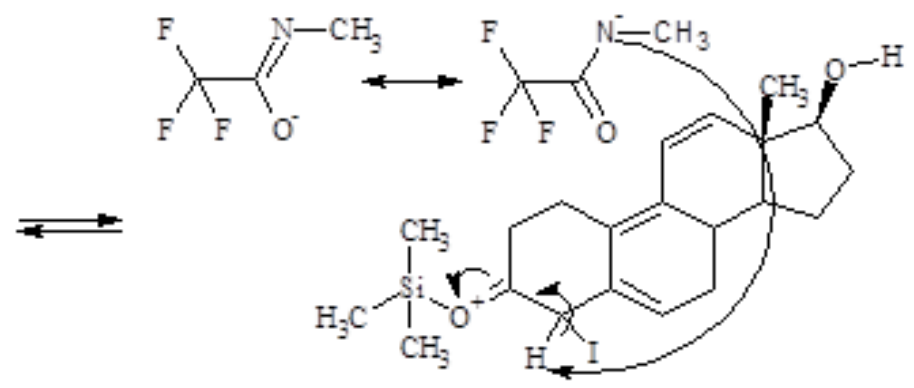

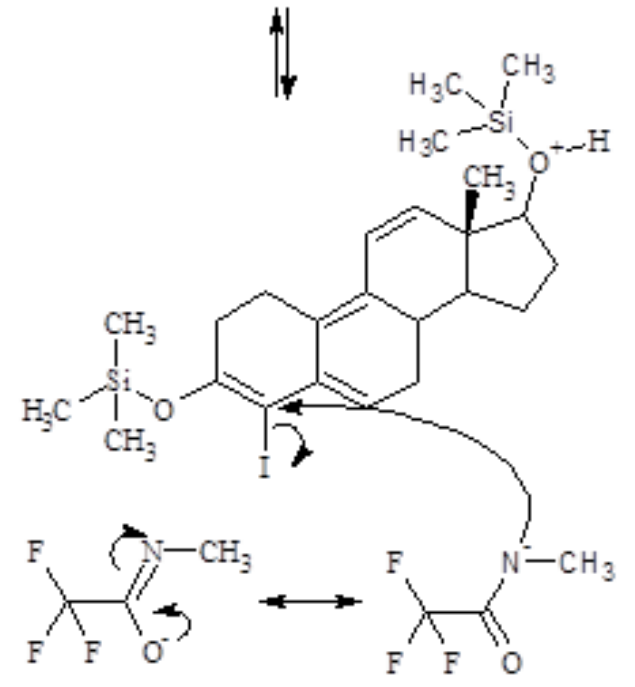

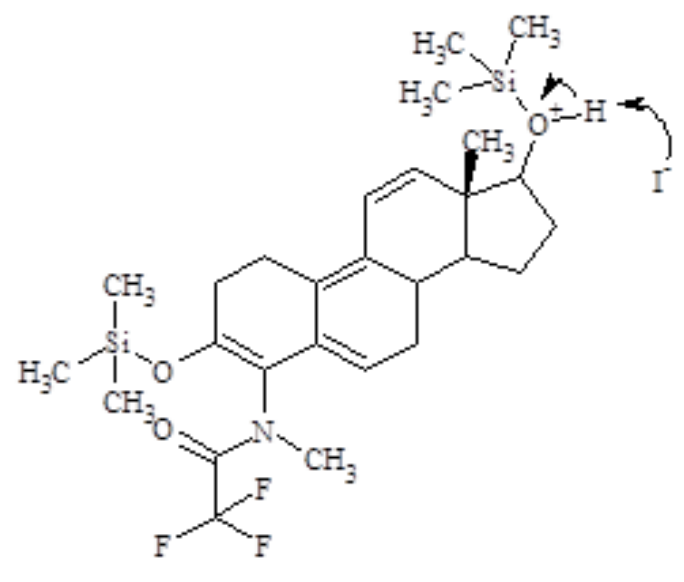<smiles>CN(C(=O)C(F)(F)F)C1=C(O[Si](C)(C)C)CCC2=C3C=C[C@@]4(C)C(CC[C@H]4O[Si](C)(C)C)C3CC=C21</smiles>

Figure 4. Mass Proposed mechanism for derivatization reaction of $\beta$ TB with MSTFA/I followed by pure MSTFA 


\subsection{Linearity, recovery and precision}

In order to evaluate linearity, the F-test was applied and the response variances were considered heterogeneous for both analytes and methods. Thus, the weighted least squares approach was applied, using the inverse of the variance of each concentration level as weighting factor, and $\mathrm{R}^{2}$-values were equal to or greater than 0.932 (Table 1 ).
Recovery, repeatability and intermediate precision met the following acceptance criteria of the Codex Alimentarius: recovery between $60-120 \%$ and repeatability with RSD lower than $30 \%$ for concentrations higher than $1 \mu \mathrm{g} \mathrm{kg}^{-1}$ (25) (Table 1).

Table 1. Parameters for evaluation of the linearity, recovery and precision of the optimized methods

\begin{tabular}{|c|c|c|c|c|c|c|c|c|c|c|c|c|}
\hline \multirow{3}{*}{ Method } & \multirow{3}{*}{ Analyte } & \multirow{3}{*}{ Slope } & \multicolumn{2}{|l|}{ Linearity } & \multicolumn{4}{|c|}{ Intra-day condition } & \multicolumn{4}{|c|}{ Inter-day condition } \\
\hline & & & Introncont & $D^{2}$ & $\mathbf{R}$ & RSD & $\mathbf{R}$ & RSD & $\mathbf{R}$ & RSD & $\mathbf{R}$ & RSD \\
\hline & & & 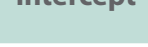 & 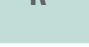 & 1.0 & PL & 1.5 & & 1.0 & PPL & 1.5 & RPL \\
\hline \multirow{2}{*}{$\begin{array}{c}\text { LC-MS/ } \\
\text { MS }\end{array}$} & $\alpha \mathrm{TB}$ & 0.085 & -0.017 & 0.932 & 83.5 & 6.8 & 91.9 & 12.0 & 88.5 & 10.9 & 87.0 & 14.1 \\
\hline & $\beta$ TB & 0.116 & 0.054 & 0.980 & 101.4 & 11.6 & 106.7 & 6.6 & 112.5 & 17.2 & 112.8 & 9.8 \\
\hline \multirow{2}{*}{$\begin{array}{c}\text { GC-MS/ } \\
\text { MS }\end{array}$} & $\alpha \mathrm{TB}$ & 51065 & -64257 & 0.964 & 94.2 & 14.2 & 84.4 & 9.6 & 111.0 & 22.2 & 86.0 & 24.8 \\
\hline & $\beta$ TВ & 36902 & -40042 & 0.940 & 103.9 & 14.5 & 86.0 & 5.1 & 114.0 & 18.5 & 87.0 & 25.5 \\
\hline
\end{tabular}

R: Recovery (\%); RSD: Relative standard deviation (\%)

\section{Conclusions}

The analysis of the real samples allowed the comparison of GC-MS/MS and LC-MS/MS methods for identification and quantification of $\alpha \mathrm{TB}$ and $\beta \mathrm{TB}$ in bovine urine. The GC-MS/MS analysis confirmed the absence of anabolic steroid in these samples, indicating that the LCMS/MS and GC-MS/MS methods can be complementary. Although the GC-MS/MS analysis is more time taking, it can be employed to investigate suspected results obtained by LC-MS/MS analysis, with more specificity.

\section{Acknowledgements}

The authors would like to acknowledge the Minas Gerais Research Funding Foundation (process: CAGAPQ-01049-15) and Coordination for the Improvement of Higher Education Personnel (CAPES) for financial support. 


\section{References}

[1] Llewellyn W (2011). Anabolics. Molecular Nutrition LLC, Jupiter

[2] https://www.canada.ca/en/health-canada/services/drugs-health-products/veterinary-drugs/maximum-residue-limits-mrls/listmaximum-residue-limits-mrls-veterinary-drugs-foods.html. Accessed: 06 Nov 2019

[3] Maximum Residue Limits (MRLs) and Risk Management Recommendations (RMRs) for Residues of Veterinary Drugs in Foods. CAC/MRL 2-2015. Updated as at the 38th Session of the Codex Alimentarius Commission (July 2015).

[4] European Community, Council Directive 96/22/EC. Off. J. Eur.Commun. 1996, L 125, 3.

[5] Instrução Normativa $N^{\circ}$ 55, de 01 de dezembro de 2011. Ministério da Agricultura, Pecuária e Abastecimento. Secretaria de Defesa Agropecuária, Brasil.

[6] Instrução Normativa $\mathrm{N}^{\circ}$ 09, de 21 de fevereiro de 2017. Ministério da Agricultura, Pecuária e Abastecimento. Secretaria de Defesa Agropecuária, Brasil.

[7] Blackwell BR, Johnson BJ, Buser MD, Cobb GP, Smith PN. Transformation kinetics of trenbolone acetate metabolites and estrogens in urine and feces of implanted steers. Chemosphere. 2015;138:901-907. Available from: https://doi.org/10.1016/j. chemosphere.2014.10.091

[8] Dickson LC, MacNeil JD, Reid JA, Neiser CD, Fesser ACE. Internal validation of screening methodology for residues of epitrenbolone, trenbolone, epi-nortestosterone and nortestosterone in bovine urine using immunoaffinity cartridges for sample cleanup. Anal Chim Acta. 2002;473:111-118. Available from: https://doi.org/10.1016/S0003-2670(02)00974-1

[9] Van Poucke C, Van Peteghem C. Development and validation of a multi-analyte method for the detection of anabolic steroids in bovine urine with liquid chromatography-tandem mass spectrometry. J Chromatogr B. 2002;772:211-217. Available from: https://doi.org/10.1016/S1570-0232(02)00090-9

[10] Buiarelli F, Cartoni GP, Coccioli F, De Rossi A, Nerib B. Determination of trenbolone and its metabolite in bovine fluids by liquid chromatography-tandem mass spectrometry. J Chromatogr B. 2003;784:1-15. https://doi.org/10.1016/S1570-0232(02)00435-X

[11] Van Poucke C, Van De Velde M, Van Peteghem C. Combination of liquid chromatography/tandem mass spectrometry and gas chromatography/mass spectrometry for the detection of 21 anabolic steroid residues in bovine urine. J Mass Spectrom. 2005;40:731-738. https://doi.org/10.1002/jms.845

[12] Blokland MH, Zoontjes PW, Sterk SS, Stephany RW, Zweigenbaumb J, van Ginkel LA. Confirmatory analysis of Trenbolone using accurate mass measurement with LC/TOF-MS. Anal Chim Acta. 2008;618:86-93. Available from: https://doi.org/10.1016/j. aca. 2008.04 .040

[13] Gasparini M, Curatolo M, Assini W, Bozzoni E, Tognoli N, Dusi G. Confirmatory method for the determination of nandrolone and trenbolone in urine samples using immunoaffinity cleanup and liquid chromatography-tandem mass spectrometry. J Chromatogr A. 2009;1216:8059-8066. Available from: https://doi.org/10.1016/j.chroma.2009.04.075

[14] Wozniak B, Matraszek-Zuchowska I, Zmudzki J. LC-MS/MS fast analysis of androgenic steroids in urine. Anal Bioanal Chem. 2012;403:2965-2972. Available from: https://doi.org/10.1007/s00216-012-5859-0

[15] Fernández-Arauzo L, Pimentel-Trapero D, Hernández-Carrasquilla, M. Simultaneous determination of resorcylic acid lactones, $\beta$ and $\alpha$ trenbolone and stilbenes in bovine urine by UHPLC/MS/MS. J Chromatogr B. 2014;973:89-96. Available from: https:// doi.org/10.1016/j.jchromb.2014.10.002

[16] Jacob CC, Dervilly-Pinel G, Biancotto G, Monteau F, Le Bizec B. Global urine fingerprinting by LC-ESI(+)-HRMS for better characterization of metabolic pathway disruption upon anabolic practices in bovine. Metabolomics. 2015;11:184-197. https:// doi.org/10.1007/s11306-014-0685-3

[17] Van Vyncht G, Gaspara P, DePauw E, Maghuin-Rogister G. Multi-residue screening and confirmatory analysis of anabolic steroids in urine by gas chromatography coupled with tandem mass spectrometry. J Chromatogr A. 1994;683:67-74. Available from: https://doi.org/10.1016/S0021-9673(94)89103-6

[18] Maume D, Le Bizec B, Marchand P, Montrade MP, Andre F. N-Methyl-N-alkylsilyltrifluoroacetamide-I as a new derivatization reagent for anabolic steroid control. Analyst. 1998;123:2645-2648. Available from: https://doi.org/10.1039/A805217D

[19] Bagnati R, Fanelli R. Determination of 19-nortestosterone, testosterone and trenbolone by gas chromatography-negative-ion mass spectrometry after formation of the pentafluorobenzylcarboxymethoxime-trimethylsilyl derivatives. J Chromatogr A. 1991;541:325-334. Available from: https://doi.org/10.1016/S0021-9673(01)88656-8 
[20] Marques MAS, Pereira HMG, Padilha MC, de Aquino Neto FR. Analysis of synthetic 19-norsteroids trenbolone, tetrahydrogestrinone and gestrinone by gas chromatography-mass spectrometry. J Chromatogr A. 2007;1150:215-225. Available from: https://doi.org/10.1016/j.chroma.2006.08.032

[21] Woźniak B, Matraszek-Żuchowska I, Semeniuk S, Kłopot A, Żmudzki J. Screening and confirmatory GC-MS methods for the detection of trenbolone in bovine urine. Bull Vet Inst Pulawy. 2013;57:559-566. Available from: https://doi.org/10.2478/bvip$\underline{2013-0096}$

[22] Akre C, Mizuno M. A screening and determinative method for the analysis of natural and synthetic steroids, stilbenes and resorcyclic acid lactones in bovine urine. Drug Test Analysis. 2016;8:448-457. Available from: https://doi.org/10.1002/dta.2012

[23] Silveira AL, de Oliveira MLG, Rocha DG, Dracz S, Borgati TF, Lana MAG, Augusti R, Faria AF. Multiresidue determination of anabolic agent residues: Steroids, stilbenes and resorcylic acid lactones, in bovine urine by GC-MS/MS employing microwave assisted derivatization. J. Agric. Food Chem. 2018;66(32):8630-8638. Available from: https://doi.org/10.1021/acs.jafc.8b02439

[24] Pearson ES, Hartley HO (1962) Biometrika tables for statisticians (2 ${ }^{\text {nd }}$ ed.). Cambridge University Press, Cambridge

[25] CAC/GL 71-2009 (2014) Guidelines for the design and implementation of national regulatory food safety assurance programmes associated with the use of veterinary drugs in food producing animals. CAC/ GL 71-2009 Codex Alimentarius, Revision 2012:2014. 


\title{
Efficient UPLC and spectrophotometric MC methods for simultaneous determination of cefixime and sodium benzoate in their dosage form and in its degradation product of cefixime-E Isomer. Application of lean six sigma and in- vitro dissolution studies
}

\section{Mahmoud A. Mohamed \\ HIKMA group, Pharmaceutical \\ Company, Beni-Suef, Egypt \\ Tel. +201124767625 \\ ch.mahmoud88@gmail.com, \\ mmabdelfatah@hikma.com}

\begin{abstract}
Resumo
O objetivo principal deste estudo é desenvolver e validar um novo RP-UPLC e métodos espectrofotométricos de centralização média para a estimativa simultânea de cefixima e benzoato de sódio em sua forma farmacêutica e em seu produto de degradação do isômero cefixima-E e aplicação de ferramentas de qualidade e Lean Metodologias Seis Sigma para interpretar a integridade dos dados de atributos de qualidade que darão força, confiança e precisão para controlar e enfatizar que o Índice de Capacidade do Processo (Cpk) é> 1,33. A condição cromatográfica isocrática foi avaliada à temperatura ambiente usando coluna Waters CORTECS $^{\circledR} \mathrm{C} 18$ (50 $\mathrm{mm} \times 4,6 \mathrm{~mm}$, tamanho de partícula 2,7 $\mu \mathrm{m}$ ), com uma fase móvel composta de acetonitrila: tampão fosfato $0,05 \mathrm{M}(35: 65 \mathrm{v} / \mathrm{v})$ na taxa de fluxo de 0,3 $\mathrm{mL} /$ minuto e deteç̧ão de UV a $230 \mathrm{~nm}$ com volume de injeção de $0,5 \mu \mathrm{L}$ e tempo total de execução de $7 \mathrm{~min}$. $O$ método de UV é a centralização média dos espectros de razão (MC), que se baseia na centralização média dos primeiros dados espectrais de razão de ambas as drogas em sua mistura binária a $225 \mathrm{~nm}$ para SDB, enquanto CFX foi detectado em espectros de ordem zero de $290 \mathrm{~nm}$, já que nenhuma sobreposição da droga combinada foi encontrada. $O$ método foi aplicado com sucesso a estudos comparativos de dissolução in vitro para cefixima (CFX) no produto Genérico; Rivaxime 200 mg Cap e Rivaxime 400 mg Cap portanto, havia sido considerado equivalente ao produto inovador; Suprax 200 mg Cap e Suprax 400 mg Cap usando meio de dissolução FDA.
\end{abstract}

\begin{abstract}
The main objective of this study is to develop and validate a novel RP-UPLC and spectrophotometric mean centering Methods for simultaneous estimation of cefixime and sodium benzoate in their dosage form and in Its Degradation Product of cefixime-E isomer and application of Quality tools and Lean Six Sigma methodologies to construe the data integrity of quality attributes which will give strength, confidence, and precision to control and emphasize that the Process Capability Index (Cpk) is $>1.33$. Isocratic chromatographic condition was evaluated at ambient temperature using Waters CORTECS ${ }^{\oplus}$ C18 column ( $50 \mathrm{~mm} \times 4.6 \mathrm{~mm}, 2.7 \mu \mathrm{m}$ particle size), with a mobile phase composing of acetonitrile: $0.05 \mathrm{M}$ Phosphate Buffer (35:65 v/v) at flow rate of $0.3 \mathrm{~mL} /$ minute and UV detection at $230 \mathrm{~nm}$ with injection volume of $0.5 \mu \mathrm{L}$ and total run time of $7 \mathrm{~min}$. The UV method is mean centering of the ratio spectra (MC), which is relied on mean centering of the first ratio spectral data of both drugs in their binary mixture at $225 \mathrm{~nm}$ for SDB, while CFX was detected at zero order spectra of 290 $\mathrm{nm}$, as no overlapping from the combined drug has been found. The method was successfully applied to comparative in vitro dissolution studies for cefixime (CFX) in the Generic product; Rivaxime $200 \mathrm{mg}$ Cap and Rivaxime $400 \mathrm{mg}$ Cap therefore, it had been considered equivalent to the innovator product; Suprax $200 \mathrm{mg}$ Cap and Suprax $400 \mathrm{mg}$ Cap using FDA dissolution medium.
\end{abstract}

Keywords: Cefixime; Sodium Benzoate; Lean Six Sigma; In vitro dissolution; MC; RP- UPLC. 


\section{Introduction}

A topic of Lean Six Sigma (LSS) has become more relevant due to the development of the medicines. During the last decades, more potent and complex drugs have been developed in which pharmaceutical companies show increasing to improve quality and productivity, reducing variation and decrease waste time. As well, it may use for growing the productivity or capacity of a manufacturing plant as many pharmaceutical factories which use Lean Six Sigma (LSS) to reduce time and eliminate defects in the process and increase the capability of the process. Cefixime (CFX), (Figure. 1a) as an antibiotic is a third-generation cephalosporin. It was chemically named as (6R,7R)- 7-[[(Z)-2-(2-Aminothiazol-4-yl)-2[(carboxymethoxy) imino] acetyl] amino]-3- ethenyl-8oxo-5-thia-1-azabicyclo [4.2.0] oct2-ene-2-carboxylic acid trihydrate. It has a molecular formula of $\mathrm{C}_{16} \mathrm{H}_{15} \mathrm{~N}_{5} \mathrm{O}_{7} \mathrm{~S}_{2}, 3 \mathrm{H}_{2} \mathrm{O}$ and a molecular weight of 507.5[1]. CFX for oral suspension is indicated in the treatment of adults and pediatric patients six months of age or older [2]. CFX E- Isomer, (Figure. 1b) was chemically named as 2-((( $E)-1-(2$-aminothiazol4-yl)-2-((((2R)-5-methyl-7-oxo-1,2,5,7-tetrahydro$4 \mathrm{H}$-furo[3,4-d] [1,3] thiazin-2-yl) methyl) amino)-2oxoethylidene) amino) oxy) acetic acid. It has a molecular formula of $\mathrm{C}_{16} \mathrm{H}_{15} \mathrm{~N}_{5} \mathrm{O}_{7} \mathrm{~S}_{2}$, and a molecular weight of 453.5. SDB is the chemical benzoate of soda $\left(\mathrm{C}_{7} \mathrm{H}_{5} \mathrm{NaO}_{2}\right)$ (Figure. 1c), produced by the neutralization of benzoic acid with sodium bicarbonate, sodium carbonate, or sodium hydroxide. The salt doesn't occur naturally. The excipient is used as antimicrobial preservative in pharmaceutical dosage forms [3]. HPLC method for determination of CFX and SDB were officially reported in both of British Pharmacopeia (BP) and United States Pharmacopeia (USP) [4]. Few analytical methods have been described for the determination of CFX and SDB individually or in combination with other drugs including (HPLC) [5-19], capillary electrophoresis and electrochemical methods [2023], thin layer chromatography (TLC) [24-27], colorimetric and spectrophotometric [28-39], and comparative in vitro dissolution studies for cefixime [40,41]. In high analytical chemistry technique, the determination of a binary mixture or more analytes simultaneously using the same method of analysis lead to reduce time and cost of analysts. So, the current work introduces a new RP- UPLC and spectrophotometric MC methods for simultaneous estimation of cefixime and sodium benzoate in their dosage form, in the degradation product of cefixime-e isomer, and application of lean six sigma and in-vitro dissolution studies.<smiles>C=CC1=C(C(=O)O)N2C(=O)[C@H](NC(=O)/C(=N\OCC(=O)O)c3csc(N)n3)[C@H]2SC1</smiles>

(a)<smiles>C=CC1=C(C(=O)O)N2C(=O)[C@H](NC(=O)/C(=N/OCC(=O)O)c3csc(N)n3)[C@H]2SC1</smiles>

(b)

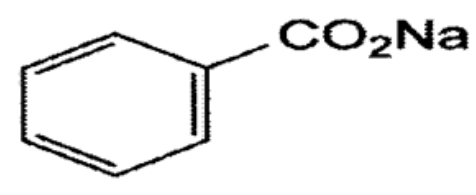

(c)

Figure 1. Chemical structures of (a) Cefixime, (b) Cefixime E- isomer and (c) Sodium Benzoate.

\section{Experimental}

\subsection{Chemicals and reagents}

CFX Astellas Pharma Inc. (Japan) and Orchid Chemicals \& Pharmaceuticals Ltd (India) were kindly supplied by Hikma pharmaceutical industries company, 
Beni-Suef, Egypt with potency (as anhydrous base) of $100.5 \%$ and $99.3 \%$, respectively. SDB was supplied by Hikma pharmaceutical industries company, Beni-Suef, Egypt with claimed purity $100.1 \%$. Innovator Product Suprax 200 and 400 mg Cap (Batch No. 2008\& 2012) were supplied by Hikma pharmaceutical industries company. Generic product Rivaxime $200 \mathrm{mg}$ and $400 \mathrm{mg}$ Cap (Batch No. 2000\&2001) were supplied by Riva Pharma company, Free zone Nasr City, Cairo, Egypt. Acetonitrile HPLCgrade, ultrapure water from an EMD Millipore Milli-Q Integral system, equipped with a Millipak $0.22 \mu \mathrm{m}$ screen filter at the final point of use, potassium dihydrogen orthophosphate, potassium chloride, acetic acid, sodium acetate trihydrate, sodium hydroxide, hydrochloric acid, hydrogen peroxide and orthophosphoric acid analytical grade, were procured from (Scharlau, Spain).

\subsection{Apparatus}

UPLC Chromatographic condition was performed using Waters ACQUITY ${ }^{\circledR}$ Arc ${ }^{\mathrm{TM}}$ UHPLC System (Waters, USA) consisting of a quaternary liquid chromatography provides plug-and-play method compatibility for UHPLC separations with 2489 UV/Vis Detector (A17VTU408A), Sample Manager FTN-R (D17VSM260N), Quaternary Solvent Manager-R (C17VQS618G) Designed with unique Arc Multi-flow path ${ }^{\mathrm{TM}}$ technology to swap between HPLC and UPLC separations. Chromatographic data was monitored and processed using Empower ${ }^{\mathrm{TM}} 3$ Software. Separation was achieved on a Waters CORTECS $\AA$ C18 column $(50 \mathrm{~mm} \times 4.6 \mathrm{~mm}, 2.7 \mu \mathrm{m}$ particle size, USA $)$. Stepwise the mobile phase composing of acetonitrile: 0.05M Phosphate Buffer (35:65 v/v) at flow rate of $0.3 \mathrm{~mL}$ /minute and UV detection at $230 \mathrm{~nm}$ with injection volume of $0.5 \mu \mathrm{L}$ and total run time of $7 \mathrm{~min}$.

An 1800 double beam UV spectrophotometer (Shimadzu-Japan) with highest resolution was also utilized. Its spectral interval is $0.1 \mathrm{~nm}$ from (190-1100 $\mathrm{nm}$ range) was used for all absorbance measurements. Matched with
$1 \mathrm{~cm}$ quartz cells. Perform data analysis by software (UVProbe 2.5.2).

MATLAB R2015a ( 8 8.5using PLS toolbox software for MC method.

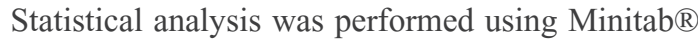
17.1.0 and Origin ${ }^{\circledR} 2018$.

\subsection{Dissolution preparation (Buffer $\mathrm{pH}$ 7.2)}

Dissolve $33.3 \mathrm{~g}$ of potassium dihydrogen phosphate anhydrous and $14.7 \mathrm{~g}$ of disodium hydrogen phosphate anhydrous in 7.0 liter with deionized water. If necessary, adjust the $\mathrm{pH}$ to $7.2 \pm 0.05$ with $1 \mathrm{~N}$ phosphoric acid or $1 \mathrm{~N}$ $\mathrm{NaOH}$.

\subsection{Solvent preparation (Buffer $\mathrm{pH}$ 7.0) for assay}

Transfer $6.8 \mathrm{ml}$ of concentrated phosphoric acid to a $1000 \mathrm{ml}$ volumetric flask; add $300 \mathrm{ml}$ of water. Adjust to $\mathrm{pH} 7.0 \pm 0.1$ with $10 \mathrm{~N} \mathrm{NaOH}$. Then dilute to volume with water.

\subsection{Sample preparation}

Weigh 20 empty capsules and calculate the average content per capsule. Weigh accurately about the equivalent to $100 \mathrm{mg}$ CFX. Then transfer completely to $500 \mathrm{ml}$ volumetric flask with the aid of $400 \mathrm{ml}$ solvent, sonicate for about 10 minutes and complete to volume with the same solvent and mix well. Filter through $0.45 \mu \mathrm{m}$ PTFE membrane filter.

\subsection{Preparation of standards}

Stock solutions (1 $\mathrm{mg} / \mathrm{mL})$ of CFX and SDB were separately prepared and dissolved in assay solvent preparation. Separately transfer different dilutions from stock standard solutions into separate series of $10 \mathrm{~mL}$ 
volumetric flasks covering the concentration ranges $(5-250 \mu \mathrm{g} / \mathrm{mL})$ of CFX and $(3-75 \mu \mathrm{g} / \mathrm{mL})$ of SDB. Mix well and filter through $0.45 \mu \mathrm{m}$ PTFE membrane filter and inject into the chromatographic system (Figure. 2).
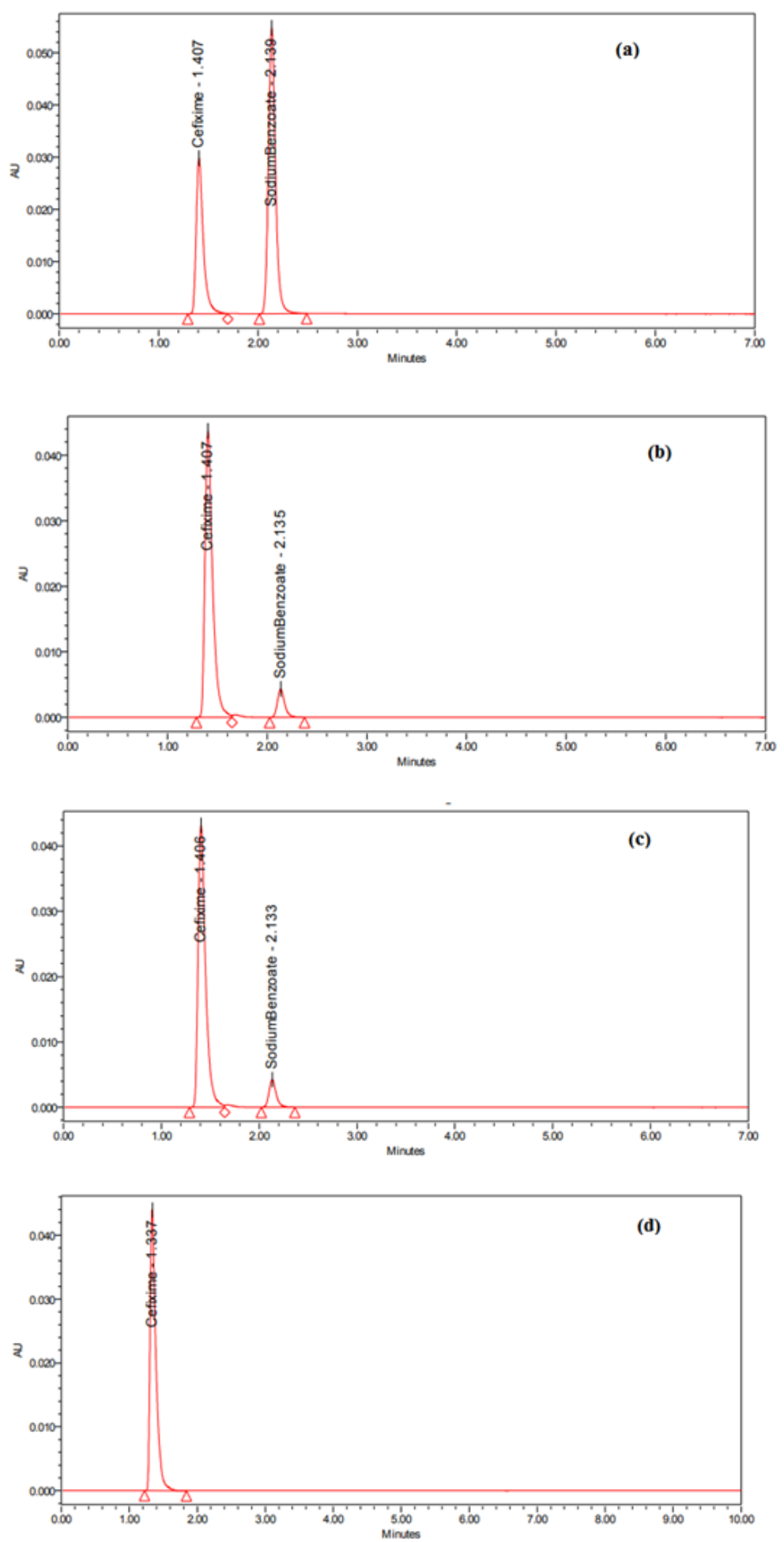

Figure 2. UPLC chromatograms of standard Solution of (a) $200 \mu \mathrm{g} / \mathrm{mL}$ of Authentic mixture of CFX and SDB, (b) $80 \mu \mathrm{g} / \mathrm{mL}$ of CFX and $2 \mu \mathrm{g} / \mathrm{mL}$ of SDB (c) Suprax $60 \mathrm{~mL}$ POS (d) Suprax 200 Cap using solvent as blank. 


\subsection{Comparative in vitro dissolution studies}

In the early stages of development, in vitro dissolution testing guides were performed to test the optimal improvement of the drug release from the pharmaceutical dosage form. Over the past 50 years, it has been used as a measure of quality control (QC), in R\&D to detect the impact of the critical manufacturing variables in Comparative Studies [42].

\subsection{Dissolution Parameters}

Apparatus: Type II (Paddle) with sinker

Dissolution medium volume: $900 \mathrm{~mL}$ of phosphate buffer $\mathrm{pH} 7.2$

Speed: $100 \mathrm{rpm}$

Temperature: $37 \pm 0.5^{\circ} \mathrm{C}$

Time: 10, 20, 30, 45 and 60 minutes

\subsection{Test preparation for dissolution}

Take 6 capsules of the product and insert each one in one sinker. Place each one from the generic product and the innovator in one dissolution apparatus vessel and immediately operate the apparatus. Discard the first $20 \mathrm{~mL}$ of the withdrawn sample and filter through $0.45 \mu \mathrm{m}$ filter, Use the obtained filtrate solution.

\subsection{Process Capability Sixpack}

Quality tools and Lean six sigma were used for comparing and evaluating between different raw material suppliers and follow up the process of suppliers during the last two years ago and assure that the Process Capability Index (Cpk) is $>1.33$. moreover, the evaluation can also be useful in selecting or modifying the process at some stages in the product design and improvement the current process capability analysis.

\subsection{Mean Centering of Ratio Spectra}

Spectrophotometric Method

In mean centering spectrophotometric method; both binary and ternary mixtures can determine without previous separation. The first ratio spectra were obtained after elimination the constant by mean centering of the ratio spectra, in addition to an extra step was performed for the ternary mixture where the mean centered ratio spectra were further divided by the mean centered vector of the other two drugs, then the second ratio spectra were mean centered [43].

\section{Results and discussion}

\subsection{Methods development and optimization}

To select buffer of mobile phase, different mobile phases were examined: methanol (100\%); methanol: purified water $(70: 30, \mathrm{v} / \mathrm{v})$; acetonitrile: purified water (70:30, v/v) and methanol: purified water (50:50, v/v). All solvents of the mobile phase were filtered through $0.45 \mu$ filter paper to remove particulate matter and degassed by sonication. Also, $(0.2,-1.0 \mathrm{~mL} / \mathrm{min})$ flow rates are measured. Initial studies have been included trying C8, C18 reversed-phase columns. Wavelengths were scanned at $(200-400 \mathrm{~nm})$ for $5 \mu \mathrm{g} / \mathrm{mL}$ for both drugs, CFX and SDB in pure form (Figure. 3), showing maximum absorbances at $290 \mathrm{~nm}$ and $222 \mathrm{~nm}$, respectively. However, the wavelength $230 \mathrm{~nm}$ was selected for the separation of both drugs because it has maximum intensity and resolution between the two peaks. The best developing mobile phase of the system was found to be a mixture of acetonitrile: $0.05 \mathrm{M}$ phosphate buffer $(35: 65 \mathrm{v} / \mathrm{v})$ at flow rate of $0.3 \mathrm{~mL} /$ minute and UV detection at $230 \mathrm{~nm}$ with injection volume of 0.5 $\mu \mathrm{L}$ and total run time of $7 \mathrm{~min}$. The retention times are quite short and sufficiently separated. The best system for dissolution was $900 \mathrm{~mL}$ of water, using dissolution media; phosphate buffer pH 7.2 using Type II (paddle) with sinker at speed rate of $100 \mathrm{rpm}$ with time intervals; 10, 20, 30, 45 and 60 minutes. 

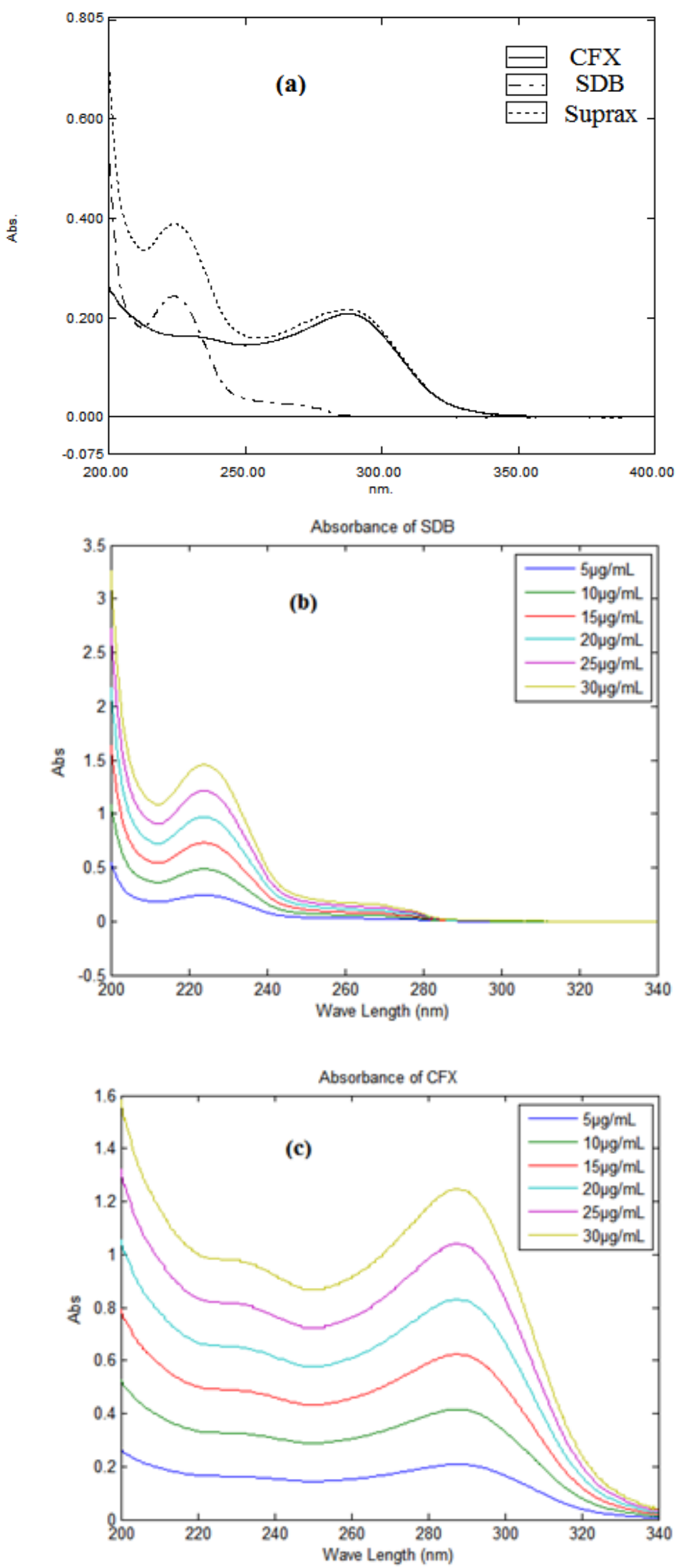

Figure 3. Zero order absorption spectra of each of (a) $5 \mu \mathrm{g} / \mathrm{mL}$ of CFX, SDB and dosage form, (5-30) $\mu \mathrm{g} / \mathrm{mL}$ of (b) SDB, and (c) CFX using Solvent as blank. 


\subsection{Method validation}

The proposed method was validated regarding linearity, detection and quantitation limits, accuracy, precision, stability of the analytical solution, system suitability and specificity, in accordance with ICH guidelines [44].

\subsection{Linearity and range}

The linearity of an analytical procedure is its ability to elicit test results that are directly, or by linear least squares regression of calibration curves in the concentration ranges $(5-250 \mu \mathrm{g} / \mathrm{mL})$ of CFX and $(3-75 \mu \mathrm{g} / \mathrm{mL})$ of SDB for UPLC method and (5-30 $\mu \mathrm{g} / \mathrm{mL})$ of both drug for MC method with coefficient of regression $>0.999$ for CFX and $\mathrm{SDB}$, respectively. The linearity results were displayed in (Table 1).

Table 1. Regression and validation parameters of the proposed method for determination of CFX and SDB.

\begin{tabular}{|c|c|c|c|c|}
\hline \multirow{2}{*}{$\begin{array}{c}\text { Parameter } \\
\text { Drugs }\end{array}$} & \multicolumn{2}{|c|}{ UPLC } & \multicolumn{2}{|c|}{ MC } \\
\hline & CFX & SDB & CFX & SDB \\
\hline Linearity Range ( $\mu \mathrm{g} / \mathrm{mL})$ & $5-250$ & $3-75$ & $5-30$ & $5-30$ \\
\hline \multicolumn{5}{|l|}{ Regression equation $\mathrm{y}=\mathrm{bx}+\mathrm{a}$} \\
\hline Slope & 747.72 & 435.12 & 1.552 & 0.065 \\
\hline Intercept & 947.45 & 117.87 & 0.82 & 0.03 \\
\hline Correlation coefficient( $(r 2)$ & 0.9996 & 0.9999 & 0.9997 & 0.9995 \\
\hline Accuracy (\% R) a & 99.53 & 100.94 & 99.72 & 100.02 \\
\hline \multicolumn{5}{|l|}{ Precision (\% RSD) } \\
\hline Repeatability & 0.12 & 0.10 & 0.09 & 0.04 \\
\hline Intermediate precision & 0.88 & 0.68 & 0.72 & 0.55 \\
\hline Robustness & 0.95 & 0.83 & 1.12 & 1.59 \\
\hline Ruggedness & 1.05 & 0.85 & 0.98 & 1.10 \\
\hline Stability of analytical solution & 0.45 & 0.54 & 0.87 & 0.25 \\
\hline LOD b $(\mu \mathrm{g} / \mathrm{mL})$ & 3.30 & 0.56 & 1.21 & 0.65 \\
\hline LOQ b $(\mu \mathrm{g} / \mathrm{mL})$ & 10.0 & 1.76 & 3.68 & 2.11 \\
\hline
\end{tabular}

${ }^{a}$ Average of three determinations

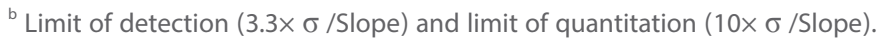

\subsection{Detection and quantitation limits}

LOD and LOQ are relied on the standard deviation of the response and the slope and can be calculated as $\mathrm{LOD}=3.3 \times \sigma /$ slope and $\mathrm{LOQ}=10 \times \sigma /$ slope, where $\sigma=$ the standard deviation of the response as listed in (Table 1). Indicate that the method is sufficiently sensitive for the analysis of binary mixture in their dosage form.

\subsection{Accuracy and recovery}

The accuracy of an analytical procedure is the closeness of test results obtained by the procedure to the true value. Accuracy may often be expressed as percent recovery by the assay of known added amounts of analyte. The recovery was calculated in triplicates of three concentrations $(50,100,150 \mu \mathrm{g} / \mathrm{mL})$ for CFX and $(15,30,45 \mu \mathrm{g} / \mathrm{mL})$ for SDB within linearity at all different media comparing the individual peak response with that of 
the reference solution and $(10,15$ and $20 \mu \mathrm{g} / \mathrm{mL})$ for both drugs for the MC method. The mean \% recoveries for CFX and SDB were between $(98.0$ - 102\%). Results were shown in (Table 1).

\subsection{Precision}

Precision express of the degree of either reproducibility or repeatability of the analytical method. Reproducibility refers to the use of the analytical procedure in different laboratories. Repeatability refers to the use of the analytical procedure within a laboratory over a short period using the same analyst with the same equipment. Repeatability is approached using less than five replicates of the standard solution of the compound being studied (223 $\mu \mathrm{g} / \mathrm{mL})$ for $\mathrm{CFX}$ and $(50 \mu \mathrm{g} / \mathrm{mL})$ for SDB in all different media. and $20 \mu \mathrm{g} / \mathrm{mL}$ for both drugs for the MC method. The system was precise as the relative standard deviation RSD $\leq 2 \%$ as shown in (Table 1 ). Intermediate precision (Ruggedness): Intermediate precision expresses the withinlaboratories variations parameter by RSD, evaluation has been tested for different days, different analysts and effect of use of different columns (different lots and/or suppliers). Good results were obtained as presented in (Table 1).

\subsection{Robustness}

The robustness of an analytical method is a degree of its capacity to remain unchanged by small but reflect variations in method's items such as: influence of variations of $\mathrm{pH}$ of the mobile phase $( \pm 0.2)$, flow rate change $( \pm 0.1$ $\mathrm{mL} / \mathrm{min})$, wave length change $(230 \pm 2.0 \mathrm{~nm})$ and column temperature change $(30,25 \mathrm{C})$. Good results were gained as presented in (Table 1).

\subsection{Stability of the analytical solution}

The standard solution was kept under specific conditions such as room temperature or fridge to ensure stability, then the solutions are measured against a freshly prepared standard; RSD $<2 \%$. Results are showed in (Table 1).

\subsection{Formulation assay}

The proposed method was used to ascertain Analysis repeatability by evaluating six samples from the commercially dosage form (Suprax $60 \mathrm{ml}$ POS, Suprax 200\&400 mg (Rap, Rivaxime $200 \& 400 \mathrm{mg}$ (Cap) to determine the assay of CFX. The obtained results were showed in (Table 2) designating that the method is sensitive

Table 2. Assay results for the determination of CFX and SDB in their dosage form by the proposed method.

\begin{tabular}{|c|c|c|c|c|c|c|}
\hline \multirow[t]{8}{*}{$\begin{array}{l}\text { Pharmaceutical } \\
\text { formulation }\end{array}$} & \multicolumn{2}{|c|}{ Suprax $100 \mathrm{mg}(60 \mathrm{ml})$ POS } & $\begin{array}{c}\text { Suprax } 200 \mathrm{mg} \\
\text { Cap }\end{array}$ & $\begin{array}{c}\text { Rivaxime } 200 \\
\text { mg Cap }\end{array}$ & $\begin{array}{c}\text { Suprax } 400 \mathrm{mg} \\
\text { Cap }\end{array}$ & $\begin{array}{c}\text { Rivaxime } 400 \\
\text { mg Cap }\end{array}$ \\
\hline & CFX & SDB & CFX & CFX & CFX & CFX \\
\hline & 101.76 & 99.87 & 101.75 & 99.93 & 101.29 & 100.42 \\
\hline & 103.27 & 104.62 & 102.55 & 99.06 & 102.49 & 98.59 \\
\hline & 102.87 & 107.72 & 103.09 & 101.76 & 103.60 & 100.20 \\
\hline & 103.92 & 103.26 & 102.59 & 100.29 & 103.09 & 101.24 \\
\hline & 102.94 & 104.87 & 101.09 & 98.84 & 101.75 & 102.94 \\
\hline & 104.41 & 103.09 & 100.65 & 99.09 & 102.30 & 100.40 \\
\hline Mean \pm RSD & $103.20 \pm 0.89$ & $103.91 \pm 2.49$ & $101.95 \pm 0.94$ & $99.83 \pm 1.10$ & $102.42 \pm 0.83$ & $100.63 \pm 1.42$ \\
\hline
\end{tabular}


for the samples without overlapping from the ingredient used to formulate.

\subsection{System suitability}

The system suitability is the established criteria, which must be met by the procedure in order to accept the results that are generated constitute an integral system that should be checked by calculating various parameters such

Table 3. System suitability testing parameters of the developed method.

\begin{tabular}{|c|c|c|c|}
\hline \multirow[t]{2}{*}{ Item } & \multicolumn{2}{|c|}{ Obtained Value } & \multirow[t]{2}{*}{ Reference values } \\
\hline & CFX & SDB & \\
\hline Tailing factor & 0.99 & 1.10 & $\mathrm{~T} \leq 2$ \\
\hline Injection precision & 0.12 & 0.22 & $\mathrm{RSD} \leq 1 \%$ \\
\hline Number of theoretical plates $(\mathrm{N})$ & 5240 & 4500 & $N>2000$ \\
\hline Resolution & - & 3.5 & Rs $>2$ \\
\hline Retention time $\left(R_{t}\right)$ & 0.08 & 0.6 & $\mathrm{RSD} \leq 1 \%$ \\
\hline Selectivity & - & 4.2 & $k^{\prime}>2$ \\
\hline
\end{tabular}

as the number of theoretical plates $(\mathrm{N})$, tailing factor $(\mathrm{T})$, resolution (Rs), precision and selectivity (k') to ensure the performance of the system. All calculated parameters were found within the acceptable limits indicating good selectivity of the method as listed in (Table 3).

\subsection{Selectivity/Specificity}

The purpose of this study is to determine the capability of the analytical procedure to measure accurately and specifically the analyte in the presence of the active ingredient, placebo and other ingredients. Selectivity may often be expressed as the degree of bias of test results obtained by analysis of samples containing added impurities, degradation products, related chemical 

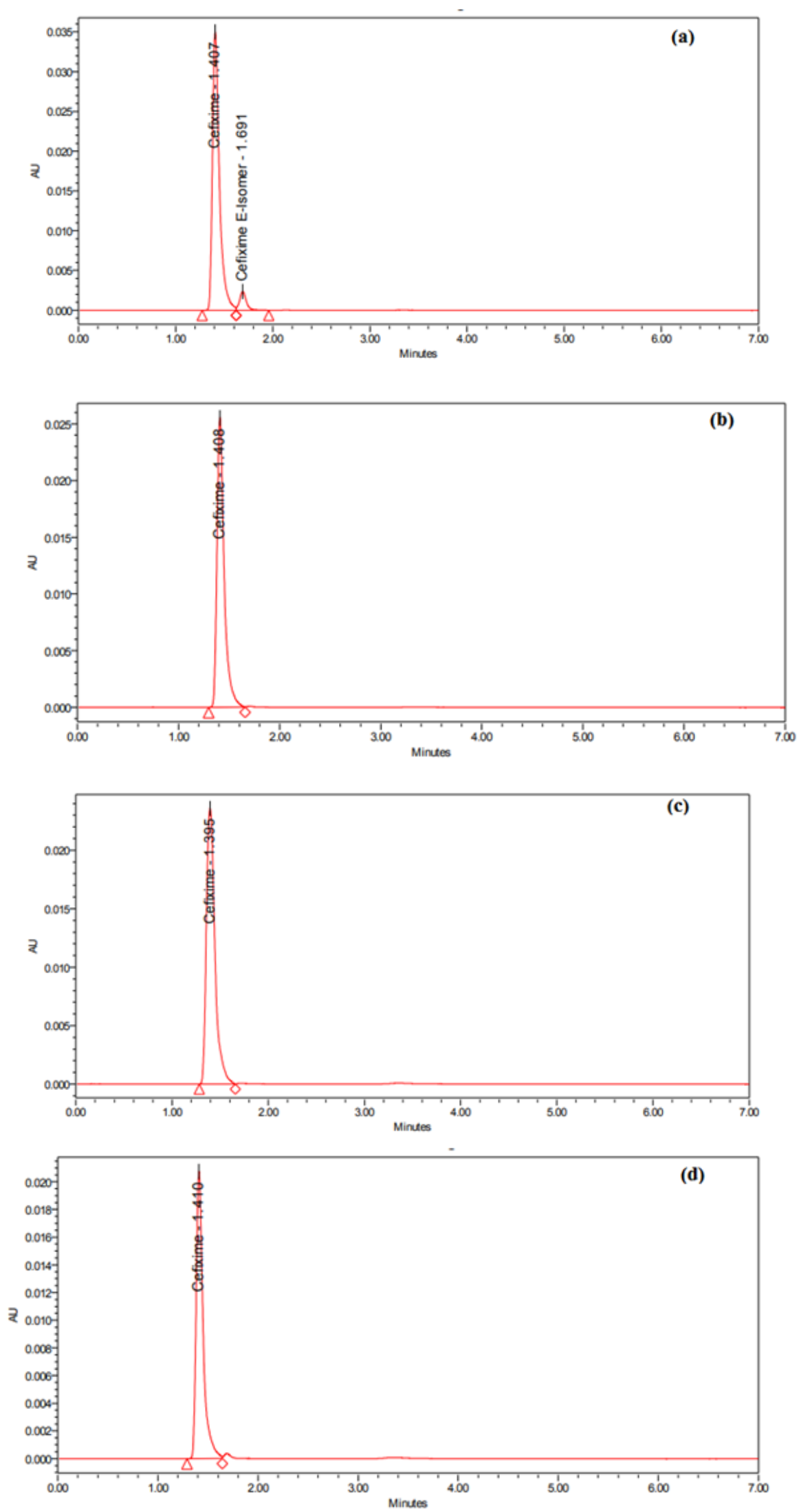

Figure 4. UPLC chromatograms of $80 \mu \mathrm{g} / \mathrm{mL}$ solution of CFX after exposure to (a) hydrolysis, (b) acid degradation, (c) base degradation, and (d) heat degradation. 
compounds, or placebo ingredients when compared to test results from samples without added substances. Method specificity was performed for the dosage form being studied and placebos matrix containing all excipients of the finished product. The results indicated that no interference was detected at the retention times of CFX in placebo solution (Figure. 4).

\subsection{Forced degradation}

The forced degradation of API (CFX) was carried out as per ICH guidelines ( $\mathrm{ICH}, \mathrm{Q} 2 \mathrm{~B})$ in hydrolysis, acid, base, and heat degradation.

\section{A. Hydrolysis degradation}

Dissolve $22.3 \mathrm{mg}$ of CFX in $100 \mathrm{~mL}$ of water. Heat on a water-bath for $45 \mathrm{~min}$ and cool in situ preparation of impurity D (CFX E- Isomer). Filters through membrane filter $0.45-\mu \mathrm{m}$, reject the first portion then Inject by HPLC.

\section{B. Acid degradation}

Accurately weigh $22.3 \mathrm{mg}$ of CFX and transfer into $100-\mathrm{mL}$ volumetric flask. Add $70 \mathrm{~mL}$ of solvent and sonicate to dissolve, add $5 \mathrm{~mL}$ of $0.1 \mathrm{~N} \mathrm{HCl}$ then keep the acidified solutions at room temperature for two hours, then complete to the mark with the same solvent and mix well. Filters through membrane filter $0.45-\mu \mathrm{m}$, reject the first portion then Inject by HPLC.

\section{Base degradation}

Accurately weigh $22.3 \mathrm{mg}$ of CFX and transfer into $100-\mathrm{mL}$ volumetric flask. Add $70 \mathrm{~mL}$ of solvent and sonicate to dissolve, add $5 \mathrm{~mL}$ of $0.1 \mathrm{~N} \mathrm{NaOH}$ then keep the alkaline solutions at room temperature for two hours, then complete to the mark with the same solvent and mix well. Filters through membrane filter $0.45-\mu \mathrm{m}$, reject the first portion then Inject by HPLC.

\section{Heat degradation}

Keep the powder sample of CFX standard in a dry oven at $80^{\circ} \mathrm{C}$ for 6 hours. Accurately weigh $22.3 \mathrm{mg}$ of CFX and transfer into $100-\mathrm{mL}$ volumetric flask. Add $70 \mathrm{~mL}$ of solvent and sonicate to dissolve, then complete to the mark with the same solvent and mix well. Filters through membrane filter $0.45-\mu \mathrm{m}$, reject the first portion then Inject by HPLC.

\subsection{Mean Centering Method}

For the estimation of SDB, the stored scanned spectra of laboratory prepared mixture of CFX and SDB were exported to MATLAB for posterior calculation. The spectra of SDB were divided by the spectrum of $5 \mu \mathrm{g} /$ $\mathrm{mL}$ of CFX, the obtained First ratio spectra were mean centered (Figure. 5). The calibration curves for SDB was constructed by plotting the mean centered values at $225 \mathrm{~nm}$ versus the corresponding concentration and the regression equations were computed. 

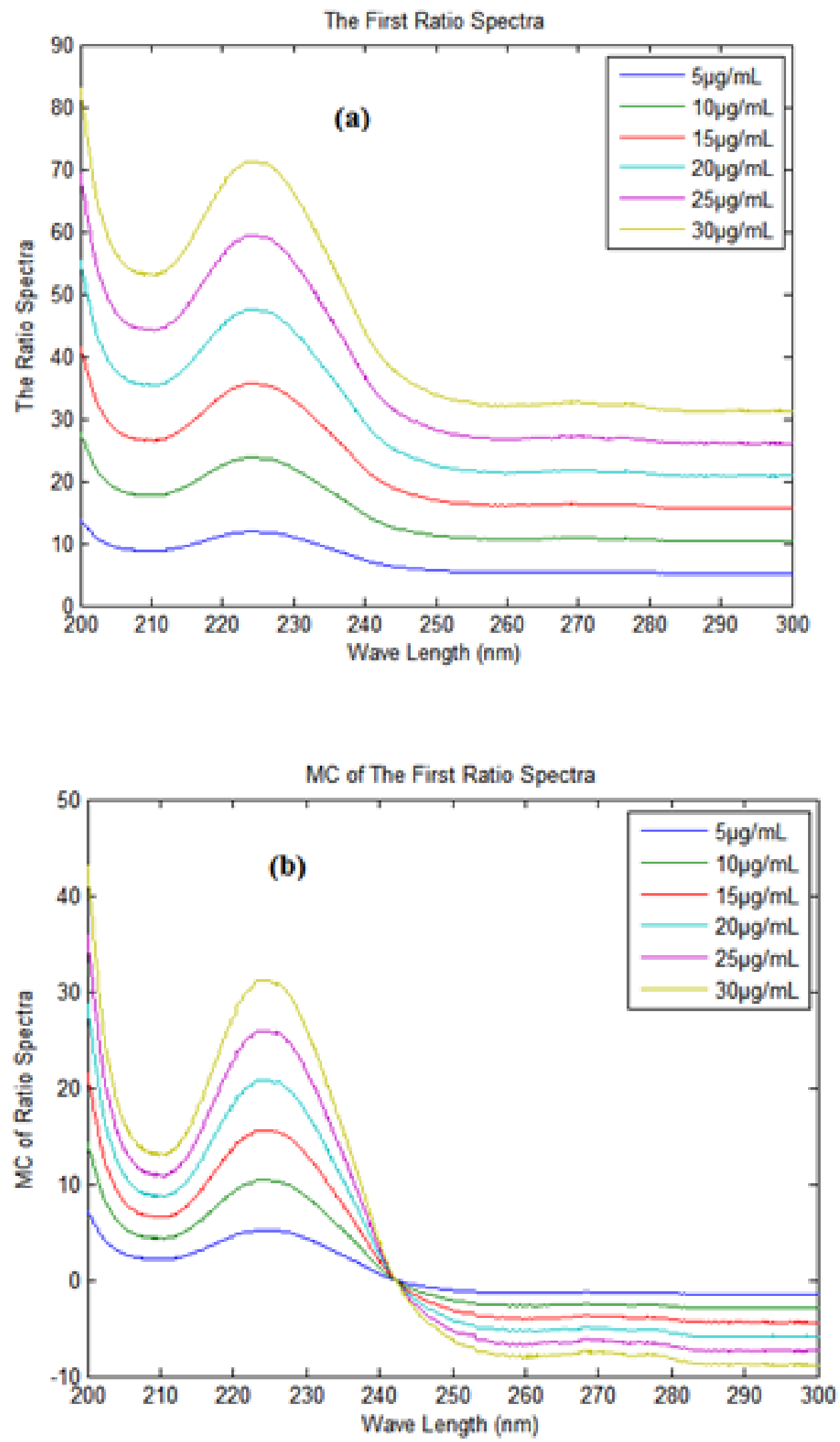

Figure 5. (a) First ratio spectra of SDB $(5-30 \mu \mathrm{g} / \mathrm{mL})$ using CFX $(5 \mu \mathrm{g} / \mathrm{mL})$ as a divisor, and (b) Mean centered ratio spectra of SDB (5-30 $\mu \mathrm{g} / \mathrm{mL})$ using CFX $(5 \mu \mathrm{g} / \mathrm{mL})$ as a divisor. 


\subsection{Application of Comparative in vitro dissolution} study for the proposed method.

Comparative in vitro dissolution was performed on two generic products viz., Rivalexin 200mg Cap and Rivalexin 400mg Cap selecting dissolution parameters as described by FDA against innovator brand e.g., Suprax 200 mg Cap and Suprax 400 mg Cap and results were considered identical. The quantitative release of drug at specified intervals from the product was determined using the validated HPLC method. The dissolution results which were displayed in (Table 4) showed that the value of RSD
$\%$ is less than $10 \%$ at the initial point and less than $5 \%$ for other intervals. Also, the in vitro dissolution profile and the cumulative percentage of generic and innovator products released were plotted against time (Figure. 6). The dissolution profile of generic brand showed similar behavior to the innovator one. There was an agreement that the $f 2$ test is not necessary when the two products each provide at least $85 \%$ dissolution in $15 \mathrm{~min}$. The percentage dissolved for all products was above $85 \%$ of the labeled claimed content from the first sampling time.

Table 4. Cumulative \% Dissolution profile of CFX in Capsule dosage form at FDA media.

\begin{tabular}{|c|c|c|c|c|}
\hline Name & Suprax 200 mg Cap & Rivaxime 200 mg Cap & Suprax 400 mg Cap & $\begin{array}{c}\text { Rivaxime } 400 \mathrm{mg} \\
\text { Cap }\end{array}$ \\
\hline Intervals & & & & \\
\hline 10 & 87 & 85 & 88 & 86 \\
\hline 20 & 89 & 87 & 90 & 88 \\
\hline 30 & 95 & 92 & 94 & 92 \\
\hline 45 & 100 & 97 & 98 & 95 \\
\hline 60 & 103 & 100 & 102 & 99 \\
\hline
\end{tabular}

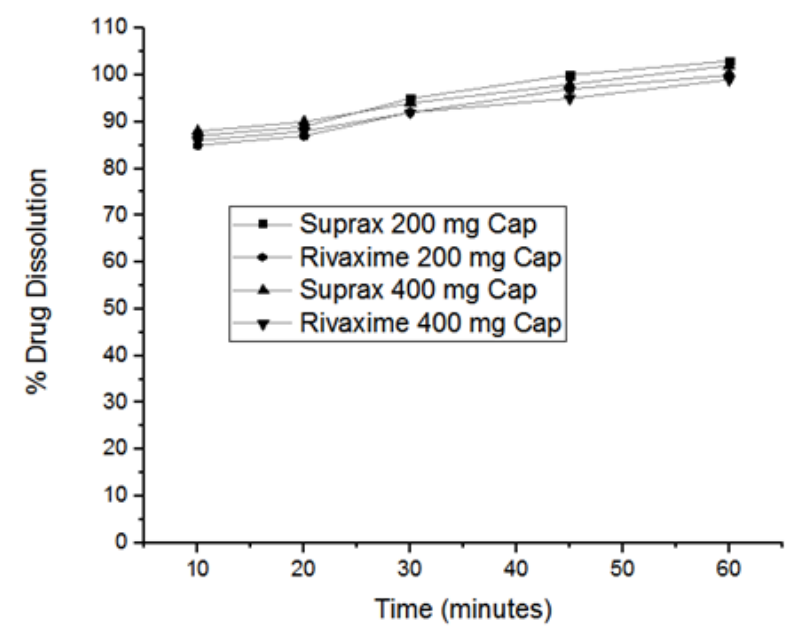

Figure 6. Dissolution Profile of CFX from Rivaxime $200 \mathrm{mg}$ Cap, Rivaxime 400 mg Cap, the generic brand and Suprax 200 mg Cap, Suprax 400 mg Cap.

\subsection{Application of Lean Six Sigma Methodology.}

Trend data of CFX for the two suppliers were collected for the last two years concerning 100 batches of assay as summarized in (Table 5) by our quality control team for monitoring the manufacturing operation of the suppliers. Then data were exported to Minitab for subsequent calculation. Process capability six-pack analysis indicates that the data for the first supplier (Astellas Pharma Inc) was capable and more accurate than the second supplier (Orchid Chemicals \& Pharmaceuticals Ltd) as Cpk is 1.96 (Figure 7), means that it meets 6 sigma level, while the second supplier was normally distributed, within the control specification and statistical control as the Cpk is 1.37 i.e., it meets 4 sigma levels. 
Table 5. Application of quality control and statistical tools to monitor Manufacturing Operation.

\begin{tabular}{ccc} 
Parameters & & Values \\
Descriptive Statistic & Astellas Supplier & Orchid Supplier \\
Mean & 99.013 & 98.932 \\
\hline Standard Error & 0.0615 & 0.110 \\
Median & 99.000 & 99.000 \\
Mode & 99.000 & 98.000 \\
\hline Standard Deviation & 0.615 & 1.099 \\
\hline Variance & 0.379 & 1.209 \\
\hline Kurtosis & -0.33 & -0.58 \\
\hline Skewness & -0.36 & 0.21 \\
\hline Range & 2.700 & 5.000 \\
\hline Minimum & 97.300 & 96.000 \\
\hline Maximum & 100.000 & 101.000 \\
\hline Sum & 9901.300 & 9893.200 \\
\hline Count & 100 & 100 \\
\hline
\end{tabular}



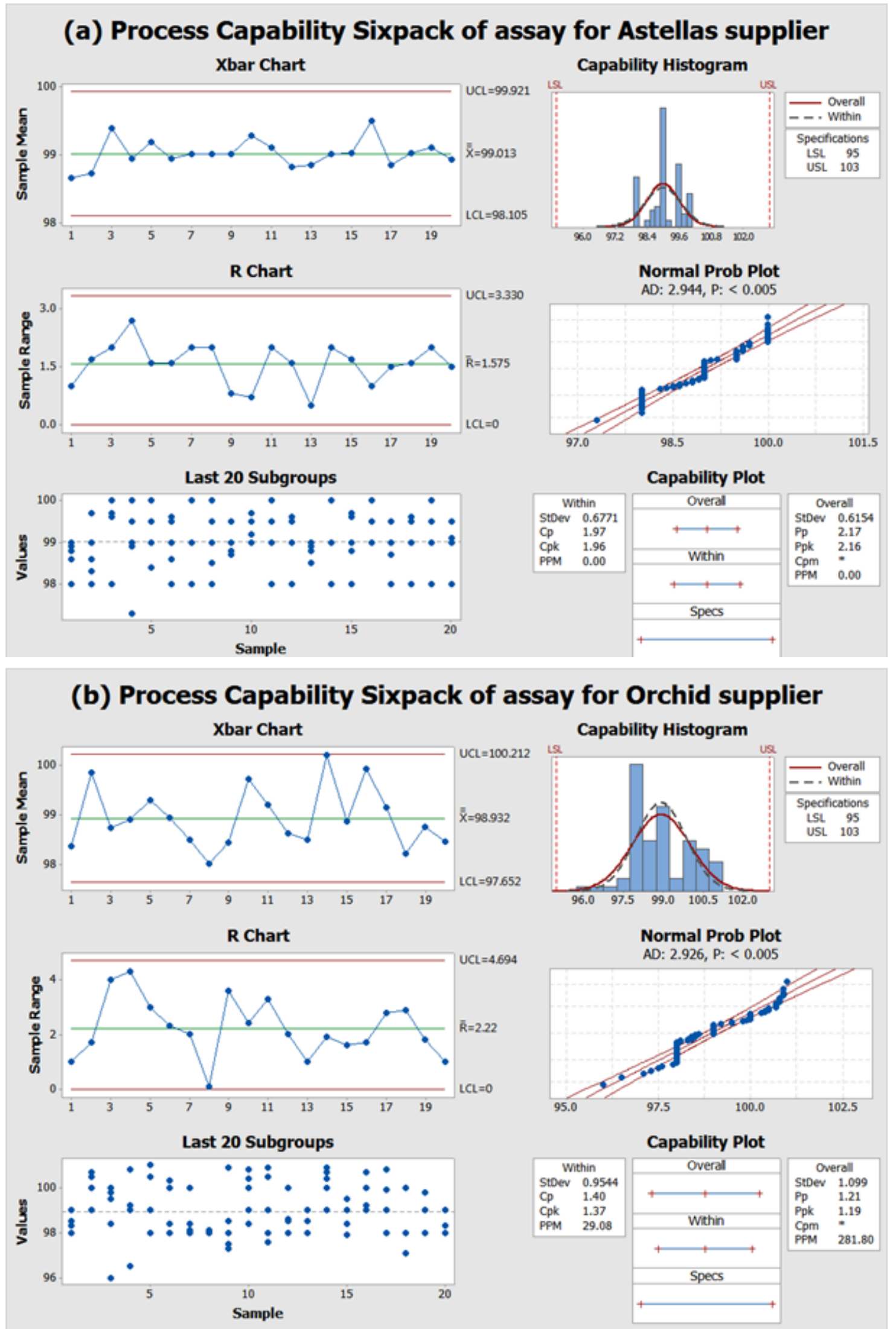

Figure 7. Process Capability Sixpack of quality tools for normally distributed assay results of 100 batches of CFX API for comparison between two suppliers (a) Astellas (Japan) supplier and (b) Orchid (India) supplier using Minitab ${ }^{\circledR}$ 17.1.0 


\section{Conclusion}

EfficientandsensitiveUPLCandspectrophotometric MC methods were validated and developed according to the requirements of ICH guidelines for simultaneous quantification of CFX and SDB in their pharmaceutical formulation and application of LSS methodology for reducing variation and increasing the productivity during the manufacturing operation, also Comparative in vitro dissolution studies have been achieved for two generic brands; Rivalexin 200\&400 mg Cap and hence it was assumed equivalent to the innovator product of Suprax $200 \& 400 \mathrm{mg}$ Cap at FDA dissolution media and the two products were considered similar.

\section{Conflict of interest}

The authors declare no conflict of interest. 


\section{References}

[1] British Pharmacopoeia. Stationary Office Medicines and Healthcare Products Regulatory Agency; London.2020, 2.

[2] Description and Clinical Pharmacology for cefixime Drug U. S. Food and Drug Administration.2012, https:// www.accessdata.fda.gov/drugsatfda.

[3] Description of sodium benzoate U. S. Food and Drug Administration.2017, https://www.accessdata.fda.gov/ scripts/cdrh/cfdocs/cfCFR/CFRSearch.cfm?fr=184.1733.

[4] United States Pharmacopoeia Convention Inc, 2020, NF 38, Revision 42.

[5] Adam, E.H.; Saeed, A.E.; Barakat, I.E. Development and validation of a high-performance liquid chromatography method for determination of cefixime trihydrate and its degraded products formed under stress condition of UV light. Int. J. Pharm. Sci. Res.2012; 3:469-473.

[6] Aşçı, B.; Dinç Zor, Ş.; Aksu Dönmez, Ö. Development and validation of HPLC method for the simultaneous determination of five food additives and caffeine in soft drinks; Int. J. Anal. Chem.2016; 2016:1-8.

[7] Attimarad, M.V.; Alnajjar, A.O. A conventional HPLC-MS method for the simultaneous determination of ofloxacin and cefixime in plasma: Development and validation. J. Basic Clin. Pharm.2013; 4:36-41.

[8] Bhinge, S.D.; Malipatil, S.M. Development and validation of a stability-indicating method for the simultaneous estimation of cefixime and dicloxacillin using the RP-HPLC method. Journal of Taibah University for Science.2016; 10:734-744.

[9] Dhara, P.; Dhananjay, M.; Vandana, P.; Devanshi, P.; Hira, P. A Validated Stability Indicating RP-HPLC Method Development and Validation for Simultaneous Estimation of Cefixime Trihydrate and Levofloxacin Hemihydrate in Pharmaceutical Dosage Form. Int J Analytical Techn.2017; 3:1-12.

[10] Danafar, H.A. quick and easy high-performance liquid chromatography method for evaluation of cefixime in human plasma. Pharm. Biomed. Res.2015; 1:29-39.

[11] Elias, B.; Alfeen, A.; Determination of Cefuroxime Axetil and Cefixime Trihydrate in Pharmaceutical Dosage Forms by RP-HPLC Method. Pharm Anal Chem.2012, 2:114-118.

[12] Gören, A.C.; Bilsel, G.; Şimşek, A.; Bilsel, M.; Akçadağ, F.; Topal, K.; Ozgen, H. HPLC and LC-MS/MS methods for determination of sodium benzoate and potassium sorbate in food and beverages: Performances of local accredited laboratories via proficiency tests in Turkey. Food chemistry.2014; 175: 273-279.

[13] Hassouna, M.E.M.; Abdelrahman, M.M.; Mohamed, M.A. Validation of a Novel and Sensitive RP-HPLC Method for Simultaneous Determination of Cefixime Trihydrate and Sodium Benzoate in Powder for Oral Suspension Dosage Form. J Forensic Sci \& Criminal Inves.2017; 2: 555600.

[14] Hussein, L.A.; Hussien, E.M.; Magdy, N.; Mohamed, H.S.; Simultaneous estimation of Ofloxacin and Cefixime in tablet form in presence of the inactive Ofloxacin USP Related compound A. Bulletin of Faculty of Pharmacy. Cairo University.2017; 55:171-176.

[15] Kundu, S.; Majumder, T.; Barat, P.K.; Ray, S.K. Development and validation of a HPLC-UV method for simultaneous determination of cefixime and ofloxacin in tablet formulation. Int. J. Pharm. Sci. Res.2015; 6:884-889.

[16] Patel, N.S.; Tandel, F.B.; Patel, Y.D.; Thakkar, K.B. Development and validation of stability indicating HPLC method for simultaneous estimation of cefixime and linezolid. Indian J. Pharm. Sci.2014; 76:535-540.

[17] Patwari, A.; Dabhi, M.; Rathod, I.; Desai, U.; Suhagia, B.; Sharma, M. Simultaneous Determination of ofloxacin and Cefixime in combined tablet Dosage Form by HPLC and Absorption correction method. Bull Pharm Res.2014, 4:112-117. 
[18] Rao M.N., Veni P.R. and Haribabu B., Stability indicating RP-HPLC method for determination of cefixime and ornidazole in combined pharmaceutical dosage form. RJC.2015, 8: 477-486.

[19] Saikrishna, I.; Ganesh Akula, E.V.; Sreedevi, K.; Saikumar Bhupathi, S.R. Validation of Reversed - Phase Hplc Method for The Estimation of Cefixime In Cefixime Oral Suspension. IJPT.2010, 2: 385-395.

[20] Afkhami, A.; Felehgari, F.S.; Madrakian, T. Gold nanoparticles modified carbon paste electrode as an efficient electrochemical sensor for rapid and sensitive determination of cefixime in urine and pharmaceutical samples. Electrochimica Acta.2013, 103:125-133.

[21] Alnajjar, A.O. Simultaneous Determination of Ofloxacin and Cefixime in Tablet Formulation using Capillary Electrophoresis. J. Liq. Chromatogr. Relat. Technol.2013, 36: 2687-2697.

[22] Baboli, M.A.; Varnosfaderani, A.M. Rapid and simultaneous determination of tetracycline and cefixime antibiotics by mean of gold nanoparticles-screen printed gold electrode and chemometrics tools. Measurement.2014, 47: 145-149.

[23] Honda, S.; Taga, A.; Kakehi, K.; Koda, S.; Okamoto, Y. Determination of cefixime and its metabolises by high-performance capillary electrophoresis. Journal of Chromatography A.1992, 590:364-368.

[24] Deshpande, M.M.; Kasture, V.S.; Gosavi, S.A. Application of HPLC and HPTLC for the Simultaneous Determination of Cefixime Trihydrate and Ambroxol Hydrochloride in Pharmaceutical Dosage Form. Eurasian J. Anal. Chem.2010, 5: 227-238.

[25] Dhoka, M.V.; Gawande, V.T.; Joshi, P.P. Validated HPTLC Method for Determination of Cefixime Trihydrate and Erdosteine in Bulk and combined Pharmaceutical Dosage Form. Eurasian J Anal Chem.2013, 8:99-106.

[26] Popović, G.; Čakar, M.; Agbaba, D. Simultaneous determination of loratadine and preservatives in syrups by thin-layer chromatography. Acta Chromatogr.2007, 19:161-169.

[27] Rao, J.; Sethy, K.; Yadav, S. Validated HPTLC Method for Simultaneous Quantitation of Cefixime and Ofloxacin in Bulk Drug and in Pharmaceutical Formulation. Pharmacie Globale (IJCP).2011, 2:1-5.

[28] Anees, M.I.; Baig, M.S.; Tathe, A. Determination of cefixime and moxifloxacin in pharmaceutical dosage form by simultaneous equation and area under curve UV-spectrophotometric method. World J. Pharm. Pharm. Sci.2015, 4:1172-1179.

[29] Azmi, S.N.H.; Iqbal, B.; Al Mamari, J.K.; Al Hattali K.A.; Al Hadhrami, W.N. Method Development and Validation for the Determination of Cefixime in Pure and Commercial Dosage Forms by Specrophotometry. Int J Chem Molec Nucl Mat Metallurg Eng.2014, 8:595-601.

[30] Ethiraj, T.; Ramadoss, R.; Amudha, M. Sensitive spectroscopic method for content analysis of cefixime in solid dosage form using hydrotropy phenomenon. Chronicles of Young Scientists.2012, 3: 299- 303.

[31] Hassouna, M.E.M.; Abdelrahman, M.A.; Mohamed, M.A. Novel Spectro photometric Methods for Simultaneous Determination of Cefixime trihydrate and Sodium benzoate in Powder for Oral Suspension Dosage form. Glob J Oto.2017, 12:555-841.

[32] Kompany-Zareh, M.; Mirzaei, S. Spectrophotometric resolution of ternary mixtures of pseudoephedrine hydrochloride, dextromethorphan hydrobromide, and sodium benzoate in syrups using wavelength selection by net analyte signals calculated with hybrid linear analysis. Analytica chimica acta.2004, 526:83-94.

[33] Kumar, A.; Kishore, L.; Nair, A.; Kaur, N. Kinetic spectrophotometric method for the estimation of cefixime in pharmaceutical formulations. Der Pharma Chemica.2011, 3: 279-291.

[34] Kumar, R.; Singh, P.; Singh, H. Development of colorimetric method for the analysis of pharmaceutical formulation containing both ofloxacin and cefixime. Int J Pharmacy and Pharm Sci.2011, 3:178-179. 
[35] Pekamwar, S.S.; Kalyankar, T.M.; Tambe, B.V.; Wadher, S.J. Validated UV-Visible Spectrophotometric method for simultaneous estimation of cefixime and moxifloxacin in pharmaceutical dosage form. J Appl Pharm Sci.2015, 5:37-41.

[36] Ramadan, A.A.; Mandil, A.; Dahhan, M. UV-VIS Spectrophotometric study for determination of cefixime in pure form and in pharmaceuticals through complexation with $\mathrm{Cu}$ (II) using acetate- $\mathrm{NaOH}$ buffer in water: methanol. International J. of Pharmacy and Phar. Sci.2013, 5: 428-433.

[37] Shreya, R.S.; Prasanna, P.; Suddhasattya, D. Quantitative estimation of cefixime and moxifloxacin in pharmaceutical preparation by UV spectrophotometric method. Int J Pharm Tech Res.2013, 5:198-204.

[38] Somya, K.V.; Ravishankar, K.; Basha, D.P.; Kiranmayi, G.V. Estimation of caffeine and sodiun benzoate in caffeine and sodium benzoate injection by isoabsorption method (isobestic method). Int J Pharm Chem Biol Sci.2011,1: 26-3

[39] Sutar, S.V.; Sancheti, H.; Patil, S.S.; Spectrophotometric Method for Cefixime Trihydrate by Using Hydrotropic Agent. International Science Press, India.2013, 6:80-85.

[40] Hassouna, M.E.M.; Mohamed M.A. Comparative In-Vitro Dissolution Studies for Determination of Cefixime in an Innovator Product of Suprax Powder for Oral Suspension Dosage Form Using RP-HPLC Method; Glob J Oto.2018, 14:555886.

[41] Kamal, M.M.; Anisuzzaman, S.M.; Begum, A.A. Comparative dissolution studies of cefixime solid dosage forms available in Bangladesh market. J Biol Sci.2013, 2:115-120.

[42] Zhang, H.; Yu, L. Dissolution Testing for Solid Oral Drug Products: Theoretical Considerations. Am. Pharm. Rev.2004, 7: 26-31.

[43] Hassouna, M.E.M.; Mohamed, M.A. Modeling and optimization of a novel RP-UPLC and MCR spectrophotometric methods for simultaneous determination of five cephalosporins in spiked human plasma: Application to lean six sigma thinking hats and antimicrobial activity. Microchemical Journal.2019, 150: 104161.

[44] ICH guidelines. International Conference on Harmonization IFPMA, Geneva, Switzerland. 2005, Q2 (R1). 


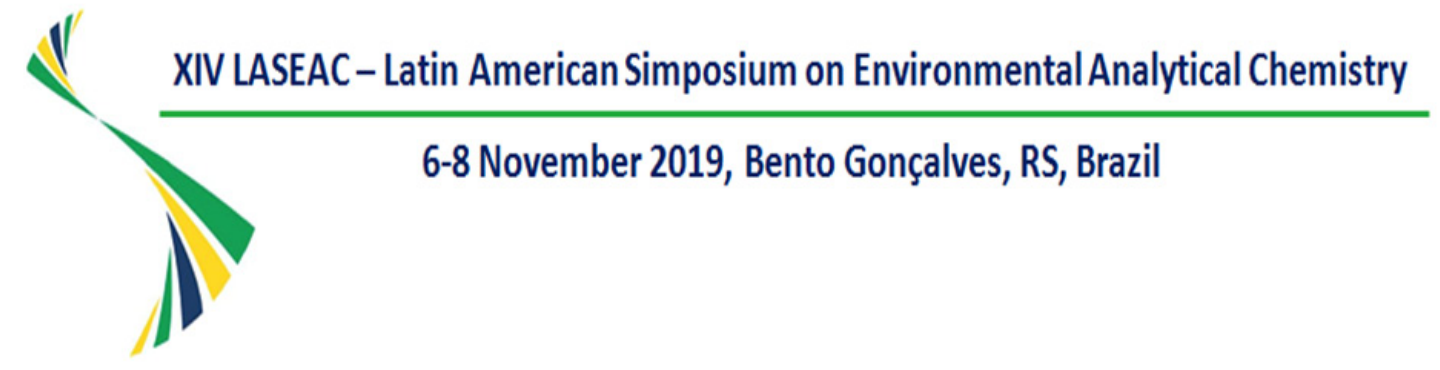

Fernando M. Lanças

Universidade de São Paulo

Instituto de Química de São Carlos

13560-970 São Carlos, SP, Brasil

No período compreendido entre 6 a 8 de Novembro de 2019 realizou-se, em Bento Gonçalves, RS, a décima quarta versão do esperado Simpósio Latino-Americano de Química Analítica Ambiental, LASEAC. O Simpósio congregou vários eventos em paralelo, todos já bem estabelecidos, o que conferiu ainda um brilho adicional ao mesmo.

No número anterior do Scientia divulgamos o programa completo do LASEAC, o qual ilustra a grande diversidade dos assuntos tratados, assim como o sinergismo dos mesmos dentro do tema central. As conferências plenárias trouxeram o estado-da-arte de várias técnicas de análise ambiental, apresentadas por especialistas nacionais e estrangeiros de grande visibilidade internacional. Os posteres permitiram uma discussão mais próxima entre autores dos trabalhos e os participantes do evento.

Vários prêmios foram entregues durante o Simpósio, inclusive a pessoas de destaque nos eventos em paralelo, a exemplo da Medalha J. Pawliszyn do WARPA ao Prof. Dr. Eduardo Carasek.

Enfim, o evento foi bastante concorrido, de excelente qualidade, e uma oportunidade impar para os pesquisadores da América Latina se encontrarem e discutirem os assuntos de interesse comum.

Deve ser salientado que Bento Gonçalves, com seus encantos sem igual, serviu como a moldura perfeita para a realização do evento.

Parabéns à Comissão Organizadora do LASEAC e dos eventos paralelos, pelo brilhante programa científico desenvolvido.

Como um ditado afirma que "uma imagem vale por mil palavras", achei melhor mostrar algumas imagens do que milhares de palavras para descrever alguns momentos especiais do evento. 


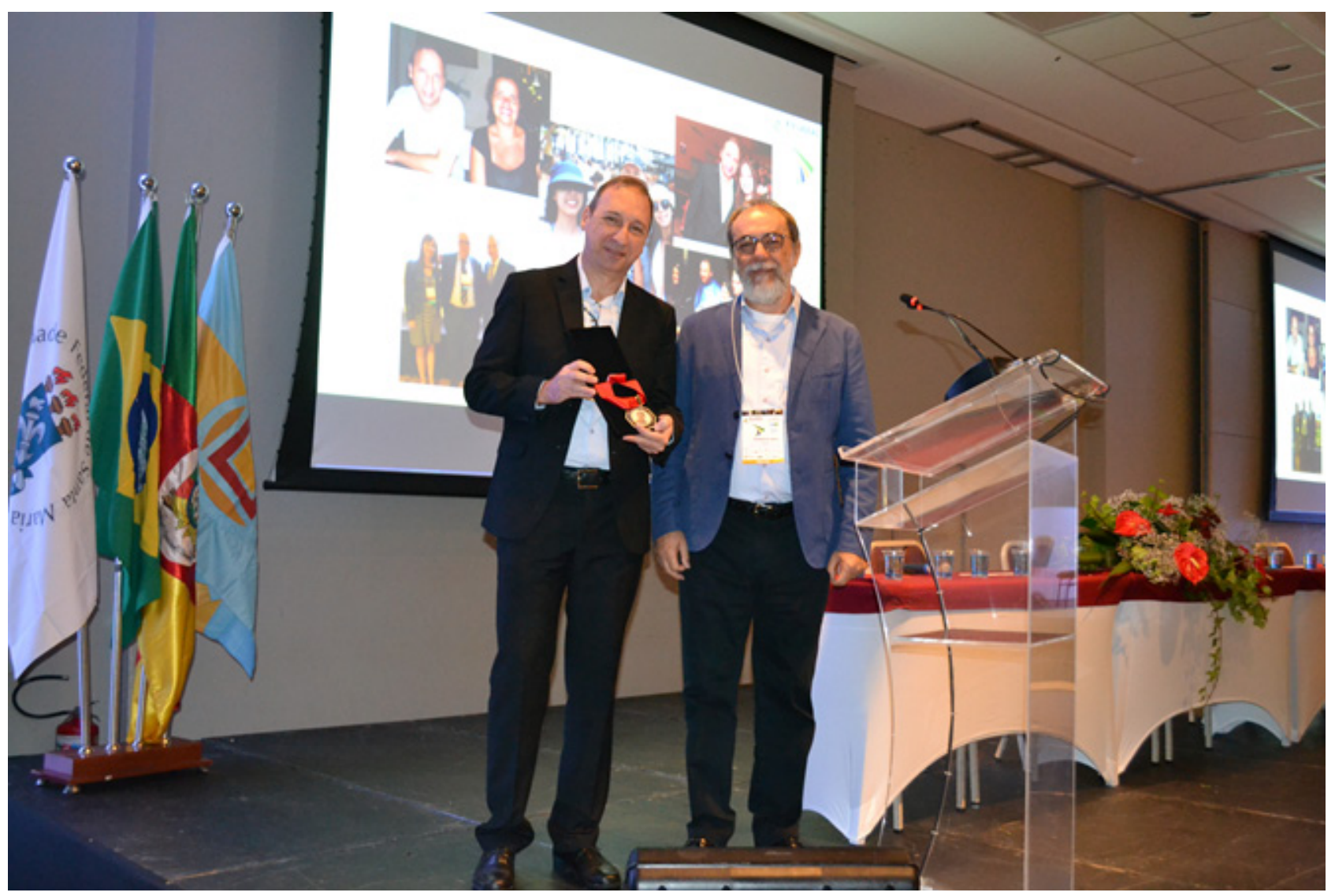

Prof. Dr. Eduardo Carasek (esquerda) recebe a Medalha Janusz Pawlyszyn - WARPA do Prof. Fernando Lanças, Coordenador do XII WARPA. 


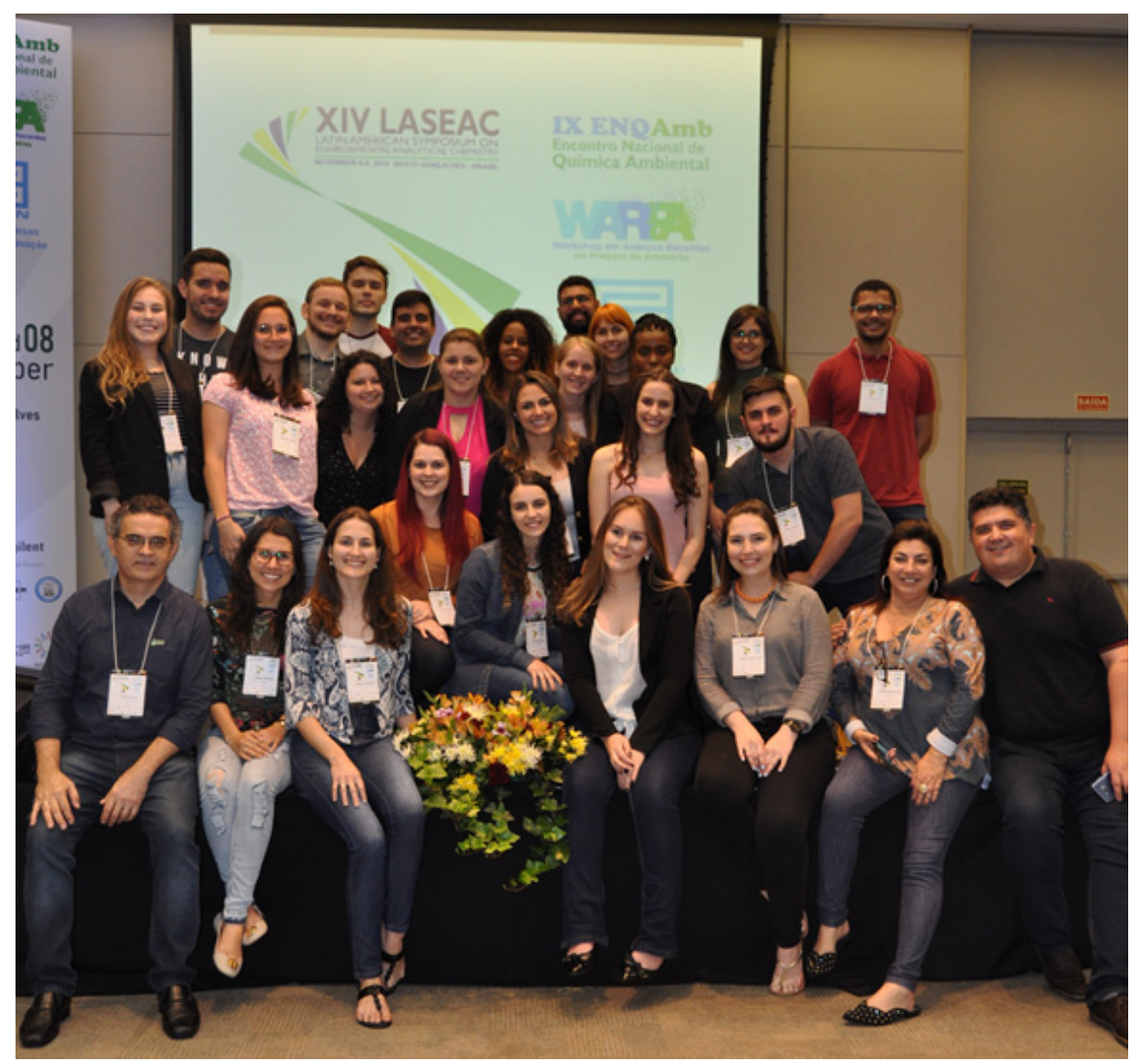

Organizadores do XIV LASEAC.

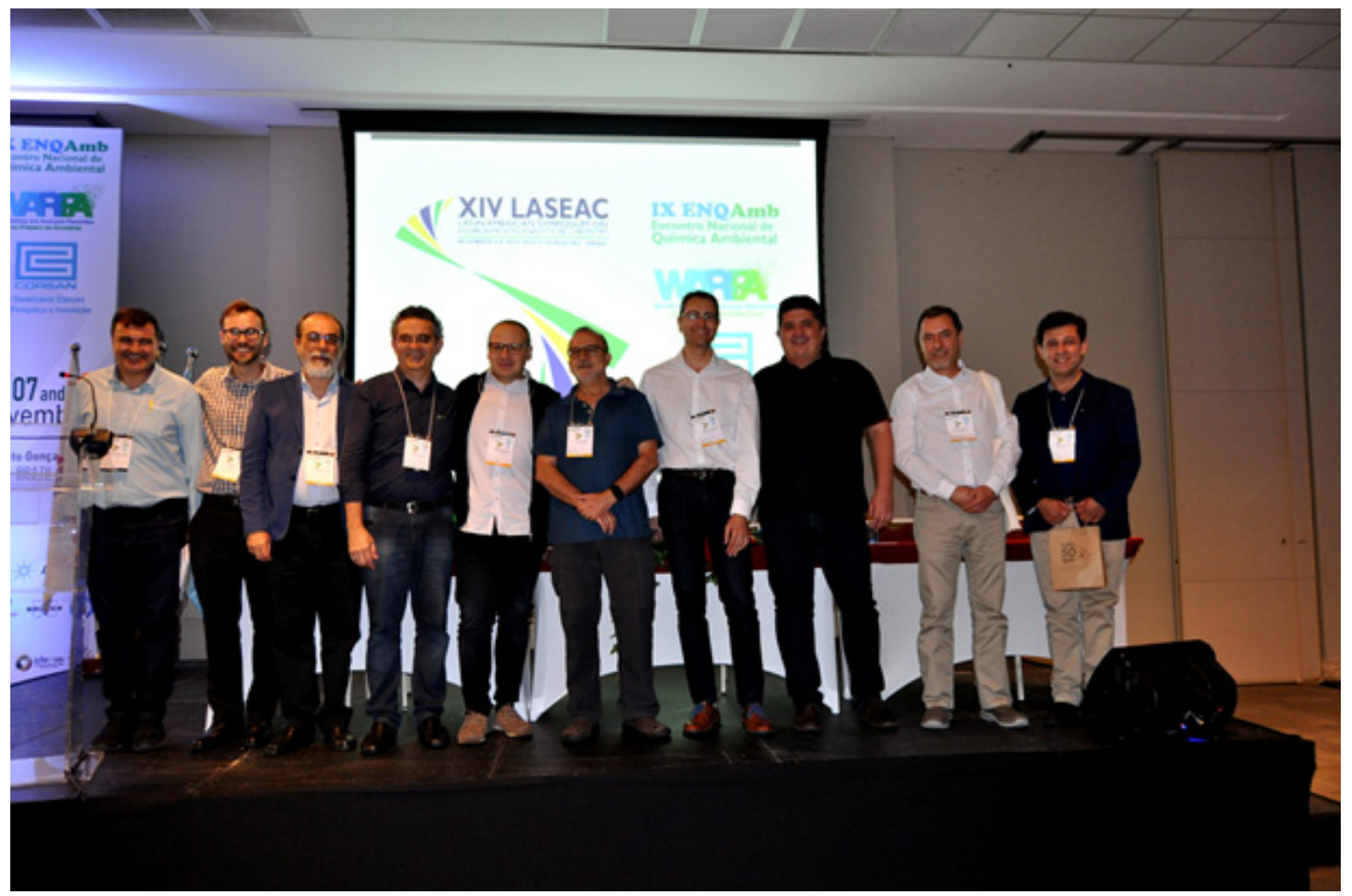

Coordenadores dos eventos realizados durante o XIV LASEC. 


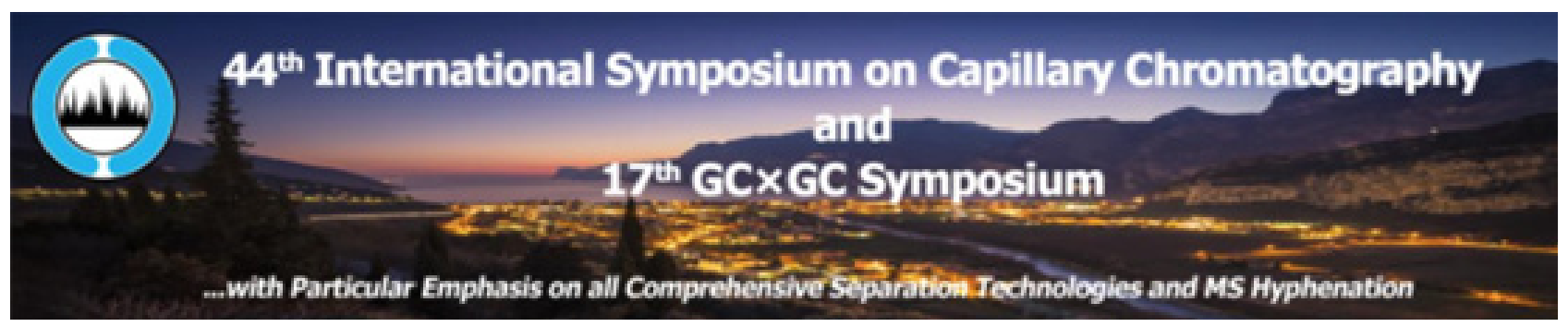

\section{$44^{\text {th }}$ International Symposium on Capillary Chromatography and $17^{\text {th }}$ GCxGC Symposium}

with particular emphasis on all Comprehensive Separation Technologies and MS Hyphenation

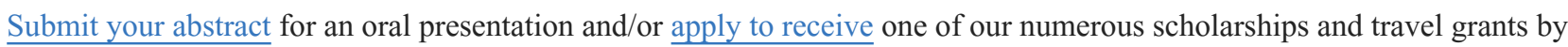

February 21, 2020.

In order to speed-up handling of scientific contributions, notification of acceptance of oral abstracts will be given by March 21, 2020.

Don't miss the opportunity to join us and take advantage of reduced-fee registration

HURRY UP!

Submit an abstract for oral or poster presentation

Scientists from academia, industry, government regulatory agencies are encouraged to submit abstracts with latest results in areas relevant to Capillary Chromatography, Micro Liquid Chromatography, Electromigration methods, Microfabricated Analytical Systems-Lab-on-a-chip, Column Technology, Coupled and Multidimensional Techniques, Sampling and Sample Preparation, with applications to: Environmental - Energy, Petrochemical and Industry - Biomedical and Pharmaceutical - Natural products, Food, Flavour and Fragrances.

Preliminary list of confirmed invited speakers

ISCC

Armstrong Daniel

Bojko Barbara

Buszewski Boguslaw

Britz-Mckibbin Phillip

Cappiello Achille 
David Frank

Desmet Gert

Dugo Paola

Fanali Salvatore

Gras Ronda

Grinias Jim

Gritti Fabrice

Hernandez Borges Javier

Hilder Emily

Hopfgartner Gerard

Huber Christian

Jacobson Stephen

Kelly Ryan

Kennedy Robert

Laemmerhofer Michael

Lancas Fernando

Lee Ed

Lee Milton

Luong Jim

Myers Peter

Novotny Milos

Ochiai Nobuo

Olesik Susan

Pawliszyn Janusz

Psillakis Elia

Ramsey Michael

Schug Kevin

Sidisky Len

Stashenko Elena

Svec Frantisek

Thiebaut Didier

Wooley Adam

$\mathrm{Xu}$ Guowang

Zini Claudia

\section{GCxGC}

Bean Heather

Cordero Chiara

Dimandja John

Dorman Frank

Focant Jeff 
Gorecki Tadeus

Harynuk James

Janssen Hans-Gerd

Marriott Philip

Perrault Katelynn

Schmitz Oliver

Stefanuto Pierre-Hugues

Synovec Robert

Tranchida Peter

Zimmermann Ralf

Key Dates

February 21, 2020 Oral Abstract deadline

March 1, 2020 Poster Abstract deadline

March 21, 2020 Acceptance of oral presentations

April 1, 2020 Deadline for Reduced fee Registration

May 1, 2020 Deadline for Registration for inclusion of the abstracts in the Book of Abstracts.

May 1, 2020 Preliminary Program

May 24-29 ISCC\&GCxGC 2020 Riva del Garda, Italy

Luigi Mondello,

Chairman RIVA 2020 
O Instituto Internacional de Cromatografia (IIC) possui como uma de suas principais missões o oferecimento de cursos de curta duração nas áreas de cromatografia e técnicas relacionadas.

Os objetivos dos cursos do IIC são o aprimoramento/formação/ atualização dos usuários das técnicas cromatográficas e afim (Preparo de Amostras, Espectrometria de Massas, Gestão da Qualidade, dentre outras), tanto do ponto de vista teórico quanto prático.

A filosofia educacional do IIC é: "ao invés de ensinar apenas como operar um equipamento específico (dar o peixe) o IIC ensina a técnica (como pescar)".

Os cursos do Instituto Internacional de Cromatografia são coordenados pelos Diretores do IIC, e ministrados pelos coordenadores, auxiliados por uma equipe técnica e científica altamente qualificada, constituída de docentes pósgraduados nos melhores centros do país na área, e pós-graduandos em fase de conclusão de suas teses. Na época em que cada curso for oferecido, uma relação dos instrutores é disponibilizada no website do IIC.

O programa detalhado de cada curso pode ser obtido através de contacto com o IIC.

Os cursos são ministrados com auxílio de recursos audiovisuais modernos (datashow-computador; vídeos, demonstrações, resolução de problemas e outros recursos instrucionais). Os alunos recebem um livreto contendo cópia de todos os slides apresentados pelos instrutores, além de material bibliográfico de apoio. Em vários cursos também são fornecidos livros de autoria dos próprios docentes dos cursos. A maior parte dos cursos também tem aulas práticas de laboratório, conforme anunciado no folheto explicativo de cada curso.

Observações:

- O I.I.C. oferece também cursos "in-house" ("in-company"). Interessados nesta modalidade devem contatar o IIC para obter mais detalhes.

- Com exceção dos cursos da área da qualidade (ISO, Validação e Auditoria) todos os demais possuem aulas teóricas e práticas de laboratório.

- O oferecimento efetivo de um curso depende de um número mínimo de inscritos no mesmo.

- O número de vagas dos cursos que envolvem laboratório está sendo limitado para melhor aproveitamento dos participantes.

- Visite o website www.iicweb.org para obter mais informações. 
O Bookstore divulgará o material de informação e formação produzido pelo IIC, incluindo Livros, filmes, slides, material didático de cursos e outras formas de divulgação dos materiais por ele produzido. Esses materiais podem ser adquiridos do IIC através do website www.iicweb.org/biblioteca.php

\section{Cromatografia Líquida Moderna - Fernando M. Lanças}

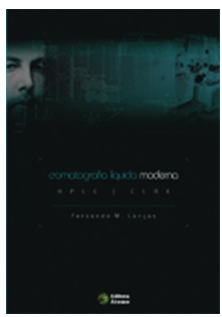

Livro publicado pela Editora Átomo em maio de 2009, aborda de forma simples e didática os principais assuntos relacionados à Cromatografia Líquida Moderna (HPLC ou CLAE), desde a Teoria, Instrumentação, Colunas, Detectores, até aspectos da Validação, Preparo da Amostra e Análise Quantitativa.

O IIC recomenda este livro para todos os interessados em iniciar-se ou atualizar-se nesta técnica.

\section{Cromatografia em Fase Gasosa - Fernando M. Lanças}

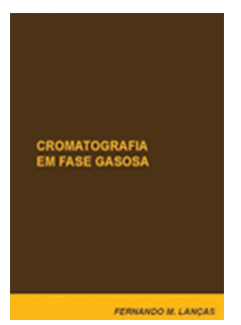

Livro de autoria do Prof. Lanças, abordando todos os princípios básicos: instrumentação, análise qualitativa e quantitativa, detectores e muitos outros aspectos da Cromatografia Gasosa.

Altamente recomendado para os iniciantes na técnica, os quais encontrarão explicações detalhadas e simples a respeito da maior parte dos fundamentos básicos da técnica.

\section{Extração em Fase Sólida - Fernando M. Lanças}

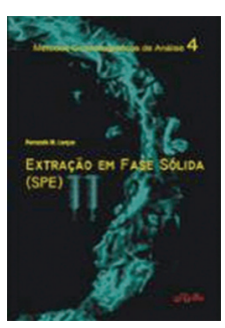

De autoria do Prof. Lanças, este livro apresenta e discute as várias formas de extração em fase sólida (SPE), desde a mais clássica empregando cartuchos até as mais atuais como discos, placas, ponteiras, e outras. Também discute os princípios da micro extração em fase sólida (SPME) e da extração por sorção em barras de agitação (SBSE). 


\section{Normas para publicação de artigos no Scientia Chromatographica (a versão detalhada está disponível em nosso portal www.scientiachromatographica.com).}

\section{Escopo}

Scientia Chromatographica publica trabalhos em todas as áreas da Cromatografia, incluindo GC (colunas capilares, empacotadas, preparativas), LC (convencional, HPLC, U-HPLC, Prep-LC, micro-LC, nano-LC, TLC, PC), SFC (colunas empacotadas ou capilares), Técnicas Acopladas (GC-MS, LC-MS, SFC-MS, LC-GC, SFE-CE, GCxGC, LCxLC) e Técnicas de Preparo de Amostras (SPME, SBSE, MEPS, QuEChERS, LLE, MAE,SPE, LLE, etc.). A partir de 2012 o Scientia publica os seguintes formatos de artigos:

- Artigos Originais de Pesquisa

- Comunicação ("Short Communication")

- Artigos de Revisão Crítica

Os artigos de Revisão Crítica deverão antes de sua submissão serem discutidos com um dos co-editores mais relacionados ao assunto em questão. Devem conter uma contribuição nova a respeito de um assunto de grande interesse atual, incluindo uma discussão a respeito das vantagens e desvantagens do mesmo. O Scientia não publica apenas relato de artigos descritos na literatura, sem uma discussão crítica sobre os mesmos.

Os artigos Originiais de Pesquisa deverão conter resultados de laboratório e/ou teóricos, que signifiquem uma contribuição expressiva para a área de técnicas de separação, seja ela conceitual, na instrumentação, ou na aplicação.

Os artigos do tipo Comunicação deverão ter a mesma qualidade dos artigos Originais, porém devido a seu caráter de comunicação preliminar usualmente são de menor extensão.

\section{Envio do Artigo}

Os artigos deverão ser encaminhados para periodico@scientiachromatographica.org. Os artigos do tipo Revisão deverão antes de seu envio pelo website ter o aval de um dos co-Editores do periódico, caso contrário não serão avaliados. Todos os artigos, independentemente do formato, deverão ser submetidos exclusivamente ao Scientia, com o entendimento de que eles não foram anteriormente submetidos, não estão sendo e não serão posteriormente publicados em outro veículo. Autores que utilizarem tabelas, ilustrações, figuras, ou textos contendo mais de 25 palavras, anteriormente publicados em outro periódico - sendo ou não autores do artigo - deverão obter a devida permissão por escrito do portador dos direitos de cópia ("Copyright"). Esse documento deverá permanecer de posse dos autores, sendo encaminhado ao Scientia, quando solicitado.

\section{Idioma}

Os artigos, com exeção dos de Revisão, podem ser escritos preferencialmente em inglês, porém em Português e Espanhol também serão aceitos. Os autores cujo idioma nativo não for o empregado na redação do artigo são orientados a solicitar a colaboração de colegas fluentes no idioma, antes de enviar o artigo para o periódico. 


\section{Tipos de contribuições aceitas para publicação no Scientia}

O Scientia Chromatographica considera para publicação quatro tipos de contribuição:

Artigos Originais de pesquisa: descrevem resultados de estudos completos. Deverão conter resultados de laboratório e/ou teóricos, que signifiquem uma contribuição expressiva para a área de técnicas de separação, seja ela conceitual, na instrumentação, ou na aplicação. Este tipo de contribuição é limitado a 6.000 palavras, incluindo as legendas das figuras e as referências, e no máximo 5 tabelas e/ou figuras somados. No momento do envio da prova de impressão, caso isto ocorra o autor será consultado se prefere revisar o artigo para enquadrá-lo em até 7 páginas, ou se prefere pagar as páginas excedentes. O número de páginas de um artigo depende muito das figuras e tabelas do mesmo. Este critério não é aplicado aos artigos convidados, cujo número de páginas será informado ao autor no momento do convite.

Comunicações ("Short Communication"): são artigos completos, porém que relatam resultados mais curtos, oportunos, e/ou cuja relevância requer sua rápida publicação. Deverão ter a mesma qualidade dos artigos Originais porém, devido a seu caráter de comunicação preliminar, usualmente são de menor extensão. Este tipo de publicação deve ter no máximo quatro páginas impressas, incluindo todo o artigo, ou seja, tabelas, figuras e referências. O autor deve indicar claramente que se trata de uma comunicação no topo da primeira página do artigo.

Artigos de Revisão crítica: revisões críticas sobre uma area específica das técnicas cromatográficas e relacionadas são também consideradas para publicação. Esses artigos devem se limitar a no máximo 10.000 palavras, incluindo as legendas, e até 10 tabelas e figuras somadas. Os artigos de Revisão Crítica deverão antes de sua submissão serem discutidos com um dos co-Editores mais relacionados ao assunto em questão. Artigos não encaminhados desta forma serão antes enviados a um co-Editor da área em que se enquadre para parecer e, somente então, serão enviados aos revisores, podendo atrasar significativamente sua publicação. Devem conter uma contribuição nova a respeito de um assunto de grande interesse atual, discutindo as vantagens e desvantagens do mesmo. O Scientia não publica apenas relato de artigos descritos na literatura, sem uma discussão crítica sobre os mesmos.

Artigos de Alta Prioridade: são publicados no primeiro número disponível do periódico, recebendo prioridade máxima de todo o sistema Editorial do periódico. Para justificar sua publicação como alta prioridade, os manuscritos deverão apresentar, de forma resumida, resultados importantes de recentes desenvolvimentos na área de cromatografia e técnicas relacionadas (espectrometria de massas, preparo de amostras, eletroforese capilar e outros). Não precisam conter resultados experimentais detalhados, sendo limitados a 2.500 palavras e três figuras e/ou tabelas combinadas. 


\section{Cursos 2019}

IIC

Calendário anual de atividades

Visite www.iicweb.org

MÊS

DATA

DISCIPLINA

HORAS

Março

13 a 15

Cromatografia Líquida (HPLC ou CLAE)

24

Abril

10 a 12

Cromatografia Gasosa Moderna

Maio

15 a 17

Técnicas Modernas para Preparo de Amostras

Junho

25 a 28

Cromatografia Líquida Acoplada à Espectrometria de Massas

Julho

24 a 26

Cromatografia Líquida (HPLC ou CLAE)

Agosto 28 a 30 Cromatografia Líquida Avançada

Setembro $\quad 19$ a 20

Como Desenvolver e Otimizar um Método em HPLC

Outubro 22 a 25

Cromatografia Líquida Acoplada à Espectrometria de Massas

Novembro 20 a 22 Cromatografia Gasosa Moderna

Dezembro 11 a 13 Cromatografia Líquida (HPLC ou CLAE) 


\section{Scientia Chromatographica}

Todas as edições disponíveis gratuitamente em versão eletrônica

Publicação eletrônica trimestral do Instituto Internacional de Cromatografia (IIC) é o primeiro e único da América Latina dedicado exclusivamente as Técnicas Cromatográficas e Relacionadas disponível de forma totalmente gratuita desde sua criação.

Também chamado de SC, o periódico está em seu $10^{\circ}$ ano de existência e está chegando na marca de 40 edições publicadas até o momento. Além dos trabalhos científicos, apresenta colunas com informações gerais da área.
Shit Visite o novo website: www.scientiachromatographica.com
Com um Corpo Editorial altamente qualificado e reconhecido internacionalmente, abrange todos os temas cromatográficos, além de discutir muitos temas correlatos.

O SC é leitura obrigatória para os profissionais e pesquisadores da área!

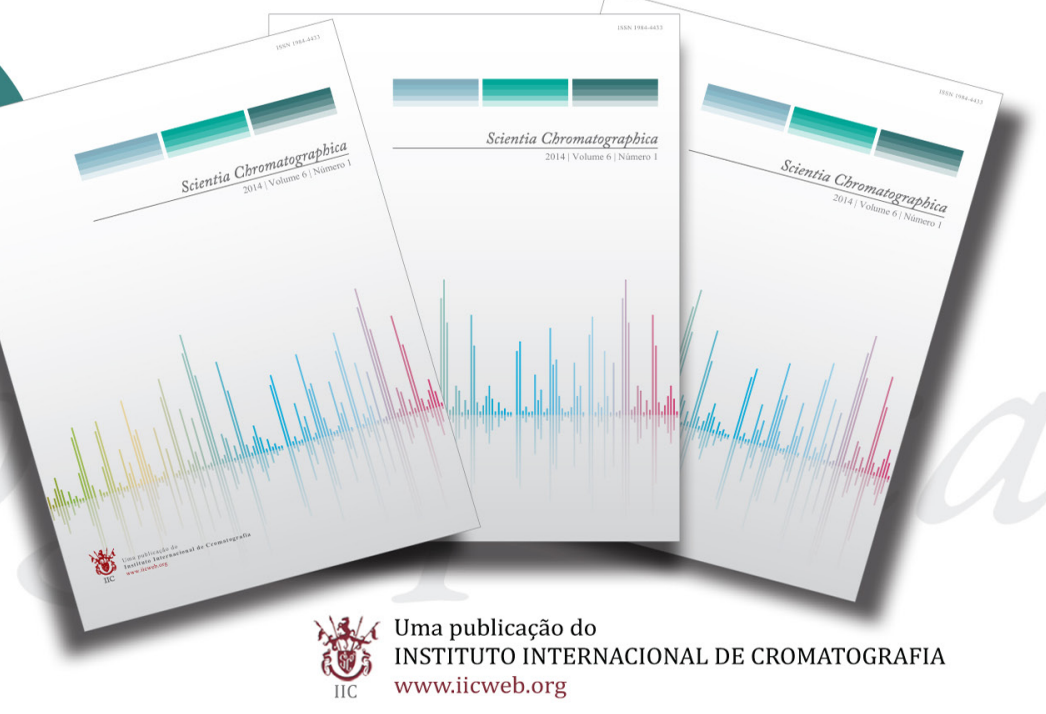




\section{A ESCOLA de CROMATOGRAFIA}
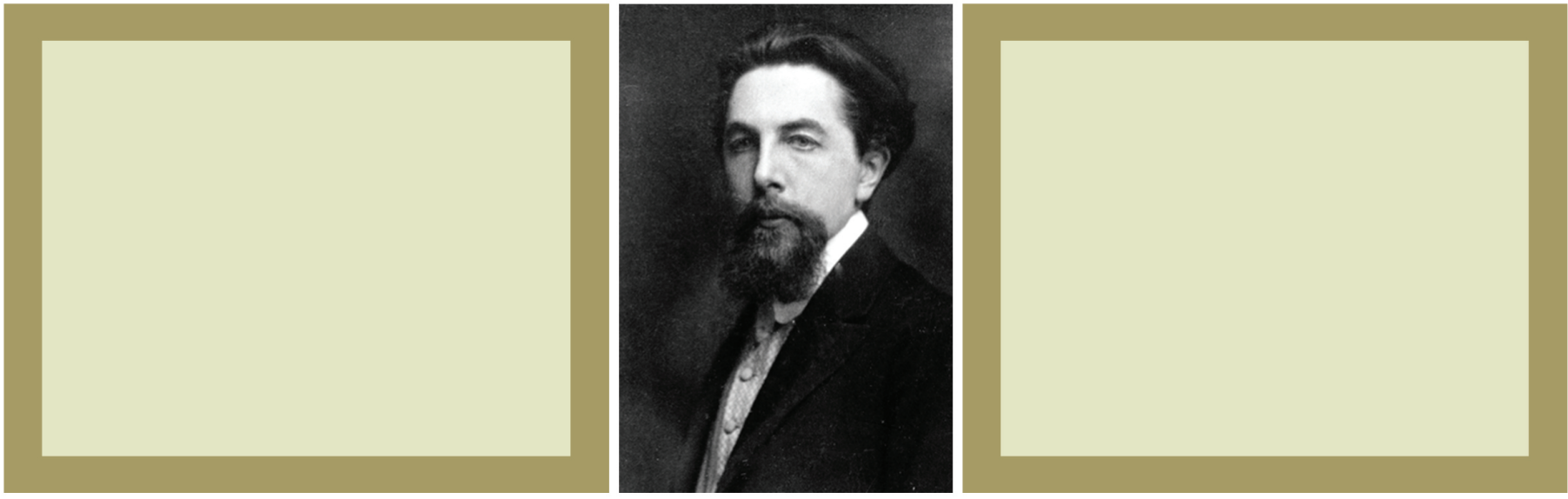

Mikhail Semenovich Tswett (1872-1919) é considerado o

"Pai da Cromatografia".

A Escola de Cromatografia do I.I.C. é uma iniciativa ímpar no Brasil. Consiste em um conjunto de eventos da área de cromatografia e técnicas afim (Espectometria de Massas, Preparo de Amostras e outras) um treinamento altamente qualificado, consistindo de cursos, palestras, workshops, aulas práticas, sessões de discussão, etc. Estes eventos são organizados a partir da constatação da carência dos mesmos em diferentes regiões geográficas do país.

Os Cursos de Iniciação são, prioritariamente, destinados aos interessados em aprenderem a teoria, a prática (ou ambas) envolvidas nas técnicas selecionadas. Tipicamente incluem duâs ou três disciplinas correlacionadas, em um mesmo tema (60 horas-aula). Não exigem pré-requisitos ou formação acadêmica.

Os Cursos de Atualização são, prioritariamente destinados aos interessados em se atualizarem na teoria, prática, ou ambas, envolvidas nas técnicas escolhidas. Tipicamente incluem entre 3 e 5 disciplinas correlacionadas, em um mesmo tema (90 horas-aula). Não exigem pré-requisitos ou formação acadêmica.

Os Cursos de Aperfeicoamento são, prioritariamente destinados aos interessados em se aprofundarem na teoria, prática, ou ambas, envolvidas no assunto escolhido, Tipicamente incluem entre 8 e 12 disciplinas correlacionadas, em um mesmo tema (180 horäs-aula). Estes cursos, por serem de Extensão Universitária, possuem como pré-requisito um curso de graduação, em qualquer área.

Os Cursos da Escola de Cromatografia envolvem um conjunto de disciplinas pedagogicamente ordenadas de forma a oferecer uma melhor visão do conhecimento técnico e científico atual da área escolhida. Estando em contato permanente com o I.I.C. e seus docentes, através das disciplinas cursadas, o aluno tera uma maior oportunidade para discutir suas dificuldades (inclusive em disciplinas anteriores), solicitar literatura complementar, utilizar a biblioteca do I.I.C., assistir palestras, workshops e outras

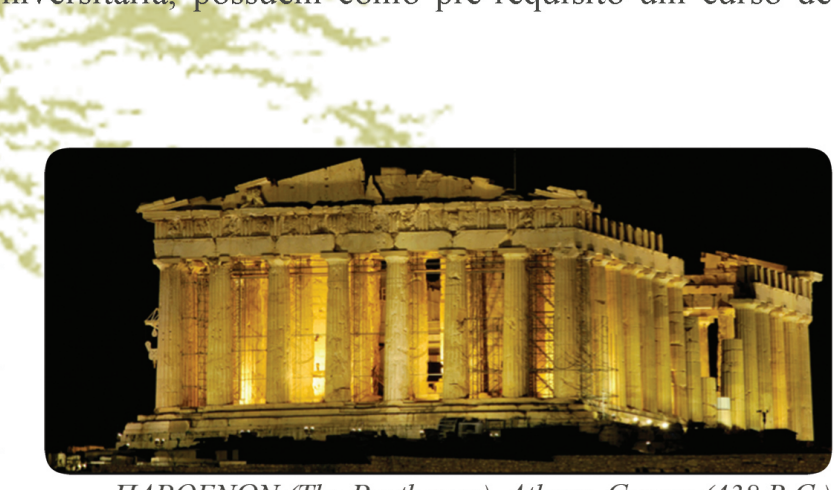

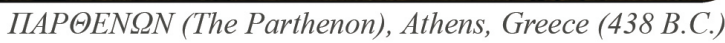
atividades as quais irão colaborar para o aprimoramento de sua formação na área de Cromatografia e correlatas.

Venha estudar Cromatografia e Técnicas Relacionadas com quem está envolvido em seu desenvolvimento 
Publicação disponível na internet:

www.scientiachromatographica.com

\section{9}

Volume 11 | Número 4

143 Novas perspectivas em técnicas de microextração estática

Alessandra Honjo Ide, José Manuel Florêncio Nogueira

156 GC-MS/MS versus LC-MS/MS for unambiguous identification of $\alpha$ and $\beta$-trenbolone in bovine urine

Amanda Lemes Silveira, Adriana Ferreira Faria

167 Efficient UPLC and spectrophotometric MC methods for simultaneous determination of cefixime and sodium benzoate in their dosage form and in its degradation product of cefixime-E Isomer. Application of lean six sigma and in-vitro dissolution studies

Mahmoud A. Mohamed 